\title{
"To Bring a Little Bit of the Land": Tanya Tagaq Performing at the Intersection of Decolonization and Ecocriticism
}

\author{
by

\section{Meredith Boerchers}

A thesis submitted to the Faculty of Graduate and Postdoctoral Affairs in partial fulfillment of the requirements for the degree of

\section{Master of Arts}

in

Music and Culture

Carleton University

Ottawa, Ontario

(C) 2019

Meredith Boerchers 


\begin{abstract}
Two needs that have grown increasingly critical in Canada throughout the twenty-first century are the reduction of global warming and the decolonization of lands, social institutions, and collectivities. Rather than operating independently, decolonization and environmentalism intersect as Indigenous actors contest Western assumptions about "nature" by asserting their own ecological frameworks. In this thesis, I explore Inuk vocalist Tanya Tagaq's artistic contributions to these efforts by analysing her musical commentaries on "nature" in light of Indigenous scholarship on "decolonization.” I argue that Tanya Tagaq performs decolonized environmental values by sonically evoking Inuit ecology and embodying Inuit ecologically-rooted ontology on stage. I further contend that Tagaq's musical practices demonstrate a decolonized approach to eco-activism by foregrounding Inuit experiences, strategies, and discourses, and advocating for environmental issues by mobilizing Inuit worldviews. Throughout this thesis, I demonstrate that Tagaq's environmentally-themed output challenges Western constructions of Inuit and the Arctic while asserting Inuit perspectives in public spaces.
\end{abstract}




\section{Acknowledgements}

First, I would like to thank my supervisor Dr. Anna Hoefnagels for her assistance throughout this project. Her expertise and guidance have been invaluable to my growth as a researcher and writer, and I am very grateful for her endless patience and encouragement.

I would also like to thank the faculty and students of the Music and Culture program. Each instructor created welcoming learning environments in their classrooms and challenged me to explore new ways to engage music practices, and the lively discussions and comradery among my classmates greatly enriched my time at Carleton. I look forward to the future of each of their careers.

Finally, I am particularly grateful for my friends and family. I truly appreciate the continual excitement, engagement, and emotional support that they provide, without which this task would have seemed all the more formidable. Their love and support are of the highest quality and value. 


\section{Table of Contents}

$\begin{array}{lr}\text { Abstract } & \text { i } \\ \text { Acknowledgements } & \text { ii } \\ \text { Table of Contents } & \text { iii }\end{array}$

$\begin{array}{ll}\text { Introduction } & \mathbf{1}\end{array}$

Theoretical Framework $\quad 5$

Related Fields $\quad 10$

$\begin{array}{ll}\text { Methodology } & 17\end{array}$

Part I: Decolonizing Ecology $\quad 22$

Chapter One: Arctic Places 23

Theoretical Considerations: "Nature" and 24

"Place"

Traditional Inuit Ecology $\quad 26$

Sounding Ecology $\quad 30$

The Transnational Arctic $\quad 34$

$\begin{array}{ll}\text { Conclusion } & 40\end{array}$

Chapter Two: Silatuniq on Stage 43

Sila $\quad 45$

Performing Interconnections $\quad 52$

$\begin{array}{ll}\text { Body and Mind } & 58\end{array}$

$\begin{array}{ll}\text { Affect } & 60\end{array}$

$\begin{array}{ll}\text { Conclusion } & 62\end{array}$

$\begin{array}{ll}\text { Part II: Decolonizing Environmentalism } & 65\end{array}$

Chapter Three: Embodied Environmentalism 66

$\begin{array}{ll}\text { Background, Methodology } & 67\end{array}$

Face, Body, and Voice of the Earth $\quad 68$

$\begin{array}{ll}\text { Sickness } & 70\end{array}$

$\begin{array}{ll}\text { Suffering } & 73\end{array}$

Rape of Women, Rape of the Land $\quad 79$

Conclusion $\quad 83$

Chapter Four: Feminism as Environmentalism 86

$\begin{array}{ll}\text { Womb-Core } & 88\end{array}$

Inuit Sexuality $\quad 93$

Indigenous Women's Environmental 100

Perspectives

102 
Closing Remarks

Works Cited 


\section{Introduction}

On April 22, 2015, Canada's Earth Day, Ottawa City Hall partnered with the Canadian Climate Forum, the World Wildlife Foundation Global Arctic Program, and the American organization Arctic 21 to host a forum titled "The Unravelling of the Arctic." While the discussions were intended to highlight the impacts that global warming has had on Arctic ecosystems, Inuk leader Terry Audla, then-president of Inuit Tapiriit Kanatami ${ }^{1}$, problematized foundational elements of these environmental discourses. Audla criticized both popular representations of the Arctic and environmental campaigns for excluding Inuit perspectives and perpetuating colonial harm. In addressing the very theme of the forum, "The Unravelling of the Arctic," he told audiences:

While the phrase is understandably designed to attract attention, it also feeds into the communications burden for Inuit... If there is an assumption that the Arctic is falling apart, one can misconstrue that Inuit are being irresponsible by hunting iconic animals [and] that it is unconscionable to contemplate any kind of industrial activity in the Arctic in order to save the world's last 'pristine wilderness' (Audla 2015, as cited in Bell 2015).

Audla reminded both researchers and activists that Arctic environmental campaigns flow from Western imaginations of the Arctic rather than local perspectives: "Those unfamiliar with the Arctic may not be aware that Inuit have long faced the challenge of the impacts of misinformed and at times romanticized visions and views of the Arctic and of Inuit." When taken to extremes, Western-based environmentalist campaigns, like recent anti-sealing protests, "vilif[y] Inuit rights to self-determination by unfairly criticizing or undermining [their] co-operative partnership in wildlife and resource management, refusing to acknowledge that Inuit subsistence activities are tied to market economics, or outright condemning a hunting way of life" (Audla 2015 in cited in

\footnotetext{
${ }^{1}$ ITK is an organization that represents, protects, and advances the rights of interests of Inuit in Canada.
} 
Bell 2015). Audla's speech addressed pressing imperatives in Canadian environmental discussions and action that continue today: the need to decolonize environmentalist initiatives and visions of both the Arctic and its inhabitants.

While decolonization is a process that takes place through many strategies and in many arenas - indeed, Audla pointed to the decolonization of Arctic lands through the Nunavut Land Claim Agreement during his speech — in recent decades Indigenous actors have used the arts to contribute to collective decolonial initiatives. Music is particularly significant to Indigenous resurgence efforts and environmental activism. In 1885, Metis leader Louis Riel said, "My people will sleep for one hundred years, but when they awake, it will be the artists who give them their spirit back" (1885). This prediction has proven true through the twentieth and twentyfirst centuries as musicians like Buffy Sainte-Marie and A Tribe Called Red have used their art to dismantle colonialist narratives and express pride in indigeneity (Mihesuah 2003, 150).

Ethnomusicologist Véronique Audet notes that Indigenous popular music, which combines EuroAmerican and Indigenous music elements, is particularly useful to such efforts:

[Indigenous popular musics] are used as cultural emblems, as instruments of resistance, and as a means to assert contemporary concerns, and they reinforce a distinct identity visà-vis dominant societies... In this music, we see the importance of revitalization and identity as well as the potential for action and transformation through personal and collective expressions and through voiced criticism of social problems. This music contributes dynamically to movements of identity and cultural assertion as well as to healing in Aboriginal circles $(2012,372)$.

Given the centrality of music to decolonial efforts, how do Indigenous musicians participate in the decolonization of ecological perspectives? In this thesis I seek to answer this question through analysing Inuk vocalist Tanya Tagaq's musical practices in light of emergent Indigenous theories and scholarship on "decolonization." I argue that Tanya Tagaq performs 
decolonized environmental values not only by sonically evoking Inuit ecology, but by embodying Inuit ontologies that emerge from human-environment interrelationships. I further contend that Tagaq's artistic output demonstrates a decolonized approach to environmentalism by foregrounding Inuit experiences, stories, strategies, and discourses, and advocating for environmental issues through the interconnections inherent to Inuit worldviews.

The four thesis chapters are thus divided into two sections: Tagaq's performance of Inuit ecology; and Tagaq's performance of decolonized environmentalism. In the first chapter, "Arctic Places," I locate Inuit views of Arctic environments in Tagaq's visual and sonic performance in the film Tungijuq (2009) and specific tracks in the albums Auk/Blood (2008) and Animism (2014). I argue that Tagaq sonically and visually evokes the socio-spiritual connections between humans and animals that are emphasized in Inuit ecology. I further suggest that Tagaq's use of Western popular music elements within these evocations reflects contemporary realities of Inuit communities: specifically, that colonialism, climate change, and globalization impact both physical environments and Inuit land attachments. Thus, Tagaq demonstrates that Inuit are part of contemporary global communities and she challenges colonialist perceptions of both the Arctic and Inuit as isolated and primitive. In the second chapter, "Silatuniq on Stage," I move away from Tagaq's studio albums and music videos to instead consider Tagaq's live performances, specifically those captured on the recording anuraaqtuq (2011). Here, I argue that if we understand performances as dynamic ecosystems, Tagaq demonstrates Silatuniq, an Inuit expression of wisdom that arises from attention to dynamic ecological relationships. Rather than directly referencing and representing Inuit traditions, Tagaq embodies an Inuit way of being in the world that flows from sensitivity to ecological interconnections. Both the first and second chapters work together to explore how Tagaq envisions and enacts decolonized environmental 
values: she challenges long-held fantasies about the Arctic and its inhabitants' isolation, sonically evokes Inuit ecological philosophies, and performs Inuit ontologies on the music stage.

The second section of this thesis focuses on those works in which Tagaq explicitly performs as an activist. Here, I argue that Tagaq's music demonstrates decolonized approaches to environmental advocacy. Chapter Three, “Embodied Environmentalism,” explores Tagaq’s musical participation in the strategies and discourses of Inuit and Indigenous environmentalism. I draw connections between Tagaq's strategy of artistically embodying the planet in ecological crisis and the rhetorical strategies of Inuit environmentalist Sheila Watt-Cloutier, which similarly position Inuit bodies and voices as representatives of the Arctic. In the tracks "Fracking" from Animism (2014), and "Sulfur" and "Retribution” from Retribution (2016), Tagaq positions herself, an Inuk woman, as the voice and body of the Earth. She characterizes the planet's experience of global warming through the realities faced by contemporary Inuit communities: as their home environments suffer from accelerated warming, Inuit physiological and emotional health correspondingly deteriorates. Further, in the music video "Retribution" and her live performance at the Polaris Prize awards ceremony in 2014, Tagaq combines strategic embodiment with related areas of Indigenous discourses that conceptually link violence against women with environmental violence. By participating in Indigenous movements and strategies, Tagaq affirms the legitimacy of Indigenous scholars and philosophers and indirectly and artistically challenges the "citational colonialism"2 (Ahmed 2014 as cited in Todd 2016) seen in mainstream discourses. The theme of mobilizing Inuit knowledge to advocate for environmental justice continues in the last chapter, "Feminism as Environmentalism." Here, I demonstrate that

\footnotetext{
2 Ahmed's (2014) “citational colonialism" is the prioritizing of Western scholars and intellectual traditions to gain legitimacy and prestige in academia.
} 
Tagaq's performance of gender and sexuality envisions powerful interconnections between womanhood and the environment based on Inuit worldview, thus performing decolonized visions of both. Tagaq's music animates these interconnections in the song "Centre" and music video for "Aorta" from Retribution (2016), wherein she resists colonialist frameworks that construe the conceptual links between women, sexuality and the environment negatively and reframes each as sources of power. Further, Tagaq uses the connections between gender, sexuality, and ecology to creatively intercede in environmental issues. Tagaq thus demonstrates a decolonized environmental advocacy by mobilizing the holism and interconnections of Inuit worldviews to speak to environmental justice from entrypoints unavailable within Western frameworks.

These four chapters, though divided into two themes, work together to demonstrate the many ways that Tanya Tagaq uses music to mitigate those issues brought up by Audla: she deconstructs colonial discourses of Arctic environments and inhabitants, asserts Inuit worldviews and contemporary experiences, and grounds her artistic environmentalism in Indigenous strategies, ontologies, and epistemologies.

\section{Theoretical Framework}

As suggested in the introduction of each chapter, this project engages Indigenous theories of decolonization and indigenization. Broadly speaking, decolonization in Canada is the "political and intellectual project having to do with the reclamation and reformulation of [Indigenous] nationhood" (Ng 2018, 50). This process includes the "centering of [Indigenous] concerns and world views" (Smith 1999, 39) and the reaffirmation of Indigenous knowledges (Knopf 2008, 100), both in local communities and within the discourse of mainstream society. 
Decolonization and indigenization overlap and feed into one another. Indigenization is defined by political activist Ward Churchill as "[drawing] upon the traditions — the bodies of knowledge and corresponding codes of values - evolved over many thousands of years by native peoples the world over" (Churchill 1993, as cited in Smith 1999, 146). Where decolonization seeks to repair the political, cultural, and spiritual traumas caused by colonialism, indigenization brings Indigenous "conceptions of world view and value systems" (Smith 1999, 146) into mainstream society. Marie Battiste (2000), Glen Coulthard (2014), Leanne Simpson (2001), Linda Tuhiwai Smith (1999), and many other Indigenous scholars write about such processes in contemporary Canadian contexts, and it is this work I look to in order to further theorize Tagaq's performance of decolonized environmental values.

Mi'kmaw educator Marie Battiste writes that in Indigenous collective experience, colonization acts as a "system of oppression" that represents the colonized as "primitive, backward, and inferior" (2011, xvi), and delegitimizes Indigenous peoples and lifeways in both thought and action. Rather than remaining an outside force acting upon Indigenous communities, the systemic nature of colonization perpetuates a "cognitive imperialism" (Battiste 1996, as cited in Battiste 2000, xvii). Colonized Indigenous minds internalize Western thought structures and constructs about Indigenous cultures through "historical, cultural, political, ethnic, aesthetic, academic, and sociological discourses" (Knopf 2008, 13), and produce collective identities alienated from their own cultural traditions, values, and philosophies. Thus, decolonization requires both challenging colonialist narratives of Indigenous peoples and healing and restoring Indigenous heritage and knowledge. In this process, the revitalization of Indigenous ecologies, consciousness, and languages (Battiste 2000, xvii) is vital to rebuilding nations, peoples, communities. Affirming and adopting Indigenous frameworks and challenging social inequalities 
that result from colonial thinking can also transform the minds of the colonizers. Sto:lo ethnomusicologist Dylan Robinson and music educator Pamela Karantonis write that decolonization leads Settlers to comprehend "repressive gender politics, the exclusionary nature of official histories, the limits of salvage ethnography, and the pursuit of individual liberation against, or in harmony with, Indigenous communities' self-determination" (Robinson and Karantonis 2011, 6). Ethnomusicologist Beverley Diamond further notes that in Indigenous music, decolonization can invite non-Indigenous audiences "into a new relationship" (Diamond 2011a,56), challenging the colonizer's “othering” of Indigenous peoples.

Decolonization is thus a process that disrupts mainstream representations and narratives about Indigenous peoples, indigeneity, and the marginalization of non-Western voices and perspectives. Decolonization also affirms Indigenous philosophies, traditions, and lifeways, and emphasizes the dignity and legitimacy of Indigenous peoples and worldviews. Cultural preservation, revitalization, reconstitution, and the protection of Indigenous communities are also implicated in decolonization (Alfred 2005; Sinclair, Hart, and Bruyere 2009; Wilson 2008, as cited in Ansloos 2017, 55). As Maori scholar Linda Tuhiwai Smith writes, Indigenous actors may also reformulate culture and traditions (Smith 1999, 110), using cultural teachings in contemporary contexts to speak to contemporary issues. Decolonization thus enacts Indigenous thought paradigms. In her contribution to the anthology Sharing Breath (2018), Roxana Ng argues that in order to move beyond decolonization as a metaphor (Tuck and Yang 2012), Indigenous peoples must occupy, relate to, and act in the world through local ontologies. As most Indigenous worldviews unify mind, body, spirit, and emotions, educators like Alannah Young Leon and Denise Nadeau (2018) see embodiment as particularly significant to the enactment of Indigenous ontologies. Using the body as a site to both understand and produce 
meaning "not only has the potential to extend the boundaries of Western knowledge construction but also help us develop the capacity to transform our own bifurcated and compartmentalized way of being [that stems from Western frameworks]” $(\mathrm{Ng} \mathrm{2018,50).} \mathrm{Decolonization} \mathrm{then}$ confirms Indigenous lifeways by acting out Indigenous lifeways and philosophies rooted in ancestral teachings (Simpson 2011, 55, as cited by Leon and Nadeau 2018, 55).

Metis anthropologist Zoe Todd adds that decolonization must also take place in those public spaces and discourses that have long prioritized Western voices. In her publication “An Indigenous Feminist's Take on the Ontological Turn" (2016) Todd stipulates that Indigenous thinkers are often left out of intelligentsia and relegated to the position of research subjects or collaborators, or referenced through white intermediaries. Todd joins fellow anthropologists Karen Brodkin, Sandra Morgen, and Janis Hutchinson in their challenge to continued colonialism in the "structural, routinised aspects of "white public space"” (Todd 2016, 13, citing Brodkin et al. 2011), specifically the legitimization of knowledge only through its reference to Western intellectuals and philosophers. "One must cite white men to get ahead," Todd writes; she continues, "In this way, we are conditioned to cite Al Gore before Sheila Watt-Cloutier; to reference Irving Hallowell before we engage with and acknowledge contemporary Anishinaabeg thinkers like John Borrows” (2016, 13). Decolonizing the academy, public discourses, and activism thus means critiquing and mitigating the silence of Indigenous scholars and intellectuals. It means holding Indigenous teachings as equally legitimate as Western intellectual traditions, thus allowing Indigenous perspectives to inform public conversations. In Todd's illustrative example of contemporary environmental discourses, decolonization means "rather than bequeathing climate activism to the Al Gores of the world," both scholars and activists need 
to take the "intellectual labour and activist work of Inuit women like Rosemarie Kuptana and Sheila Watt-Cloutier seriously" (Todd 2016, 7).

Notably, Todd's use of contemporary environmental discourses to demonstrate the marginalization of Indigenous perspectives in public arenas touches an issue at the heart of colonization and decolonization. According to Kanien'kehá:ka scholar, educator and activist Taiaiake Alfred, colonialization breaks down the relationship between Indigenous peoples and their local environments, thus erasing the place-based relationships that undergird Indigenous philosophies and values:

The problem that we have inherited in this generation is our disconnection from what it is to be Indigenous. This problem has been framed in many complicated ways, but really, what is colonization if not the separation of our people from the land, the severance of the bonds of trust and love that held our people together so tightly in the not-so-distant past, and the abandonment of our spiritual connection to the natural world? [...] Now, then, and forever, the fight is for the land. The land, and all it has to teach, to give, and all it demands, and what it means to be Indigenous [...] Alienation and disconnection from the land create confusion and discord in our minds and souls. The threats to our people come in all forms and they are all real. But fighting for our survival in the twenty-first century is less about defeating the aggression of an external enemy than it is about finding new ways to love the land, and new ways to love ourselves and our people (Alfred 2008, 910).

As Alfred suggests, if colonization is built on separating people from their lands, efforts to decolonize will instigate and implicate Indigenous environmental justice. The connections between cultural genocide and the occupation of traditional lands for economic development make Indigenous peoples' resistance to both equally interconnected. Indeed, educators Warren Cariou and Isabelle St. Amand write "the numerous Indigenous-led occupations, protests, road blocks, marches and other forms of public expressions" that are part of Indigenous environmental advocacy expose "the ways in which Indigenous environmental ethics are 
conceived of, imagined, called upon, embodied, and expressed." This assertion of the "storied relationship between the people and the land" fosters Indigenous political and cultural resurgence at the same time (Cariou and St-Amand 2017, 7).

\section{Related Fields}

While my thesis explicitly engages Indigenous theories of decolonization, related areas of study inform my work. The conceptual tools I use to approach Tagaq's contestations of "nature" emerge from the ecocritical writings in Indigenous Studies. "At the intersections between Indigenous Studies and ecocriticism," writes ecocritics Birgit Däwes and Marc Maufort, scholars "explore the ethnically and/or culturally specific implications of nature, environment, and the land" $(2014,11) \cdot{ }^{3}$ Ecocritic Joni Adamson's theorizations are particularly significant to the growing academic interest in the intersections of ecocriticism and Indigenous Studies. She stipulates that thoughtful ecocriticism requires historically and culturally sensitive investigations to tease out "the connections between social injustices and environmental degradation" (Adamson 2001, 9, as cited in Däwes and Maufort 2014, 20). As Adamson and Salma Monani's anthology Ecocriticism in Indigenous Studies (2016) demonstrates, many Indigenous artists, activists, and scholars around the world challenge audiences to see ecological degradation as part of a nexus of social issues, and to re-think "nature" through local cultural frameworks. While these scholars, artists, and activists work within specific contexts, each attend to the "underlying

\footnotetext{
${ }^{3}$ Däwes and Maufort note that although ecocritical studies in Postcolonial Studies also interrogate ecological imperialism, environmental racism and the ecological implications of cultural diversity, such works also perpetuate constructions that are harmful to Indigenous peoples, such as the "wilderness topos," "ecological Indian," and viewing Indigenous peoples as "keepers of planetary spirituality" (Däwes and Maufort 2014, 12).
} 
discourses, power structures, and ideologies in representing [environmental and social] injustices" (Däwes and Maufort 2014, 12).

As my own study brings ecocriticism into music, the recently-emergent field Ecomusicology is also foundational to my work. Jeff Todd Titon writes that Ecomusicology "probes the relationship between music and sound, nature and culture, and the environment in a time of environmental crisis" $(2016,69)$. In the introduction to their publication Current Directions in Ecomusicology, Allen and Dawe characterize the field as a space for interdisciplinary cooperation, as "part of the movement to champion a more connected place for humanistic and posthumanistic scholarship, as the environmental humanities are doing" (Allen and Dawe 2016b, 5). Allen and Dawe point out that the barrier between nature and culture is replicated in the barriers between physical scientists and literary intellectuals, but this field's connections with music, culture, and the environment means it "straddles the arts, humanities, social sciences, and sciences" (Allen and Dawe 2016b, 5). As a multi-perspectival field, ecomusicological studies take on a number of methods and theoretical frameworks. "Ubiquitous and implicit throughout ecomusicological studies," however, is "the prevalence of engagements with place and the critique of the nature-culture binary" (Allen and Dawe 2016b, 5). The field includes several trajectories; however my own study joins those that "us[e] an ethnomusicological or anthropological lens [to] engage directly with human social and cultural behaviours" (Guyette and Post 2016, 42). Guyette and Post label such studies "ethnoecomusicological" $(2016,42)$, as participants bring together local knowledges, social relationships, ecological events, and expressive forms to demonstrate the significance of humanenvironment relationships within music. Seeger points out that Western naturalist thinking on nature, animals, humans, and music treats each of these as distinct and separate categories, and 
ecomusicologists must think about how these are defined among different populations. In non-

Western frameworks, "humans, animals, and plants are not necessarily separate and independent beings, and they may be linked through place, resource use, and... sound" (Seeger 2016, 96).

This, of course, strongly relates to the ecocriticism within Indigenous Studies, which envisions nature and multispecies relations through local cultural, social, and political contexts.

Ecomusicology is the field that locates this work in music and sound. ${ }^{4}$

Indigenous Theory, ecocriticism in Indigenous Studies, and Ecomusicology all highlight the need for socio-cultural specificity in research. Tagaq identifies as an Inuk, maintains a close connection to her cultural background, and advocates for Inuit communities, so I look to the field of Inuit Studies to understand Tagaq's socio-cultural context. Inuit Studies is a field that considers a wide variety of research topics, including environmental issues, through a cultural lens. This field has experienced several turns in the past century, with scholars renegotiating their research frameworks, topics, and methodologies. Significant shifts in the field that are foundational to my own study include the focus on local and contemporary perspectives in research, and the transformation of the "status of knowledge" (Collignon 2016, 411). While the first wide-scale turn towards contemporary issues and local perspectives came about partly due to the influence of the Inuit Land Use and Occupancy Project, ${ }^{5}$ geographer Béatrice Collignon

\footnotetext{
${ }^{4}$ Nancy Guy's study of musical ecological imaginations in Taiwan (2009), Titon's reframing of Thoreau as an ecomusicologist (2016), and David Ingram's research on ecocriticism within popular music (2010) all informed or inspired my own research.

${ }^{5}$ Headed by the Inuit Tapirisat of Canada (now Inuit Tapiriit Kanatami) and anthropologist Martin Freeman, this project relied heavily on Inuit knowledge and Inuit oral history to document land use, with researchers emphasizing local perspectives during the project's documentation process. Rather than mapping local observations of the land, researchers mapped "aboriginal peoples" perception of their history and significance of the land" (Usher 2003, 375). The finished report went beyond land occupancy to discuss "the deep connections that Inuit had with the land and its resources" (Aporta 2016, 357). The ILOUP's partnership between Inuit organizations and researchers, the participation of local Inuit agents, and the investigation of complex layers of cultural meaning in land reshaped Inuit Studies as a "matter of the Inuit and for the Inuit" (Krupnik 2016, 16), and spurred advances in ecological anthropology, Indigenous governance and self-determination, and research on Aboriginal practices in land use and place-names.
} 
notes that through the 1980s, although there was a symbiotic relationship between Inuit and social scientists, what the Inuit knew was considered empirical data, not a "global interpretative framework worth being taken into consideration" (Collignon 2016, 412). Inuit supplied observations and information, and researchers supplied theoretical frameworks, research topics, methodologies, and analysis (Collignon 2016, 412). This changed in the $1990 \mathrm{~s},{ }^{6}$ when the implicit privileging of Western 'knowledge' and romanticizing of Inuit epistemology came into question. A change in perspectives on Inuit knowledge advanced a supplementation of "traditional ecological knowledge" (TEK) through engaging Inuit Qaujimajatuqangit (IQ). TEK, which has a "propensity towards facts about animals and natural elements" (Wenzel 2004, 239) from Inuit observers, tended to overlook "how Inuit conceptualize human-animal relations" (Wenzel 2004, 238). IQ, which encompasses "all aspects of traditional Inuit culture including values, worldview, language, social organization, knowledge, life skills, perceptions and expectations" (NSCD 1998, as cited in Levesque 121), provides a framework for organizing "Inuit thoughts and actions, tasks and resources, family and society" (Arnakak 2000, as cited in Wenzel 2004, 242). Thus scholars researching ecological topics within Inuit Studies worked to consider both Inuit observations and the ideational relationships between Inuit and the environment (see for example Fienup-Riordan 1994; 1999, Stairs and Wenzel 1992). With a general shift towards considering Inuit worldviews in contemporary contexts, scholars in Inuit Studies now step away from "reify[ing] Inuit culture as something located in a primordial past

\footnotetext{
${ }^{6}$ During this time a constellation of factors worked together to reshape the field: first, Inuit Studies conferences became much more accessible to people living in remote locations, thus raising Inuit attendance and participation. Inuit became the main actors in the discussion, researching their own culture on their own terms, and working with co-researchers to define research agendas (Collignon 2016, 411). At the same time, Inuit political and cultural empowerment was growing around the polar region. Inuit leaders took roles in the UN Working Group on Indigenous Populations, the Nunavut Land Claim Agreement was ratified, and Nunavut (an autonomous Inuit-led territory) was established in 1999. Inuit gains in administrative autonomy put them "in a position to assert the importance of their knowledge about everything related to their world..." (Collignon 2016, 412).
} 
that can only be accessed through elders' narratives or reconstructions of pure cultural forms untainted by contact with outsiders" (Stevenson 2006, 13); instead scholars link contemporary Inuit culture with larger national and international social, economic, and political processes. ${ }^{7}$ The research, discussions, and methodological lenses within Inuit Studies all inform my own research, as questions of Inuit identity, epistemology, and ontology in relation to Arctic environments recur throughout this thesis. Specifically, the studies that have been invaluable to my own research are Mark Nuttall's publications on the relationships between Inuit identity and ecology (1992; 1998), Julie Cruikshank's studies in ethnoecology (2005), Willox's literature about the psychological impacts of climate change in Inuit communities (Willox et al 2012, 2013a, 2013b, 2015), and Béatrice Collignon's publication on Inuit “geosophy” (2006).

Readers will also find that "embodiment" and "performance" recur throughout my thesis. My invocation of these topics emerges from frameworks in performance studies and feminist musicology. In the 1990s, the conceptual transformations that pervaded the humanities and social sciences also entered musicology. Briefly termed "new musicology," scholars here participated in a "wider postmodern move to displace positivism and the concept of the autonomous musical work" by engaging disciplines outside musicology to alter frameworks of musicological discussions (Kramer 2010,63). One of the many trajectories music scholarship followed was a new engagement with the body as a site of knowledge and meaning production. As Krystal Morrison summarizes, anthropologist Thomas Csordas forwarded an "embodied paradigm" that viewed the "body as a productive starting point for analyzing culture and self" (Csordas 1990,

\footnotetext{
${ }^{7}$ In the same way, the question of what makes a "real" Inuk - argued by anthropologists in the 1970s and 80s in terms of an Inuk's participation in land-based activities - is today reframed within Inuit Studies as open to redefinition by young Inuit, "who may have different notions of what makes a real Inuk. For them a real Inuk must neither be judged by the standards of an earlier era (Moller 1992) nor be held up as a mythical and misleading model unobtainable today" (Graburn 2006, 154).
} 
18, as cited in Morrison 2018, 9). In such studies, "performance" is defined as "symbolic yet intentional expressive reenactments and validations of cultural values," and "performativity" as "small, generally unmarked and expressive gestures of the human body and voice that are performed as we move along in our daily lives... that legitimize and reproduce social and cultural norms" (Koskoff 2014, 151). Embodiment encompasses both "performance" and "performativity": as feminist ethnomusicologist Ellen Koskoff notes, “one’s ways of knowing are often performed or felt through the body in specific situations" $(2014,63)$. In music scholarship, engaging the body steered writers in numerous directions. Bringing in Butler's theorizations of gender as a performed construct, ${ }^{8}$ feminist musicologists such as Susan McClary (1991) and Suzanne Cusick (1994) found metaphors of gender identity in music analysis and elements of bodily performances. My own consideration of Tagaq's body in performance and its creation of socio-cultural meanings draw on these studies, particularly Cusick's suggestions that "musical performances can be deciphered as simultaneously individual and social enactments of power" (Cusick 1994, 20) and that the researched "work" is not always the score, but includes “the performer's mobilizing of previously studied skills so as to embody, to make real, to make sounding, a set of relationships that are only partly relationships among sounds" (Cusick 1994, 18). My research is also informed by Nicholas Cook's assertion of the need to bring scholarly attention to all aspects performance events, including the performers' and audiences' bodies (Cook 2001, as cited by Morrison 2018, 21). ${ }^{9}$ In musicological studies of performance, musicians' sounds, movements, interactiveness, intersubjectivity, ${ }^{10}$ and the socio-cultural context

\footnotetext{
${ }^{8}$ Citing Butler (1990; 1993), West and Zimmerman (1987), and Price and Shildrick (1999), Ellen Koskoff explains that gender is "performed into existence through repeated acts, eventually constituting a 'natural' set of normative behaviours" (Koskoff 2014, 63).

${ }^{9}$ According to Margaret Kartomi, ethnomusicologist Ruth Stone's research on traditional Kpelle music and dance culture in Liberia in 1982 helped popularize musical interest in total performance events $(2014,195)$.

${ }^{10}$ Intersubjectivity, in this case, refers to the bonds between musicians.
} 
of the event are all legitimate sites for investigation (Kartomi 2014, 190). As Simon Frith's Performing Rites (1996) explores, these elements of musical performances involve thoughts and actions that are not only related to the music to be performed but also to the occasion itself (Davidson 2014, 186). My own inquiries into Tagaq's practice thus stem from the approaches taken by Frith, Cook, and Cusick: I consider significant aspects of Tagaq's performances, paying particular attention to her bodily practices as they relate to cultural, social, and gender politics.

Finally, I also need to point out that my study both borrows from and adds to the growing body of publications about Tanya Tagaq by scholars in Musicology, Film Studies, Indigenous Studies, and Political Science. Some of the first publications about Tagaq engaged her innovation of traditional katajjaq and its reception within Arctic communities (Ladoucer 2006; Diamond 2011b; Conlon 2013; van den Scott 2016). The work of musicologist Sophie Stévance was particularly useful to my own writing. Stévance analyzes the micro- and macro- sonic structures (including pitch, rhythm, vocables) in Tagaq's improvised performances to delineate how Tagaq sonically blends Inuit and Western music styles (2015), and compellingly describes Tagaq's work as "transnational" and "cosmopolitan" (2017). Furthermore, Stévance engages the symbolic elements of Tagaq's performing body, asserting that Tagaq subverts clichés about femininity in both Inuit and Western cultures (2017). Indeed, the themes of gender, indigeneity, transformations of cultural practices, Indigenous-Settler relations, and embodiment are frequent throughout the literature about Tagaq. Alexa Woloshyn writes both about the auto-eroticism in Tagaq's electroacoustic work (2012), and Tagaq's contestation of colonialist stereotypes about indigeneity through music and social media activity (2017). V.K. Preston similarly notes that Tagaq's restaging of Robert Flaherty's 1922 film Nanook of the North deconstructed the harmful representations about Inuit in the original film (2016). Since Tagaq's rise to fame coincided with 
a Canadian national discourse of "reconciliation" between Indigenous peoples, Settler populations, and the Canadian State, several publications take the public reception of Tagaq's music as an entry point to discuss Indigenous-Settler relations. Rule's publication notes that the online backlash and accusations of unfit Indigenous motherhood in relation to Tagaq's participation in the \#sealfie movement in 2014 exposed the continuation of colonialist ideologies (2018). Through considering the poetics of music journalists' and reviewers' texts about Tagaq's performances and albums, Taylor-Neu demonstrates that ideologies of the voice relate to reconciliatory projects yet reinforce fantasies about indigeneity (2018). Writers Smith (2018) and Fratila (2016) allude to the affective qualities of Tagaq's output—-both writers reference the ability of Tagaq's music to physically and emotionally act upon audiences, shoring up reconciliatory sentiments. Blais-Tremblay finds Indigenous-Settler power dynamics in the composition and orchestration of Tagaq's collaborations with non-Inuit artists (2014). While these studies are all transdisciplinary and engage similar themes from alternate angles, to my knowledge there has not been a published study characterizing Tagaq's music as ecocritical. As ecomusicologist Nancy Guy observes, the "trinity of critical issues, namely race, gender, and to a lesser extent, class" $(2009,218)$, has received the most attention from scholars. My own research adds an ecological focus to such themes, considering how music can effectively communicate, interrogate, and transform perceptions of natural environments and affective bonds with nonhuman elements (Guy 2009, 219).

\section{Methodology}

In the following chapters, readers will notice that I foreground Tagaq's own explanation of her practices. While I did not personally interview Tagaq, the vocalist has participated in 
many rich discussions with journalists and scholars since the beginning of her vocal career. This interest in Tagaq's musical practices is at least partly due to the vocalist's meteoric rise to stardom: at her first staged vocal performance Tagaq was scouted by friends of the international popular music icon Björk. The Icelandic pop star brought Tagaq on her international Medúlla tour (2004) and subsequently co-produced Tagaq's first album Sinaa (2005). Given Tagaq's recent and rapid rise to international fame and her unique musical style, many in-depth interviews and discussions with Tagaq are widely available online. Within these interviews Tagaq openly discusses her own cultural roots and passionately advocates for fellow Inuit, leading to discussions about climate change, individual and collective traumas left by colonization, and current healing efforts. Furthermore, Tagaq often talks about using musical expression to comment on and intercede in these areas. As I started my research process, I thus discovered that Tagaq has already addressed the topics that I discuss in this project. My research then seeks to reconcile Tagaq's comments with her artistic practice, using the intellectual work of Indigenous artists, activists, and educators to come to a more fulsome understanding of her work and its relationship to decolonization. Often, this means confronting my own presuppositions about art and ecology which reflect my upbringing in Western society. By emphasizing Tagaq's ability to speak for herself and the legitimacy of Inuit, First Nations, and Metis intellectual perspectives, my hope is to recognize that the imposition of inappropriate cultural frameworks and assuming objectivity and authority in research can contribute to colonialism within academia.

Thus, in this thesis I take a contextualist approach to my research. Rather than thinking that Tagaq represents a group of people (women, Inuit, North American Indigenous peoples), I seek to examine how Tagaq's artistic commentary on nature is informed by her socio-cultural 
context. As Tagaq self-identifies as an Inuk woman, this means that I engage Inuit theorists, writers, artists, and activists that have been raised up by their communities as cultural ambassadors in order to learn about Inuit worldviews (including views of ecology and feminity) and lived experiences. By putting Tagaq's practice in dialogue with these actors, I aim to understand how Tagaq's artwork evokes and enacts her own vision of Inuit worldviews and traditions, while still demonstrating cultural continuity. In Chapter One, I explore Tagaq's practice in relation to the eco- and cosmological perspectives described by Inuit elders and nonInuit anthropologists. Additionally, I look to studies in contemporary Inuit communities to discover how global presences and processes within Arctic environments impact Inuit experience and ecological visions. I find such allusions to both traditional and contemporary Inuit ecology explicit in sound editing techniques, vocal motifs, and the visual and sonic narratives created in music videos. As Inuit knowledges are embodied, in Chapter Two I compare the processes at work in Tagaq's live performances to the processes Inuit see at work in dynamic ecosystems. Here I foreground the descriptions of Sila and Silatuniq by Inuk philosopher Jaypeetee Arnakak and Tagaq's description of her own improvisational process. I then locate the similarities - the sensuous attunement to ecological components — in aspects of Tagaq's live performances, particularly her body movements and improvisations with musical collaborators. The theme of embodiment continues into Chapter Three, where I attend to Tagaq's body and the meanings that arise from the juxtaposition of sound and visuals in specific music videos. Here, I contextualize Tagaq's intentional activist methods within past decades of Inuit environmentalist methods, looking to the work of Inuk Sheila Watt-Cloutier to understand how Inuit approach environmentalism. Chapter Four briefly dips into lyrical analysis, but again centres on locating cultural allusions in the visual and sonic aspects of music videos. Again, here I put Tagaq's 
statements about environmental justice in dialogue with Indigenous views of gender, sexuality, and ecologies, as explained by educators like Kim Anderson and Qwo-Li Driskill. In keeping with the value of prioritizing Tagaq's intentions as an artist, my research encompasses all of Tagaq's album recordings except her first Sinaa (2005). This exclusion is largely for two reasons: neither Sinaa nor Tagaq's interviews at the time of the album's release seem to emphasize environmental themes with the same prominence that arises in her later practices. This is not to say they cannot be located within Sinaa or Tagaq's collaborations on other projects with other artists, such as the Kronos Quartet and Derek Charke, but it is more fruitful to inquire where there seems to be explicit intentionality.

"Relationality" emerges throughout this thesis and, indeed, Indigenous worldview. Having introduced my research interests and methodologies, I now take the rest of this introductory chapter to identify myself and my connections to this project following the approach suggested by Indigenous pedagogues Leon and Nadeau. I was raised in Laurier, a small community within Treaty No. 2 land in Manitoba, traditional Anishinaabe (Ojibway) territory. I am a second-generation Euro-Canadian, with family origins in Germany. Both my mother's and father's families entered Canada soon after World War I and, although they landed in different parts of Canada, each family began their own farming practices after raising enough funds to purchase land. I was raised surrounded by my paternal relations in the Parkland region of Manitoba among predominantly Metis, Euro-Canadian, and Ojibway families, and today I recognize that I benefited from various systems that privilege European heritage and perpetuate injustices against Indigenous peoples. ${ }^{11}$ Identifying myself through family ancestry and

\footnotetext{
${ }^{11}$ Like, for example, Manitoba's education system, which is built upon Western knowledges and pedagogies rather than adhering to educational models from local traditions, and Canadian economic capitalist values of "private property" that allow Native land to be bought and sold.
} 
territories I still call home is necessary not only for my own process of seeing myself, a EuroCanadian student and researcher, as part of a web of relationships and connections, but also because it was in this context that I first encountered Tanya Tagaq. In 2006 I saw the Canadian Broadcast Corporation's television special on Tanya Tagaq's and the Kronos Quartet's collaborative piece Nunavut while doing homework in my parents' basement. This was my first real exposure to Inuit culture outside of museum displays and the children's books like Julie of the Wolves (1972). My pride begs me to say that I was enraptured by the profundity of the performance, but as an eleven-year-old I was more preoccupied with the bizarreness of Tagaq's vocals and the Kronos Quartet's extended string techniques. My sense of Nunavut's strangeness somewhat lessened in later years as I learned more about contemporary music and Arctic Indigenous peoples through university courses and personal experiences. I tell the reader these things to point out that although Indigenous music has occupied my recent academic interests, my relationship to Tagaq's music stretches further into my background than most of my academic projects. Additionally, I write about the complexities of Indigenous-Settler relationships partly from living through them in my home, rather than assuming a false objectivity. Through describing, rather than erasing, my personal connections to this project and identifying myself through my relationships with my family and my home, as Indigenous philosophy recommends, my hope is to both participate in the continued decolonization of academic writing and the overall transformation of scholarship through reflexive thinking. 


\section{Part I: Decolonizing Ecology}

Upon first hearing, any listener could easily understand that Tanya Tagaq's artistic work contains environmental themes. The sounds of ravens croaking, wind blowing, and snow crunching recur throughout Tagaq's albums, and the Inuk vocalist frequently mimics the howl of a wolf on stage. Furthermore, the photographs released with her most critically acclaimed album, Animism (2014), depict Tagaq dressed in furs and feathers, with antlers rising from her hair. Although these visual and sonic markers obviously indicate Tagaq's interest in nature, her artistic practices lead attentive listeners to more foundational questions: how are ideas about “nature," performatively defined by Tagaq, different from her audiences' ideas of "nature”? What does the alterity of non-Western ecologies teach us about the underlying power structures and ideologies in representations of "nature"? How can the communication of non-Western-in this case, Inuit-ecologies disrupt such ideologies? In the first two chapters of this project, I explore Tagaq's performance of Inuit ecological perspectives in albums, music videos, and on stage. By evoking and enacting such standpoints — which Tagaq roots in both traditional Inuit cultural beliefs and contemporary Inuit experience-Tagaq artistically demonstrates the continuity and legitimacy of Inuit worldviews. Furthermore, as Inuit ecology, cosmology, and ontology are inextricably intertwined, I investigate how Tagaq enacts Inuit ways of being on the performance stage. 


\section{Chapter One: Arctic Places}

Many Indigenous musicians - ranging from Robbie Robertson to Xiuhtezcatl Martinez

- have used their music to advocate for environmental protection and justice by expressing environmental values that emerge from their cultural perspectives (Hasek and Lindala 2016, 123). Inuk musician Tanya Tagaq has been particularly active in this regard, challenging destructive fossil fuel and mineral extraction practices and colonial perceptions of conservation. Her social media activity, interviews, and speeches testify to these efforts, particularly in her criticisms of celebrities' and advocacy groups' attacks of Inuit seal hunting practices. While Tagaq's words show her personal connection to Inuit environmental values, in this chapter I discuss how Tagaq's artistic output similarly demonstrates Inuit ecological perspectives.

Throughout this thesis I argue that Tagaq's artistic commentary on the environment through visual and sonic performances demonstrates Inuit-centered concepts and experiences of Arctic environments. Unlike Indigenous artists who articulate environmental values in the lyrical content of their output (Hasek and Lindala 2016), Tagaq's artistic practice rarely includes lyrics; as such, my discussion investigates the sonic and visual qualities of Tagaq's performances. This line of inquiry fits with Tagaq's comments about her vocal practice, as she has told journalists that her vocal sounds partly emerge from the land (Prasad 2010). Therefore, I suggest that Tagaq's artistic evocation of the environment demonstrates Inuit-centered concepts and experiences of Arctic environments. In the first part of this chapter, I discuss how Tagaq's album Animism (2014) and short film Tungijuq (2009) perform traditional Inuit ecological concepts, specifically the socio-spiritual connections between humans and animals that formulate a world comprised of broad ecological relationships rather than de facto categories. In the second part of 
the chapter, I explore Tagaq's evocation of nature through musical "transcultural expression"12 (Stévance 2017). I argue that since Inuit conceptual and physical environments are not isolated from the rest of the world, but have altered due to both intercultural exchanges and the ecological fallout of global industries, Tagaq's transcultural musical expression and collaborations convey the complexity of contemporary Inuit environmental experiences and views.

\section{Theoretical Considerations: "Nature" and "Place"}

This chapter builds on existing intellectual work that re-theorizes "nature" as inseparable from human cognition and activity. While various Indigenous cultures like those in Canada have long understood humans as part of, rather than outside of nature, Western culture has only reconsidered its separation of pure social force and pure natural mechanism in the last sixty years (Clegg 1995, 154). Growing from the influence of French phenomenological writings, especially those of Maurice Merleau-Ponty, and Heidegger's existential work, "place" arose in the late twentieth century in the negotiation of the relationship between physical space and human cognition. The concept of "place" in the social sciences goes beyond the physical dimension of space and location to include the ways humans relate to a locale: through activity and meaningmaking, people gain "subjective and emotional attachment[s]" (Agnew 1987, as cited in Cresswell 2015, 14) and construct a sense of place. ${ }^{13}$ Tim Cresswell describes how this relational

\footnotetext{
${ }^{12}$ Stévance invokes this term in her description of Tagaq's practice to refer Tagaq's artistic blending of "established customs of different cultural spaces (from that of their origins to a more global one)... [to] create unique identities through aesthetic, cultural, and technological exchanges" $(2017,48)$.

${ }^{13}$ Many musicological studies attend to the relationships between music and place (see for example Cohen 1995; Bennett 2002). Martin Stokes theorizes beyond music as part of the social constructions of place to consider how music can evoke place (1994). Publications by Leyshon, Matless, and Revill (1995; 1998) explore music's production and articulation of geographical imaginations at a variety of scales, and Connell and Gibson wrote about "world music" as a deterritorialization of culture $(2003 ; 2004)$ through the "construction and contestation of discourses of otherness and place" (Hudson 2006, 628).
} 
approach to place changes its significance in the foundational publication Place: A Short

\section{Introduction:}

When we look at the world as a world of places, we see different things. We see attachments and connections between people and place. We see worlds of meaning and experience... Place is how we make the world meaningful and the way we experience the world $(2015,18-19)$.

The contingency of place upon individual and collective meanings and experiences is further seen in recent theorizations of "nature" in the environmental humanities. After the cultural turn of the 70s and 80s and the influence of postmodernism in the 90s, anthropologists in the early twenty-first century moved away from a Western transcendentalist view of "nature" to contend that nature, ecosystems, and ecologies, like place, do not exist apart from their social constructions, which are ultimately fluid, subjective, and collective (Kidner 2000, Mason 1990, Caloupka and Cawley 1993, Burr 1995, and Escobar 1996, as cited in Kopnina and ShoremanOuimet 2011, 17). Now understood as implicating systems of social relationships that embody distinct cultures and multiple meanings, identities, and practices, "place" and "places" are thus "contested and continually in the process of becoming, rather than essentialized and fixed, open and porous to a variety of flows in and out rather than closed and hermetically sealed" (Hudson 2006, 627). The title of this chapter, "Arctic Places," thus refers to this body of literature that has paved the way to thinking of the Arctic as simultaneously real, narrated, and collective. When seen as a social construct, it is then possible to understand that there are multiple "Arctic"s and ecological paradigms concurrently existing and, in the context of environmental discourse and activism, in competition. 


\section{Traditional Inuit Ecology}

In 2015, Tanya Tagaq sat with journalists at Massey Hall to discuss her artistic inspiration. While in other interviews Tagaq describes meditating on memories, dreams, and concepts in her improvised performances, here Tagaq adds "I'm very, very interested in preChristian, Inuit life" (Live at Massey Hall 2015). This interest is apparent throughout her practice: her most widely acclaimed record, Animism (2014), is a tribute to traditional ${ }^{14}$ Inuit spiritual practices. Given Tagaq's self-espoused interest in traditional Inuit culture, I suggest that Tagaq's musical evocation of nature, as evident in Animism (2014), Retribution (2016), and the short film Tungijuq (2009), is similarly rooted in pre-Christian Inuit ecological views. In this section, I point out Tagaq's performance of a key ecological concept in traditional Inuit environmental values: the extension of personhood to nonhumans.

At the foundation of Inuit ecologies is an understanding that all the world is animated and interconnected by spirits and cosmic forces. Inuk scholar Jackie Price describes these views:

Traditional Inuit spirituality... recognizes the constant presence of spirits and respects the authority of spirits to challenge Inuit physical survival. Spiritual authority exists within an intrinsic spiritual network of relationships that guides Inuit existence, which included Inuit, the land, weather, and the animals $(2008,131)$.

This "constant presence of spirits" refers to the inseparability of Inuit spiritual and cosmological beliefs and the environment. One of the principal understandings in interwoven Inuit spiritual and ecological perspectives is that each part of an ecosystem—-human and nonhuman—is indwelled by spirits known as inuat. ${ }^{15}$ The oral testimonies of Inuk elder Hubert Amarualik

\footnotetext{
${ }^{14}$ The use of the word "tradition" is not without contestation. I use it here because Tagaq uses the term when describing the differences between her vocalizations and katajjaq practiced in Inuit cultures before its suppression by Christian missionaries. Furthermore, Tagaq often uses "traditional" when referencing pre-Christian and pre-colonial Inuit lifeways. Rather than setting up a binary between "traditional" and "modern" or alluding that "traditional" means "authentic," my use of the term refers to those cultural practices and worldviews that originate in pre-colonial Inuit culture, and does not assume that such practices and values are static, extinct, or antiquated.

${ }^{15}$ Inuat is the plural form, inua is the singular.
} 
describe these inner souls of all objects, animate and inanimate: "Everything, rocks and other solid objects or anything else have their inua (inner person). Anything that is made or created has an inua" (Amarualik in Bennett and Rowley 2004, 43). Animals and other ecological elements thus "[possess] both immortal souls and awareness comparable to that of human persons" (Fienup-Riordan 1990, 172, as cited in Nuttall 1998, 84). Inuat may take on human form, but rather than signifying that animals are humans, the presence of inuat demonstrate an extended sense of personhood beyond humans to include all ecological components. Anthropologist George Wenzel writes:

Animals share with humans a common state of being that includes kinship and family relations, sentience and intelligence. The rights and obligations that pertain among people extend to other members of the natural world. People, seals, polar bears, birds and caribou are joined in a single community (Wenzel 1991: 61).

Through knowing the environment as animated by the spiritual indwellers inuat and the universal force Sila —-which I describe in Chapter Two-Inuit understand the world as cosmocentric or cosmomorphic, rather than ethnocentric or anthropomorphic (Gautier 2016, 130). Ana Maria Ochoa Gautier notes that within this perspective, "instead of having to prove that [Inuit] are humans because they distinguish themselves from animals, we now have to recognize how in-human we are for opposing humans to animals in a way they never did: for them nature and culture are part of the same sociocosmic field" (Gautier 2016, 131).

Tanya Tagaq herself reiterates the unified, social-spiritual view of the world in her conversations about the album Animism. In an interview with Jian Ghomeshi for CBC Radio's program $Q$, Tagaq describes the title of the album as the belief that humans and animals are indwelled by spirits, "extended even to technically inanimate objects... I think that animals that exist_I've been closer to some of them than most people ... We're the same. We're flesh, we're meat, we're so stupid to think we're not" (2014). Such comments affirm the perspective that 
animality, rather than humanity, is the common condition between humans and animals. Tagaq further states that her use of the term "animism" was an attempt to connote those pre-Christian Inuit beliefs, and the album Animism is her tribute to traditional Inuit life (Six Shooter Records 2014).

As Ghomeshi and Tagaq continue to discuss the album in the interview, the conversation turns to the inspiration behind the tracks. Nearly every track on Animism references nature in some capacity: "Caribou," "Umingmak" (muskox), "Rabbit," and "Tulugak" (raven) refer to specific animals; "Uja” names a portion of seal meat; "Genetic memory," "Howl," "Flight," and "Fight" signify animal survival instincts; and "Damp Animal Spirits" refers to inuat. When asked about these titles, Tagaq tells Ghomeshi:

When I'm at home and I go out on the land by myself... I'm just watching musk oxen go by and falcons flying around. It's so peaceful and so beautiful. I find within society sometimes I can take animal behaviours and apply them to humans and it makes a little more sense psychologically... I just like to point out all the mistakes humans make (2014).

The mistakes Tagaq alludes to and seeks to mitigate through music is that separation of humans from the rest of nature:

Humans, because we've detached ourselves from nature so much have lost [...] genetic memory and instinctive patterns that we all secretly know... Humanity has made a really huge error in thinking we're above everything... it's us who belong to the earth, not the other way around (Tagaq to Ghomeshi 2014).

In these statements, Tagaq alludes to an underpinning dichotomy within Western culture that continues to "cascade internationally through debates about environmentalism, biodiversity, global climate change, and Indigenous rights" (Cruikshank 2005, 11): the nature-culture binary. Rooted in enlightenment philosophy, Western intellectual traditions have historically defined and divided the world into distinct categories of human/culture and nonhuman/nature, and 
investigated each of them as separate ontological zones. Bruno Latour calls this division "the Great Divide" (1993) and recognizes it as false dichotomy: "Nature's laws cannot be known without human construction: from primitive pumps to sophisticated electrospectographs that which, putatively, belongs to Nature can only utter its message where human agency contrives that it can do so" (Clegg 1995, 154). From such a division of nature and culture grows a set of tacit assumptions in Western society that treat humans as exempt from ecological rules and constraints $^{16}$ —or, as Tagaq puts it, "thinking we're above everything." This underlying framework has been renegotiated in the past sixty years through various epistemological turns and cultural movements; ${ }^{17}$ however, its continuation manifests in discourses about "the environment," "wilderness," climate change, and conservation management.

While Tagaq describes her view of the environment clearly in interviews, she further demonstrates the inseparability of humans from the environment in sonic material by creatively challenging those divisions between the human and the nonhuman. Since her first reference to this viewpoint on her debut album Sinaa (2005) in the song "Ilunikavi," meaning "we are blood/ we are animals" (Diamond 2011,97), Tagaq's musical style has continually dissolved the boundary between the human and the nonhuman through a variety of practices, including manipulating recordings of animals, performing animal-like sounds herself, and visually demonstrating the personhood of animals. In the following section, I describe each of these techniques.

\footnotetext{
${ }^{16}$ Sociologists Catton and Dunlop named this the "Human Exemptionalist Paradigm" in the 1970s.

${ }^{17}$ Notably the adoption of Catton and Dunlop's relational "New Ecological Paradigm" throughout the social sciences.
} 


\section{Sounding Ecology}

The music within Tagaq's albums often contains sound clips of animal calls, blowing wind, and crunching snow. At times, these found sounds play freely under the more structured sonic material, largely free of electroacoustic manipulation. However, there are instances within Tagaq's albums where she and the sound engineers manipulate these recordings in the same way as Tagaq's vocal improvisations. Just as electronic looping and layering techniques are vital to produce the vocal effects found on Tagaq's albums, several clips of found sounds receive similar treatment to create the desired musical effect. While remaining recognizably "found" —in this case originating from animals in their natural environments - these recordings become an integral part of the music's motion and direction, and even take on some of the characteristics of particular music styles. One of the clearest examples of this is found in the song "FoxTiriganiak" from Auk/Blood (2009). ${ }^{18}$ Here, recordings of fox yips are mixed through the channels to simulate the same back-and-forth exchange of katajjaq. In the track "Centre" from Retribution (2016), ${ }^{19}$ raven calls appear in the musical texture after Shad's rap, fading and reentering in time with the four-beat groupings of Tagaq's vocals. These raven croaks correspond to Tagaq's vocalizations — as the vocalist's rhythmic patterns double in speed every four pulses, the raven croaks increase in volume and freneticism. The use and manipulation of animal recordings in the same manner of human vocal and instrumental tracks demonstrates an equality and unity between these sources. Human sounds - encompassing the human voice and those human sounds manipulated through technology—are no more superior or musical than animal

\footnotetext{
${ }^{18}$ Available at https://www.youtube.com/watch?v=WUi9UnK5Xh0\&list=PLxSv3XHIMHVMOrOTSDppchMf7Zw9SUuy

${ }^{19}$ Available at https://www.youtube.com/watch?v=aPpZex_QxGE
} 
sounds. This does not suggest that they are the same, but rather demonstrates that one is not more valuable than the other, as the beings from which they flow are equals.

On many occasions Tagaq's voice and accompanying instrumentals further dissolve the constructed boundary between the human and the nonhuman by recreating the sounds of animals themselves. This practice emerges as a prominent part of Animism (2014). In the track "Tulugak" (raven), ${ }^{20}$ Tagaq alternates between singing the word "Tulugak" - transforming it into a layered, katajjaq-like rhythmic sequence - and mimicking raven croaks with her own voice. In the subsequent track "Howl,"21 sustained pitches in brass instruments, strings, electronics, and background vocals reference animal howls (as alluded in the track title). During the second half of the track, Tagaq's vowels and rising and falling tones even more closely imitate wolf howls. In "Summoning"22 from Retribution (2016), one of the choir's improvised sound effects are the peeps of Arctic birds. While creating animal sounds is part of traditional katajjaq practice, in the context of Tagaq's interest in pre-Christian Inuit life this practice gains additional dimension. Through their re-creation and aestheticization of sounds made by animals, Tagaq and her collaborators creatively demonstrate that the human and nonhuman should not be divided or organized into a hierarchy. Gautier writes that "the history of Western music's analytical categories - melody, rhythm, and perhaps most crucially of all, the voice — is traversed by a zoopolitics of the acoustic that is obsessed with separating the human from the nonhuman" (Gautier 2016, 131, emphasis added). Tagaq's artistic use of animal sounds, either those manipulated recordings or her own re-creations, mobilize the same tools Western music has used to separate the human from the nonhuman to perform their unity. The most "human" of all the

\footnotetext{
${ }^{20}$ Available at https://www.youtube.com/watch?v=DTP1UmBrR-Q

${ }^{21}$ Available at https://www.youtube.com/watch?v=fd3645ki1y4

${ }^{22}$ Available at https://www.youtube.com/watch?v=WCeFJWy82rM
} 
instruments - the human voice - recreates animal sounds not to bestow humanity, but to perform their likeness. By using the same compositional and analytical tools that would divide humans and nonhumans to instead demonstrate their similarities, Tagaq uses "modenity's tools" to "respect traditional ways" (Monani 2014, 236) and assert worldviews that colonial history has oppressed.

The artistic extension of personhood to nonhumans is clearest in Tagaq's collaboration with Paul Raphaël, Felix Lajeunesse, and Zacharias Kunuk in the short film Tungijuq ("What We Eat," 2009). ${ }^{23}$ Here, both visual and sonic material work together to demonstrate that humans and animals are connected through their shared spiritual kinship and the cycles of life and death. The film opens with Tagaq covered in furs, alone in a snowy landscape. Tagaq's vocal growl on the accompanying soundtrack synchronizes with her abrupt turn to look over her fur-clad shoulder on-screen. The vocal track, Tagaq's sudden movements, wild hair, coloured contact lenses, pale makeup, and thick furs introduce a sense that Tagaq here is playing a wolf. This is confirmed in the next two scenes, when Tagaq's back to the camera reveals a swinging wolf tail as the vocalist stares across the tundra, apparently sensing the running caribou revealed in the next shot. Tagaq's position as a predator on the hunt is further established as the camera zooms into Tagaq's eyes as they fixate on the distant target. On the soundtrack, Tagaq sustains an intense groan that slowly increases in volume as the camera zooms into her gaze. The synchronized zoom of the camera and rising volume of the track seem to suggest that the music set to this video represents the character's internal voice - in this case, suitably characterized as a human voice. In the next scene, the wolf chases its prey, running down the caribou and biting its neck. Tagaq no longer plays the wolf in the video, but the audio track continues to position her

\footnotetext{
${ }^{23}$ Available at http://www.isuma.tv/tungijuq/tungijuq720p
} 
voice as the animals: her stylized throat-singing mimics the panting of the running animals on video, abruptly cutting off with a gasp as the wolf grabs the caribou's throat. In the next scene, the caribou is no longer shown as a fully computer-generated animal but is now played by Tagaq in a new costume of caribou fur and antlers. The music switches to pained sobs, as Tagaq performs the caribou's pain both in the video and audio. Tagaq as the injured caribou suddenly transforms onscreen to a fully human, injured woman. Gone are the fur and antlers, however Tagaq's naked body still displays the injuries sustained by the wolf hunt. If the previous two minutes of the video suggested that animals share a common nature with humans through Tagaq's performance of their internal voices and her embodiment of each animal, the suggestion becomes more of a statement with this visual transformation from animal form to human. In the next minute, Tagaq transforms once more from human back to animal when she rolls into the icy water and her body changes to that of a seal. The seal is shot and harvested by two Inuit, one of whom is revealed to be Tagaq again, this time dressed in Inuit clothing made of furs. Tagaq, this time as an Inuk hunter, eats the seal's raw meat as her performance on the audio track takes on the more structured elements of traditional katajjaq, such as its alternation between two voices and the repetition of the leader's pattern.

This film was conceived by Kunuk as a response to the anti-seal hunt lobbying of celebrities like Brigitte Bardot and Paul McCartney; he evokes "the eternal reality of hunting" (Isuma TV 2009) and "the organic and indisputable reality of hunting in Inuit culture" (Munday 2012). Here, many aspects of Inuit culture and worldview are referenced: over the span of the film's five-minute duration, the cycles of birth, death, and re-birth, inuat and their transformative abilities, and the values of respect and sharing within hunting practices all come into play. What is prominent through Tagaq's performances on the visual and audio components is a creative 
expression of Inuit ecological views that does not separate humanity from the rest of the world, and believes that each human and nonhuman has its own spiritual force. By performing each of the "characters" herself (wolf, caribou, seal, human), Tagaq suggests that each are equal and linked to one another, sharing in a common spiritual condition of personhood. The choice to perform the conscious state of the animals through the human voice and vocal idioms that include groans and sighs, rather than simply sounding out animal vocal patterns further reinforces that humans and animals are part of the same cosmic family.

\section{The Transnational Arctic}

As I have discussed, Tanya Tagaq's artistic practice incorporates several elements of traditional Inuit ecological views. The dissolution of the human/nonhuman boundary recurs throughout Tagaq's albums, alongside other allusions to the cosmological dimensions of the environment. The music videos for "Sivulivinivut" ("ancestors"), ${ }^{24}$ for example, creatively alludes to the residence of ancestral spirits in nature by showing video collages of northern lights during Tagaq's whispered prayer to her ancestors. However, Inuit communities and the Arctic itself are not completely isolated from global forces and societies. As such, Inuit constructions of place are not just based on traditional culture, but also emerge from living with and adapting to transnational forces and phenomena. For example, many traditional subsistence practices adapted with the influx of new tools from cross-cultural exchanges. In the Canadian Arctic's more recent history, Inuit ways of interacting with the land have transformed in the face of the Canadian government's displacement of Inuit groups from their traditional homelands into southern-style settlements, imposition of a wage-based labour economy, and marginalization of traditional

\footnotetext{
${ }^{24}$ Available at https://www.youtube.com/watch?v=qtAUoIbsTAQ
} 
judicial systems. With these abrupt changes to Inuit practices, traditional ways of knowing and viewing the land have also changed. The effects of these and other transnational interactions continue in Arctic communities today, where Inuit continue to negotiate between local values and imported systems (see for example, Billson and Mancini 2007; Nuttall 1992, 1998, Dorais 1997).

Tagaq's own musical practices testify to transnational presences in the Arctic and their impact on its inhabitants. The vocalist taught herself throat-singing while living in Halifax as a young adult by listening to cassette tapes sent from her mother in Cambridge Bay. Although it has now experienced a resurgence, katajjaq nearly disappeared due to suppression by Christian missionaries (Nattiez 2019). Rather than hearing traditional Inuit music practices as a child, Tagaq grew up listening to her father's records: Led Zeppelin, Boney M, Peter Tosh, Simon and Garfunkel, Jimi Hendrix, the Doors, the Beatles, and Janis Joplin; as she recounts, "A lot of really good, high quality, awesome exploratory music" (Tagaq to Green 2016). Tagaq thus fuses elements of many Western music genres with those of Inuit throat-singing in a variety of ways, bringing the "intonation contours, exhaled and inhaled sounds, voiced and voiceless sounds, the throat technique, and imitation of animals in the voice and in the body movements" (Nattiez 1999, 412, as cited in Taylor-Neu 2018, 116) together with orchestral elements, electronic dance music, and hip-hop, for example (see Stévance 2014, 2017 and Taylor-Neu 2018 for more information). "[All these genres] were living in my body anyway," Tagaq explains (Red Bull Music Academy 2016).

Even Tagaq's use of music to explore the relationships between humans and the environment demonstrates an interplay between local cultural traditions and Western popular music ideologies. Inuit vocal genres have traditionally involved a relationship with the 
environment, either through inspiration or interaction. While katajjaq largely involves vocal mimcry of environment sounds and pisiiq (Inuit drum-dance songs) poetics are inspired by being on the land (Conlon 2010, 9), Inuit shamanic songs delve into using sound - songs chants, etc.to communicate with and influence the outside world. Daniel Merkur notes that in pre-Christian Inuit practices, "Inuit shamans have a lore of their own. A secret language is employed whenever they converse with spirits. Magic words or spells and magic songs may be used to control both malicious and helping spirits" $(2014,5)$. Shaman activity here focuses on interacting with spirits, ghosts, and inua, the spiritual indwellers of nature to facilitate healing, influence hunting outcomes, and predict weather events (Merkur 2014, 6). As the land and its inhabitants are seen as animate and sentient, sound has prominence in Inuit ways of interacting with these forces. Arctic explorer and ethnographer Knud Rasmussen, in his description of a song festival on Igloolik Island, notes that qilaut, the Inuit drum, "means literally: 'that by means of which the spirits are called up'," and that "the old ones"-Inuit elders - teach that "song came to man from the souls in the Land of the Dead, brought thence by a shaman; spirit songs are therefore the beginning of all song" (Rasmussen 1929, 228-229). While I cannot speculate whether Tagaq is similarly using sound to personally interact with spiritual forces that indwell the environment, her use of sound to denote a relationship between active, autonomous beings, human and nonhuman, can be considered as part of the lineage of Inuit musical practices that similarly use sound within the dynamic relationship between humans and environmental forces.

Tagaq's practice also partly grows out of Western music traditions, which also have a legacy of artists using sound to mediate human-nature relationships. In the convergence of Bloch and Adorno's theorizations of music's ability to model utopian ideals, composer John Cage's reframing of music as ecology, and the influence of the New Ecological Paradigm in the arts 
(Ingram 2010, 12), artists and scholars in the late twentieth century began to explore art as a means to realize the "ecological self": ${ }^{25}$ Suzi Gablik's ecological theory of art in The Reenchantment of Art forwards art's ability to "[emphasize] our essential interconnectedness rather than our separatedness" $(1991,62)$, and Charles Keil and Patricia Campbell's project Born to Groove (2006) mobilizes music to revitalize people's connections with each other and with nature (Wagner 2010, 243). This "ecologization of sound” (Ingram 2010, as cited in Gautier 2016, 125) positions music and listening as "that which politically resolves the separation between nature and the human" (Gautier 2016, 125). David Ingram, author of Jukebox in the Garden (2010), suggests that since the 1970s, popular music genres incorporate theorizations of music and ecology in their practice. A wide range of popular music styles, including folk, blues, country, rock counterculture, electronica, and jazz, explore music's capacity to "tune the relationship between the humans and the world" (Gautier 2016, 118). Beyond fusing sonic elements of Western music and Inuit throat-singing, Tagaq's very use of music to evoke Inuit ecological perspectives thus demonstrates the negotiation between Inuit traditions and Western ideologies of sound. This at least partly emerges from growing up in an Arctic community that had experienced an importation of southern culture and suppression of local traditions - those same transnational forces that impact local constructions of place. Therefore, Tagaq's use of transcultural musical expressions in evoking place within her music is congruent with Inuit environmental perspectives, which similarly contend with transnational processes.

\footnotetext{
${ }^{25}$ In contrast to the individualism of Liberalism, ecological self is a relational view of self in the world, where one is connected in a web of relationships to other components of the natural world. This view of self-in-relation is thus more attuned to the interests and actions of other ecological components and the self's interaction with them (Ingram 2016, 15).
} 
Tagaq's fusion of Inuit and non-Inuit music styles to evoke Arctic places occurs throughout Animism (2014) and Retribution (2016). "Umingmak"26 from Animism, for example, “takes listeners atop the Augustus Hills near Tagaq's hometown of Cambridge Bay, where she recalls spending a blissful day watching a herd of muskox graze by" (Rogers 2014). In this song, the memory of muskox is performed through signifiers of Inuit culture such as the Inuktitut title and the vocal stylistic elements of katajjaq, free improvisations on the violin and drums and, for the last third of the song, electronic dance music. While performing a memory of a place through musical fusion demonstrates Tagaq's own artistic agency, it also flows from the reality that Inuit build and experience local places through a nexus of complicated transnational processes. The track “Summoning” on Tagaq's next album Retribution (2016) displays similar characteristics. One of the most expansive tracks on the album, this eight-minute long recording features the album's largest ensemble of musicians performing live improvisations. Here, Tagaq is joined by her regular collaborators Jean Martin (drums), Jesse Zubot (strings), Bernard Falaise (guitar), the experimental group The Element Choir led by Christine Duncan, and uses sound recordings from Cambridge Bay of footsteps on snow and ravens croaking recorded by her father, Rick Gillis. In her commentary about the track with Carl Wilson, Tagaq describes "Summoning" as a soundscape:

You know how smells will give you a memory, or looking around at your environment will give you a feeling? I feel like some of these sounds, you can really see where you are or where you're going. I love the idea of having an environment placed around you sonically and have it be intangible (Tagaq 2016b).

In "Summoning," Tagaq and the musical ensemble build the environment through an array of musical techniques stemming from a variety of music cultures. While Tagaq vocalizes using katajjaq-style pitched inhalations and exhalations, Christine Duncan and the Element

\footnotetext{
${ }^{26}$ Available at https://www.youtube.com/watch?v=O9-HuHhm5fs
} 
Choir improvise using extended vocal techniques that spring from both jazz and avant-garde art song traditions. Jesse Zubot improvises drones, extended techniques, and four-note motives on violin, and Jean Martin adds rhythmic layers on drum kits and through electronics. Heavily distorted electric guitar, played by Bernard Falaise, adds a thick layer to the sonic texture about five minutes into the track. Such a wide array of performers and music styles produces a particular quality of sound, but also demonstrates that life in the Arctic today is constituted of transnational relationships and forces. While Inuit may see the land animated by those sociocosmic relationships and governed by maligait, rules to respectfully interact with the metaphysical world (Price 2008, 127), these environments includes local and non-local inhabitants: multicultural settlements, international transport vessels, and resource extraction technology and practices. Moreover, the local features of the environment transform in response to global phenomena: global warming, exacerbated by the burning of fossil fuels and the clearing of land for agriculture and industry around the world, is seen in the Arctic's melting multi-year sea ice, altered seasonal patterns, and shifting water currents due to rising sea levels. It is heard in the rising noise levels of underwater environments, as shipping vessels, fossil fuel exploration, and military sonar push further and further north due to the opening of previously inaccessible northern water passages (Luber 2018). As the local features of the environment alter in response to this global phenomena, Inuit view of the environment similarly change. Fear of the unpredictable and dangerous conditions, for example, run through interviews of Inuit who feel the effects of climate change (Sila Alangotok: Inuit Observations on Climate Change 2000). Inuit ways of connecting with the land are further altered by global forces: consuming "country foods" like seal meat and Arctic char, long believed to a significant part of forging personal connections between Inuit and their environments, becomes increasingly dangerous due to the 
persistent organic pollutants found in the animals' bodies. Inuit experiences and responses to climate change will be explored in Chapter Three, but the point here is that the life in the Arctic implicates broad transnational interactions, so Inuit experiences and views of the land are similarly affected by transnational processes. Jackie Price makes this point clear in Lighting the Eighth Fire:

Climate change and resource development are changing the land physically, and this is changing the relationship Inuit have with the land. It is important to acknowledge that these new changes are in addition to challenges Inuit continue to experience as a result of being forcefully removed from their independent and subsistent lives on the land. New political strategies are needed in order to strengthen the relationship Inuit have with each other, and with the land (Price 2008, 127).

As transnational presences and processes like colonization and climate change impact Inuit views of the environment, Tanya Tagaq's performance of place through transcultural musical expressions thus resonates with contemporary Inuit views of place, which similarly emerge from local values and transnational processes. Tracks like "Umingmak" and "Summoning" demonstrate the reality that Arctic environments are constituted of transnational presences, and Inuit conceptualizations of the land are influenced by transnational processes.

\section{Conclusion}

While lyrics educate audiences in thought-provoking ways, human language can be a limited medium to express the nonhuman realm and relations (Bellarsi 2003, 164). Tagaq's musical practices demonstrate an "ecocritical aesthetic" (Bellarsi 2003, 164) that engages both Inuit and non-Inuit music forms, techniques, and technologies to communicate decolonized Inuit environmental perspectives. In doing so, Tagaq contributes to the decolonization of Western and Inuit minds by affirming the "dignity and legitimacy of Indigenous peoples and their 
perspectives" (Ansloos 2017, 55), and rejecting Western constructions of Arctic environments and their residents. Western visions of the North, formed through "a history of repetition of the constant return to fixed topoi and intertexts" (Ryall et. al 2010, x), manifest in environmental discourses throughout Canada. The Arctic has long been viewed by southern Canadians through the elastic construction of northern "wilderness"-- by one turn the Arctic is imagined as "deadly, cold, empty, barren, isolated, and mysterious," and another as rich in "sublime beauty, abundance, natural sources, and waiting to be exploited, and of great spiritual power" (Grace 2001, 16). In these ideas about the north, "the we, my, us, or our that is tacitly assumed as authoritative speaker or attentive listener rarely lives north of sixty and cannot possibly inhabit North" (Grace 2001, 16). As an Indigenous Arctic resident, Tagaq's performance of Inuit views of the Arctic supplants outside visions with environmental views that are formed from within the Arctic. Furthermore, by artistically performing the transnational systems within Arctic environments, Tagaq faces down popular mythology about Inuit. As Laura Martin notes,

Arctic peoples, among the most easily recognized ethnographic populations, remain a poorly understood group about whom other easy generalizations are routine: they eat only raw meat, they give their wives as gifts to strangers, they rub noses instead of kissing, they send their elderly out on ice floes to die. We are prepared to believe almost anything about such an unfamiliar and peculiar group (Martin 1986, 420, as cited in Steckley 2008, 9).

Tagaq's musical demonstration that life in the Arctic is not isolated from transnational exchanges challenges romantic notions of the Arctic and Inuit as static and pre-modern, and reflects the reality that Inuit are as interconnected to global communities and phenomena as any other people. In these ways, Tagaq's performance of pre-Christian Inuit ecological perspectives and contemporary realities of Inuit life on the land answer Kanien'kehá:ka scholar Taiaiake 
Alfred's call to find "new ways to love the land, and new ways to love ourselves and our people" (Alfred 2008, 10). 


\section{Chapter Two: Silatuniq on Stage}

In their publication "Decolonization is not a Metaphor," authors Eve Tuck and K. Wayne Yang remind readers that decolonization does not occur in the mind alone. "We agree that curricula, literature, and pedagogy can be crafted to aid people in learning to see settler colonialism, to articulate critiques of settler epistemology, and set aside settler histories and values in search of ethics that reject domination and exploitation; this is not unimportant" (2012, 19). What is needed in addition to "conscientization" is real action to undo colonization. ${ }^{27}$ As colonization occurs within a variety of sites for different people, decolonization will then necessarily "take a different shape in each of these contexts" $(2012,5)$.

In this chapter, I suggest that Tanya Tagaq's creative processes in live performances demonstrate Yang and Tuck's call to action through her embodiment of Inuit ontology. While Yang and Tuck describe colonization as targeting Indigenous "sexuality, legality, and raciality, language, religion and property in specific ways" $(2012,21)$, Roxana $\mathrm{Ng}$ adds that ways of being - everyday habits — can further produce and sustain systems of oppression:

We produce oppression through normalized patterns of behaviour that have developed over time and have become "natural," automatic, and unconscious actions and ways of being in the world. Thus, I use the notion of decolonization to indicate the practices in which we can engage to free us from ideas and ideology, on the one hand, and action and behaviour, on the other, that serve as sources of separation $(2018,51)$.

\footnotetext{
27 To Battiste's “cognitive colonialism” Yang and Tuck (2012) add "external colonialism” and "internal colonialism." Where the former refers to the "expropriation of fragments of Indigenous worlds, animals plants and human beings, extracting them in order them to - and build the wealth, the privilege, or feed the appetites of - the colonizers" $(2012,4)$, "internal colonialism" is the biopolitical and geopolitical management of people, land, flora and fauna within the "domestic" borders of the imperial nation" $(2012,4)$.
} 
In light of Ng's point towards decolonizing the ways individuals act in collectivities, I turn attention away from Tagaq's artistic products — whether they are albums, music videos, or films - and towards engaging Tagaq's artistic process. Tagaq's live performances work through a network of relationships: the performance space, audience members, and other musicians are all implicated in Tagaq's artistic productions. When framed as an ecosystem, I suggest that Tagaq's dynamic exchanges with each member of this system acts through the same relational view of self-in-world that permeates Inuit ecology and underlies the principles in Inuit ontology. By actively participating in an Inuit-centered way of occupying the world on stage, Tagaq actively, rather than metaphorically, performs the extended ontological implications of decolonized Inuit ecology.

To tease out Tagaq's performance of Inuit ontology, I use social scientist Timothy Leduc's and Inuk philosopher Jaypeetee Arnakak's dialogue on Sila ${ }^{28}$ and Silatuniq ${ }^{29}$ as an entry point to understanding the relationality of Inuit ecology and ontology. I then apply the contextualizing lessons of Sila and Silatuniq to Tagaq's collaborations on stage. While Tagaq does not explicitly name either Sila or Silatuniq in interviews, I suggest that recurring elements of Tagaq's artistic processes adhere to the improvisational way of living that Sila teaches in Inuit ecology. Specifically, I point to Tagaq's sensitivity and reactivity to the interconnections between "ecological" components on stage as demonstrating the same attunement to

\footnotetext{
${ }^{28}$ The capitalization of Sila varies throughout scholarly work. As Sila appears in writings about Inuit wisdom, traditional ecological knowledge, and a spirituality, there does not seem to be a consensus on how Sila should be stylized. Following Arnakak's example and for consistency's sake, in this thesis I use the uppercase for both Sila and Silatuniq.

${ }^{29}$ As will be described in more detail later, Sila is a cosmological/environmental force that ties together atmospheric phenomena and a body's soul, understanding them to be in a simultaneously affecting and affected relationship. Silatuniq is the wisdom that arises from attention to Sila and inquires Silatuniq into "the context and consequence of applying knowledge and/or how our interacting with the surround affects that surround."(Arnakak in Leduc 2011).
} 
environmental fluxes that Inuit conduct requires. I further suggest that Tagaq's corporeal practices resonate with the Inuit concept Silatuniq, the wisdom that arises when living a deeply interconnected existence. I end with a discussion of the affective nature of Tagaq's performances, comparing Tagaq's intentions to make her audiences "feel" to the experiential and bodily ways of knowing the world that Inuit ecology and ontology emphasize.

Sila

Over the last decades both scientific and social science studies of environmental issues in academia have increasingly incorporated Indigenous knowledges into their inquiries. In the Arctic, Inuit observations of ice freeze and thaw cycles, changing animal migratory routes and populations, and other ecological phenomena are integral to climatic research. A problematic pattern has emerged however: scientists frequently divorce these observations from their cultural frame of reference. By isolating quantitative observations from interpretive frameworks, researchers participate in epistemological colonialism that ignores the complexities of Indigenous knowledge and experience. As Shari Fox notes, “Although many northern scholars acknowledge how deeply Inuit are tied to the land in terms of subsistence, knowledge, culture, and spirituality, they often fail to address the latter two themes in discussions related to environmental change.” (2002, 45, as cited in Leduc 2007, 239). The dissonance between Western and Inuit perceptions of the environment is exemplified in the inconsistent and inappropriate translations of Sila.

The Inuktitut word "Sila” and its regional variants appear in two Western literatures: scientific climatic studies and Inuit ethnographies. In the first, Sila is translated into English as 
“weather" (Jolly et al 2002; Thorpe et al 2002, as cited in Leduc 2010, 20). Alternatively, Inuit ethnographies published in the early twentieth century characterize Sila as a central deity in Inuit societies. As Leduc recounts in Climate Culture Change, ethnographers such as Knud Rasmussen heard Sila described as "the spirit of the air, a mystic power permeating all of existence and a god-like 'Supreme being"' (2010, 20). Najagneq, an Inuk shaman, describes Sila as:

So mighty that his speech to man comes not through ordinary words, but through storms, snowfall, rain showers, the sea, through all the forces that man fears, or through sunshine, calm seas or small, innocent children... When times are good, Sila has nothing to say to mankind. He has disappeared into his infinite nothingness and remains away as long as people do not abuse life but have respect for their daily food. No one has ever seen Sila. His place is so mysterious that he is with us and infinitely far away at the same time. (cited in Leduc 2010, 21-22).

While these two definitions of Sila may be difficult to reconcile, researchers and writers from southern $^{30}$ institutions and organizations have dialogued with Inuit elders and philosophers to further understand Sila and its importance to Inuit worldviews (e.g., Merkur, Leduc, Ernsting). Through correspondences that extended over the past decade, Inuk philosopher, author, and political advisor Jaypeetee Arnakak and social scientist Timothy B. Leduc define many of the intricacies of Sila, its potential to bridge the divides between separate cultural environmental views, and its significance to Inuit ontology: "Trying to give me a broad sense of [Sila]," writes Leduc, "[Arnakak] described Sila as an ever-moving and immanent force that surrounds and permeates Inuit life, with it most often being experienced in the weather" $(2010,19)$. Sila is recognized to have its own, autonomous consciousness that responds to the behaviour of the other members in Arctic ecosystems, including humans, animals, the land, and the sea. As

\footnotetext{
${ }^{30}$ Many pieces of literature about Northern North America refer to the more the more densely populated areas of Canada, especially along the American border, as the "south."
} 
Laugrand writes, "If human beings misbehave, the weather, the land, or the animals will retaliate" $(2016,150)$. Given that Sila responds to living behaviours, it thus has regional variance: a set of relations and interactions in one region affect Sila in the surroundings to behave one way, where in another region it may behave in another (Leduc 2007, 239). Still, while action and reaction may account for Sila's flux, Arnakak and Leduc emphasize that, as a sentient consciousness, Sila itself is unpredictable. It may manifest a calm, gentle breeze one moment, then swing into a volatile storm in the next.

Sila is not understood as just one component in a web of dynamic relationships in northern ecosystems, but rather a force that encompasses the whole of the system, connecting humans and nonhumans in intimate ways. In traditional Inuit beliefs, Sila was understood as the principal animator of the world, who can be known through the weather. Rachel Qitsualik, an Inuk philosopher and writer for Nunatsiaq News, explains:

Sila, for Inuit, became a raw life force that lay over the entire land; that could be felt as air, seen as sky, and lived as breath... Life itself was in fact the breath, the Sila, and when Sila was drawn into a body, it was alive and animate... Although today as "air" or "weather" or even "outside," the modern translations of Sila only convey to non-Inuit ideas associated with English words. When I speak of "air" to a southerner, what immediately comes to his or her mind is the idea of invisible, breathable gas: the nitrogen, oxygen, and other gases that make up Earth's atmosphere (Qitsualik 1998, as cited in Leduc 2010, 24-25).

Qitsualik's description illuminates the stark contrast between Western and Inuit ideas of weather. She illustrates a vision that connects life, death, and air, where one cannot be isolated from the others. Daniel Merkur describes Sila as the "breath-soul" (Merkur 1983, 24), the life force which enters living things upon their birth and is released back into the atmosphere upon their death. Qitsualik adds that "when any creature— human or beast—perished, its Sila (breath/life) was essentially believed to leave that particular body, after which it could linger for a time, dissipate 
into the larger whole, or find its way to a new form" (1998, cited in Fredrickson 2015, 82). In this view, all atmospheric phenomena and living things share and participate in a common cosmic force.

As Sila is the source of all life, Inuit consider themselves a manifestation of Sila. Arnakak explains "Sila is not our personification, as represented in much of ethnographic literature, but "we are the personification of Sila"" (Leduc 2010, 28). Arnakak further describes Sila as the substance of life by detailing Silarjuaq — the suffix "rjuaq" referring to something big, great, or large:

Silarjuaq is without a creator. Beings — whether they be animal, human or spiritbecome and pass away within it. Silarjuaq just is. Silarjuaq is also in a state of constant flux and change — reflecting the human mind... To outsiders (e.g., Rasmussen), Silarjuaq would be said to be anthropomorphized, but some Inuit would say that it is we living beings that are Silarjuapomorphized. Silarjuaq has natural rhythms and cycles as seen in the changing seasons... everything is mutable - only sentience, order and change are constant (Leduc 2010, 30).

Arnakak's “Silajuapomorphization" demonstrates an inversion of Western frameworks. Rather than understanding Sila as "secondary to human conceptions" (Leduc 2010, 30), Silajuaporphization situates humans (and nonhumans) as emerging from a broad cosmological force that encompasses ecological networks. Not only are all members of such systems similarly emergent and connected, human will, thoughts, and creativity are also functions of Sila. In his record of the Fifth Thule Expedition, Knud Rasmussen includes a Netsilik poet's explanation of the relationship between Sila and the human mind:

There are so many occasions in one's life when a joy or a sorrow is felt in such a way that the desire comes to sing... All my being is song, and I sing as I draw breath... Songs are thoughts, sung out with the breath when people are moved by great forces and ordinary speech no longer suffices. Man is moved just like the ice floe sailing here and there out in the current. His thoughts are driven by a flowing force when he feels joy, when he feels fear, when he feels sorrow. Thoughts can wash over him like a flood, making his breath 
come in gasps and his heart throb. Something, like an abatement in the weather, will keep him thawed up. And then it will happen that we, who always think we are small, will feel still smaller. And we will fear to use words. But it will happen that the words we need will come of themselves. When the words we want to use shoot up of themselves - we get a new song (Rasmussen 1931, 321 as cited in Merkur 1983, 27).

Daniel Merkur explains that this "likening of 'an abatement in the weather' to a temporary inability to create a song is... not metaphoric but sympathetic" (Merkur 1983, 27). To this poet, song, thought, and breath are functions of Sila, and participate in its flux. Nuttall further explores the connection between Sila and the mind in his study of child development in Kangersuatsiq, where he finds that Sila is implicated in Inuit views on maturation. He writes:

Sila is the natural order, a universal consciousness and breath soul that contains within it all individual breath souls... Sila connects a person with the rhythms of the universe, enlarging and integrating the self with the natural world... Sila links the individual self and the environment, the personal and the universal. As the universal Mind, [S]ila is the ground for the existence of every individual sub-mind present in each person. A person who lacks [S]ila is said to be separated from an essential relationship with the environment that is necessary for social and psychological well-being. In the sense used here, [S]ila refers to a person's consciousness, intelligence and reasonable and sensible behaviour.... Sila is an external force that interacts with the persona and manifests itself in what we understand as intelligence and awareness. It is inextricably linked with isuma; 'mind/rationality'. Sila is present in every child in latent form and develops as the child grows and explores the surrounding world (Nuttall 1992, 69).

Nuttall's description of Sila here indicates an important point: Sila is not just significant to Inuit ecological and cosmological systems but forms the foundation for Inuit views of themselves and appropriate ways of interacting with the world. Sila becomes the spiritual reference that contextualizes human relations "within broader ecological processes like the weather" (Leduc 2010,27), discouraging self interest and building a sense of reciprocity between all ecological components (Leduc 2010, 189). Arnakak calls this the "Sila hypothesis":

This hypothesis confronts a Western view of climate change as an external process that can be predicted, controlled, and even profited upon, and in its place prioritizes an ethic 
of social responsibility towards an uncertain, animate, and responsive world (Leduc 2010, 244).

Silatuniq ("wisdom") arises from experiencing and acting on the contextualizing power of Sila (Fredrickson 2015, 59). According to Arnakak and Leduc, Silatuniq "is concerned with a way of living that is aware of the limits to knowledge in a deeply interconnected existence.

Wisdom is a kind of etiquette for complementing and contextualizing what is knowable" (Leduc 2013, 108). This wisdom is one that recognizes that "interacting with the surround affects that surround" (Leduc 2013, 108), and applies knowledge in view of this deeply interconnected way of being. To be wise, then, is to recognize that outcomes are contingent on an infinite combination of relationships and are thus unpredictable, and people must live open and responsive to the unknown. In Inuit hunting practices, for example, hunting parties constantly shift consensus concerning where game might be found, demonstrating a flexible practice that accepts the interconnections of all possible factors. Every decision is alterable in light of changing circumstances (Leduc 2010, 192). This open-ended approach to hunting permeates Inuit ontology. Rebecca Fredrickson aptly terms this as an "improvisational style of inhabiting the world" (Fredrickson 2015, 27). While Silatuniq is connected to isuma- which refers to ration, thought, and action (Fredrickson 2015, 110)_Silatuniq engages an inner knowing that is complementary to reason. To be wise according to Inuit Qaujimajatuqangit (IQ), as Inuit elders explain, is to use "head and heart together" (Leduc 2010, 213). Silatuniq, as Arnakak and Leduc explain, is to "allow Sila 'to own us', to allow that uncertain sentience that surround the human field of experience to inform knowledge" (Leduc 2007, 245).

The qualities I have outlined above are a few of the key concepts to understanding the importance of Sila and Silatuniq to the interwoven systems of Inuit ecology, cosmology, and 
ontology. Sila, as the immanent breath-soul, not only becomes the source of human will and creativity, but also contextualizes humans as one component in a reciprocal and equal network of relationships in a given environment. Silatuniq, or wisdom to Sila, requires a sensitivity to interconnections between self and the world, and advocates a way of being where one is continually attuned to the environment. Although Sila and Silatuniq typically only enter academic discourses on Arctic ecology, traditional Inuit cosmology, and Inuit child-rearing practices, the ontology that emerges from Sila and Silatuniq permeates Inuit lifeways. When studying Tanya Tagaq's artistry, I suggest that the fundamental principles of connectedness, sensitivity to relationships, and flexibility that undergird Inuit ecology, cosmology, and ontology also form the foundations of Tagaq's musical processes. As ecocritic Lisa Woynarski writes, "it is through the enactment of Indigenous cosmologies or dramatugies that a nuanced Indigenous ecology may inform theatre and performance" $(2015,189)$. In the following discussion, I consider Tagaq's performances as ecosystem ${ }^{31}$ comprised of both human and nonhuman actors, and compare Tagaq's practices to the relational values of Sila, relying primarily on the vocalists' interviews and recordings of her concerts.

\footnotetext{
${ }^{31}$ My comparison of musical events and ecosystems builds from an approach taken by Ellen Waterman and Alice Boyle in their chapter of Current Directions in Ecomusicology (2016). In "The Ecology of Musical Performance," Waterman and Boyle explored the possibilities for uniting musicology with scientific ecological research, noting that "both disciplines... are centrally concerned with performance broadly defined; that is, the study of how individuals act and interact within a particular place/space/time" (Waterman and Boyle 2016, 36). I deviate from the authors' approach by focusing on the principles that guide such interactions, both in ecosystems and performances. Where Western frameworks might consider ecological studies a non-social pursuit, Inuit ecological perspectives are encompassed by Inuit Qaujimajatuqangit (IQ), which grounds humans in "relational ways of knowing and being that are anchored in the land" (Greenwood 2017, 221), and teaches respect towards "Elders, the land, sea and sky and all living things; and harmony and balance in relationships between people and the living environment" (222). In contrast to Western models, Inuit see ecosystems as a unified whole with dynamic components, in which humans are completely integrated. Furthermore, cultural memory, strong emotions, and personal ties to the land are integral to ecological knowledge (Collignon 2006, 75). Collignon noted that many Inuinnat (Inuit in Cambridge Bay) question the relevance of Western scientific methods $(2006,27)$. Taking incentive from Waterman and Boyle's view of the concert stage as an ecosystem, and learning from ecocritical studies that "ecosystem" signifies different values for different peoples, in this chapter I investigate the ways Tanya Tagaq's live performances embody Inuit ecological principles.
} 


\section{Performing Interconnections}

"Connection" and "relationship" emerge as common themes throughout Tagaq's interviews. To summarize her performances, Tagaq tells journalist Filipenko "my singing is really based in improvisation and freedom from choruses and licks—it's about feeling connected" (Filipenko 2011). This feeling of connection pervades all levels of the vocalist's performances, and displays the values of equality, interaction, and reciprocity that Sila implies. Perhaps the most explicit way Tagaq's demonstrates her values of "connection" and "relationship" is in her collaborations with other musicians. Tagaq is known for making music with people from different countries, cultures, and music genres. Her first album Sinaa (2005) was produced in collaboration with Icelandic superstar Björk and features Basque percussionist Ugarte Anaik; her second album Auk/Blood (2008) features Buck 65, Cree-Mennonite cellist Cris Derksen and beat-boxer Shamik Bilgi. Animism (2014) features Toronto's improvisational Element Choir throughout and the Belgian opera singer Anna Pardo Canedo. On Tagaq's latest album, hip-hop artist Shad, Tuvan throat singer Radik Tulush, and Inuk drum-dance singer Ruben Komanjapik join Tagaq's vocals. Her own albums aside, Tagaq collaborates on many other projects with various artists. She has frequently worked with Kronos Quartet, classical composer Derek Charke, and symphony orchestras across Canada. In 2015 she joined Mike Haliechuk from the hardcore punk band Fucked Up to release Our Own Blood. More recently (2017), Tagaq worked with alternative rock bands July Talk and Weaves.

When asked about creating music cross-culturally and across genres, Tagaq describes her choice in partner as a matter of friendship:

I think my number one collaboration thing is they can't be a jerk. I need to like people because I firmly believe if you get along with someone then you'll make good music. 
Anytime I've tried to work with someone that I don't like, it feels wrong. It's very intimate for me. It's a sharing and something very sacred; you know like breaking bread at a really good meal that you spent a long time making. Or having sex with someone... Making music is something you need to honor... Basically, music and sex have the same moral status for me: you don't do it with everyone. Of course, they have to be good at what they're doing and they have to feel right... I'd try anything if it came in the right form. So I wouldn't say I'm drawn to anything in particular and my second album, the musicians I picked were all friends of mine. Like I picked them regardless of what they did; I chose to work with them... So when people go, "Why do you do all that hip-hop stuff in there?" I go I knew Rich [Ricardo Terfry a.k.a. Buck 65] for 12 years and he's awesome and my friend [Vancouver-based vocalist] Shamik is a really good beat-boxer. It's that simple and I kind of lead my life that way (Callen 2010).

As statements like this demonstrate, Tagaq's choice of partners comes from a place of inner knowing - a feeling about the person with whom she works. This inner knowing prioritizes the relationship between Tagaq and the other musician, as this connection will shape the music.

Social ethic takes precedence over other aspects of creating music, such as technical ability, as Tagaq recognizes that music is sensitive and responsive to relationships. In the same way, Tagaq and Jesse Zubot — her frequent collaborator-emphasize the equality and reciprocity between musicians on stage. During their improvisations, Tagaq and the other musicians switch roles as leaders and followers. Each is attuned and responsive to the other's musical direction, while also enjoying the freedom to begin a new "movement" 32 at any time. Tagaq describes this relationship in an interview with The Globe and Mail reporter Everett-Green, saying "Someone's always leading, but the leader can change at any moment. In that way it's like traditional throat singing." (2014) Jesse Zubot goes into further detail about the relationship between performers on stage in an interview with Fuse TV (2017):

Every show we've ever done... it'll be totally improvised. Except there's a few things that reoccur in shows that will come in certain times, but we don't know when they're going to happen. We just have to go by the feel. The leader of the scenario changes. There'll be moments where Tanya will start something and I'll jump on her back and

\footnotetext{
${ }^{32}$ Zubot uses the term "movement" to describe the different areas of intensity and musical themes that occur during their long performances.
} 
start kind of supporting her. Sometimes Jean will start playing to support both of us, or he might play something completely different to piss us off. And then Tanya might potentially go with him to make him feel good for a little while, and then I'll stay where I was just to make the moment feel stretched out and uncomfortable. And we'll go through this and do these shifts around the stage and everything will come together and rise and become more powerful (Fuse TV 2017).

The unpredictability that Zubot describes will be discussed further on, but here Zubot gave some insight to the nature of what occurs on stage. As with a relational ecology, Zubot notes that their performance relies on interactions. One person's music gesture, motive, or intensity provokes a response from the other musicians, which provokes another response, and on and on. What arises from the whole of these interactions is the music- encompassing all the relations that occur within it, where a balance of power creates a balance of sound. Thus in Tagaq's musical collaborations we can see an enactment of Silatuniq. Every performance is unpredictable and open-ended: each collaborator is sensorially attuned to the other musicians, anticipating and responding to the flux of relationships on stage. Furthermore, Tagaq's value on personal connections, friendship, and sharing musical leadership resonates with the ramifications of Sila - as each human and nonhuman emerge from the same cosmic source, every member is equal, all are connected in a spiritual kinship, and a conduct of respect is required of all members.

Tagaq's and Zubot's comments on their approach to improvisation and collaboration are heard in action in their live performances. Tagaq's 2011 live album anuraaqtuq ${ }^{33}$ is a recording of Tagaq, Martin, and Zubot performing an hour-long improvisation on stage at the $26^{\text {th }}$ Festival International de Musique Actuelle in Victoriaville, Quebec, in 2011. The album is divided into five different tracks, although it would be more apt to call these "movements" of the unified

\footnotetext{
${ }^{33}$ Available at https://www.youtube.com/playlist?list=OLAK5uy_nPBaYpcp9qoG5PtG88Htt41JKwuQmXw_g
} 
performance. Throughout the performance, Martin, Tagaq, and Zubot alternate roles as leaders and followers; occasionally a solo emerges from one of the performers, with the other two adding responses to fill out the sound. The fourth movement, "Plume," for example, begins with Tagaq singing Qiujaviit — an Inuit song she added to her album Sinaa - a capella. She transforms the "ajaaja" refrain into the repeated rhythmic, voiced inhalation and exhalation typical of katajjaq, which then becomes a textured backdrop for the entrance of Zubot's sonorous violin passage which occupies the sonic foreground. Tagaq pushes the intensity of their duet forward as she raises the pitch and volume of her repeated rhythms, switching to vocal belting for the pitched sections of her rhythmic motive. Both she and Zubot climb in pitch, sustain a high tone, and come back down in volume, pitch, intensity, etc. Martin joins with a steady pulsing drumbeat, and here Tagaq, Zubot, and Martin sustain the sonic space - there is no push or pull of intensity, no leader. Each performer is improvising independently: Zubot continues his improvisations around sustained pitches; Martin keeps a steady pulse, emphasizing off beats sporadically; and Tagaq creates a mish-mash of sound effects that includes giggles, gasps, voiced inhalations/exhalations, growls, and buzzes. While each performer practices autonomy in their own part of the music, displaying a degree of individualism, they are equally sensitive to each other as they complement each other's intensity, and mutually agree to prolong the moment. The attention to each other's movements and sounds is evident when the moment passes, marked by Tagaq creating a rhythmic line in sync with Martin where previously they each performed according to their own tempo. Martin and Tagaq then move the music forward in a rhythmic duet, with Zubot joining by rubbing the violin strings in time with them. All of this music occurs within the first five minutes of the track; this equal, shared, and responsive partnership characterizes the entire performance. 
In the recording anuraaqtuq we can hear the relationships between musicians. Hidden in the recording, however, is the sense of how the audience effects the performance. For Tagaq, this relationship between performers and audiences is a crucial part of her live performances. "The audience provides so much of the energy," Tagaq tells Sarah Greene from NOW Magazine. "They'll push forth their energy and then I'll release it out of my mouth and it affects them and changes their energy and then they give me more - it's this circle." (2014). She repeats the theme of energy and synergism with the audience to Mary Dickie from Musicworks Magazine:

The audience is giving me this massive amount of energy, and I'm siphoning it through my throat and giving it back. So it's like a circle. We go somewhere together. I like being in that altered state onstage - it's this really pure state of being. I get to live in the exact moment. It's like when you're giving birth, eating a great meal, having an orgasm (2014).

Rather than positioning her audience as the receivers of music, Tagaq considers them as equals to the people with whom she physically occupies the stage. Their act of being present, listening, and responding affects the creation of the music. In this way, a performance is made up of the interactions of all its participants and is responsive to their relations. Audiences then are cocreators with Tagaq: "The audience holds so much power... That's why I love improvisation, because we're working off the audience without their really realizing it" (Edwards 2016).

Tagaq attributes the reciprocal relationship between performers and audience to the fundamental life that all living things share: breath. She tells Jian Ghomeshi from CBC's radio show $Q$ "I love the similarities within humanity. And not just humanity, within life. That's why breath — breath is so important. That's our common denominator" (2014). She goes into further detail about the connections between herself and the audience in an interview with Mike Doherty from Macleans: 
Let's just look at life's lowest common denominator, which is breath and consuming and rejecting waste. This is how I tend to think as a person on a lot of levels: I'll look at things in a very small sense and then I'll blow them up to a very big sense. When it comes to art, I've found if you boil things down to greatest common denominators, then everyone will be able to understand (2018).

Just as Sila is known by Inuit to animate and connect all things in the most basic life function of breathing, Tagaq's comments to Doherty show a similar ideology of rooting interconnections in fundamental mechanics of life. Tagaq does not explicitly connect any of her performance practices and processes to Sila or Silatuniq, however her explanation of her performance processes demonstrates a continuity of the concepts associated with both Inuit terms: life flows from breathing in a shared atmosphere, and this life-giving act thus connects all members of a collectivity. Collectivity and connection are then sensed with the body in ways that the mind may not immediately comprehend, and responsive action must flow from one's sensitivity to dynamic relationships.

In light of Tagaq's emphasis on connections between musicians and audience members and her open-ended approach to creating music, Tanya Tagaq's artistic processes demonstrate a continued enactment of Inuit eco-centered ontology. Inuit ecology understands ecosystems to be comprised of countless interactions with countless outcomes. As anthropologist Jean Briggs writes, "Inuit regard the world as a place where little can be taken for granted, where answers are not fixed and nothing is ever permanently knowable (Briggs 1991, 262 as cited in Fredrickson 2015, 28). Performances, for Tagaq and her collaborators, are similarly unpredictable. As previously noted, Zubot remarks in interviews that he and Tagaq and Martin never know when things are going to happen on stage, and that the musicians rarely discuss a performance beforehand. Tagaq reiterates the unpredictability of her performances herself, noting that she rarely goes into a live performance with a clear view of what will happen on stage (AMBY 
2016), saying "What we want is to be servants to the music. Whatever comes along, we'll be lucky" (Tagaq 2016). In navigating the ecosystem of the stage, Tagaq thus enacts Inuit ontology built on the relationality and flexibility exemplified through Sila and Silatuniq.

\section{Body and Mind}

We've seen that the interpersonal interactions that constitute Tagaq's performances enact a continuity of Inuit ontology. Narrowing the scope even further to consider how Tagaq interacts with herself on stage, I argue that Tagaq's explanation for the inspiration behind her vocal and bodily gestures demonstrates the same embodied attunement to surroundings that are implicated in Silatuniq. As I discuss, Sila's immanence not only surrounds those operating in an environment, but also contributes to the creativity and will of the individual; what Leduc calls "Sila without" and "Sila within" (2010, 30). Heart and mind work in conjunction, however Arnakak notes that "in IQ, it is believed that the physical body is aware of the environment way more than the conscious ego - which one must regard with scepticism and forbearance" (Leduc 2010, 213). Silatuniq then is not necessarily located in rational thought, but in letting the bodysenses, affects, instincts, hunches — guide the mind as it senses its place in the world (Leduc 2010, 213).

Tagaq's internal creative processes mobilize the same bodily awareness that Silatuniq cultivates. In an interview with Jian Ghomeshi in 2014, Tagaq speaks about her creative practices, saying that her own instincts and emotions play a significant role in her performances (Ghomeshi 2014). She characterizes her vocal improvisations not as emergent from conscious reasoning, but rather a corporeal sensitivity to her surroundings: "If they are good shows, I pretty 
much lose consciousness. Nothing exists, but it's not scary, it's total peace. I will hear a tiny voice, and it sounds like it is far away and it gets louder and louder, and then I realise it's coming from my mouth" (Khaleeli 2015). A comment like this might be interpreted as Tagaq isolating her own mind from the world around her, but in light of the relational nature of her performances, I suggest that she is rather giving her body's sensorial awareness and responses to the environment priority over her conscious ego. Tagaq describes her practice as opening herself to the environment:

It is really focusing on that one sense and almost broadening horizons that way. It's kind of ... you're opening. Almost like feeling around for what's happening and responding... I will hear something, and it becomes an idea in my mind or a feeling or a concept and it comes out of my mouth almost involuntarily (Kembrey 2018).

Tagaq's bodily gestures similarly emerge from body awareness. Tagaq's body movements have received attention from researchers such as Sophie Stévance, who has established that Tagaq's body gestures contain symbolic dimensions that address stereotypes of femininity (2014). I will engage with this point more thoroughly in Chapter Four; what interests me here is the following response to Stévance's question of whether Tagaq's body movements evoke something in particular, such as a specific animal: "Most of the time I am unaware of my body movements. Depending on the mood I am in, sometimes, I feel more physical with my sounds, sometimes I feel like retreating physically" (Tagaq in Stévance 2017, 51).

Stévance explains that the co-modal relation between voice and body is procedural, implying "an amplification of the voice's gesture by the movements of the hands or the arms, the intentions of which are intimately connected to body language" (Stévance 2017, 51, paraphrasing Golse 1999). However, as ecocritic Jaqueline Shea Murphy reminds us: 
Indigenous dancers' bodies, despite the physical effects of colonization, are a location of ways of being and knowing, held in bodies and everyday movements. And movement practices - including contemporary movement practices - are tools for locating and unearthing these ways of knowing (2007, 9-10).

Following Murphy and like-minded ecocritic's assertions that body presences and movements demonstrate the continuity of Indigenous lifeways, I view Tagaq's physicality on stage as ontologically significant. Tagaq's bodily gestures seem to proceed from her embodiment of Silatuniq, wherein action proceeds from relational networks, and Inuit ontology that hold the body as more attuned to the world than the mind. ${ }^{34}$

\section{Affect}

The value placed on the sensorial goes beyond Tagaq's artistic inter- and intrapersonal processes to include how she hopes to impact her audiences. According to Tagaq, her practice is one that touches people not just in their heads, but also in their hearts. She tells James Keast from Exclaim! magazine:

For many years, my whole shtick was trying to spread awareness for Indigenous rights and human rights, but when I was younger, people would just roll their eyes. So I [started] doing this wordless performance, to have people understand what it felt like to be an Indigenous woman. And it worked! People were leaving thinking 'Why am I feeling this? What's resonating within me?' (2016).

"Feelings"-including emotions and non-rational, physiological responses like hunches and gutreactions - recur throughout Tagaq's discussions about her performances. "When I sing, I always hope there is one person that starts feeling a feeling that was dead inside them for a long time.

\footnotetext{
${ }^{34}$ See for example Fiskio 2016.
} 
That kind of a goal to wake people up to themselves" Tagaq tells journalist Callen from Pop Matters (2010). Zubot describes in an interview with Everett-Green that "what [Tanya] does is about the moment, and about channelling a place. Most people may not understand where that place is, but they feel it." (2014) To Ghomeshi, Tagaq says she hopes that listeners will "feel what they need to feel from it and then examine that feeling" (2014). As for how audiences actually respond to her performances, listeners seem to have a wide range of reactions - some laugh, break into tears, or express derision (Edwards 2016). "You touched my soul," a listener told Tagaq after a performance in Meaford, Ontario (Giilck 2017). These responses encompass a range of feelings that includes emotional reactions, corporeal responses, and a sense of transcendence. All of these are congruent with "affect." "Most simply put," writes Robert Strachan (2010), "we can understand affect as describing a neurological response to external stimulus." Affect theory arose to contend with the experiences afforded by media or environment that are sensorial and evade cognitive calculation (Massumi 2002; Brennan 2004). Affect implicates mind and body: an affect interacts with human functioning systems like motor control and cognition (Thompson and Biddle 2010,7) and may more or less be translated into reaction or emotion. Strachan notes that Massumi wrote "within affect there is always a residue which escapes capture... an emotional response to an external phenomenon actually derives its intensity and power from elements of affect being untranslated and unknowable" (Massumi 2002, 35, as paraphrased in Strachan 2010). What remains untranslated is integrally linked to the sensor's perspective. "That is why it is classically described as being outside of oneself, at the very point at which one is most intimately and unshareably in contact with oneself and one's vitality" (Massumi 2002, 35, as cited in Strachan 2010). Affectivity in music and sound discourses centres on "notions of interiority, immediacy, [and] immanence" (Scrimshaw 2010, 27), as the 
immersive experience of sound turns senses both inward to the body, and outward to the environment.

There are clear resonances between affect and the wise conduct advocated in Silatuniq. Both contextualize bodies in a dynamic surrounding, where relationships and fluctuations "shape the experiential in ways that may impact upon but nevertheless evade conscious knowing" (Thompson and Biddle 2013,6). As Fredrickson writes, affect may be used to open up a sense of the relationality of the north $(2015,85)$. By seeking to artistically arouse profound, yet unknown, feelings and emotions in her audiences, Tagaq mobilizes a way of knowing the environment that emerges from Arctic cultures. She unites her capacity for reason with those "more sensorial and mimetic ways of knowing” (Leduc 2010, 32), and creates music through "direct, participatory engagement with the local and the particular" (Leduc 2010, 32; Fredrickson 2015, 51), as Inuit ontology requires. Affectivity in Tagaq's performances draws audiences into relationship with each other and with their surroundings in a way that is congruent with Inuit ontology, inviting audiences into Inuit ways of being and knowing the world around them.

\section{Conclusion}

As the body of work by ecomusicologists (Ingram 2010; Pedelty 2012; Allen and Dawe 2016a) demonstrates, music can be an effective tool to recognize, engage, capture, and portray Earth's landscapes and environments (Allen and Dawe 2016b, 7). Furthermore, local environments may shape musical practices: Simonett notes that "musicking and dancing are based on skills, sensitivities, and orientations that have developed through experiencing life with the movements, sounds, and gestures of animals" (Simonett 2016, 102), while ecocritical writers 
like Joanna Mansbridge (2018) suggest that the Indigenous artists act out "ways of relating to the nonhuman world" in their performances (Mansbridge 2018, 118). Within Inuit worldview, ecological wisdom emerges from the body's sensitivity and responsivity the world and its inhabitants. Tagaq's practice goes beyond signifying these values to mobilizing them on stage. Her relationships with audiences and musicians practice a continuity of the connected views of the world that Sila teaches, and Tagaq's musical sensitivity and responsivity to the flux between each relationship around her demonstrates the improvisational way of being implicated in Silatuniq. By allowing her own vocal practices to emerge from an unconscious, corporeal awareness, Tagaq foregrounds the sympathies between the body and the environment, and the environment's ability to act upon and within an individual. She does not try to revive Inuit cosmology by explicitly relating her performances to Sila or Silatuniq, but applies the ontological concepts grounded in cosmology — connectivity, reciprocity, subjectivity — to her performances. Through these practices Tagaq acts out the ontological implications of a decolonized ecology. At the same time, these performances may perpetuate decolonization. By applying the contextualizing lessons of Sila in her music-making Tagaq demonstrates that Inuit traditional knowledge is not limited to the past. Rather, Tagaq's practice exemplifies Joe Karetak and Frank Tester's assertion that Inuit knowledge is relevant and important as a way of being and a way of looking at the world today $(2017,1)$. Furthermore, Tagaq's performance of Inuit ways of being, operationalizing a "felt sense of connection," demonstrates a decolonization of the body. "In retraining our senses to remember how we are related to the rest of creation," writes Nadeau, "we provide an intervention that seeks to decolonize the body's sense of disconnection" (Leon and Nadeau 2018, 78). The affective qualities of her performances similarly invite listeners to renegotiate how they interact with their environment, fostering an ontological 
slippage in mainstream audiences towards Inuit ways of being in the world (Randerson and Yates 2016, 52). Tagaq thus actively, rather than metaphorically, decolonizes public spaces, bodies, artistic processes, and invites audiences to transform their own ways of knowing the world and their place in it. 


\section{Part II: Decolonizing Environmentalism}

Tagaq's performance of Inuit ecological perspectives encompasses a sonic evocation of place (Chapter One) and an enactment of ecologically-rooted ontology on stage (Chapter Two). By working through both Inuit visions and philosophies, Tagaq contests Western constructions of Inuit and Arctic environments and performs Inuit perspectives in public spaces. Such assertions of Inuit values and experiences demonstrate and contribute to a decolonization of both artistic practices and mainstream environmental conceptions. These strategies are more implicit than explicit — rather than directly stating a political or ecological message, Tagaq uses musical performances to invite audiences into new relationships and ways of experiencing the world around them. According to Maori scholar Linda Tuhiwai Smith (1999), “decolonization” also necessitates affirmative social political action, and as noted in the introduction to this thesis, Indigenous eco-activism has long been a site to assert Indigenous environmental perspectives and traditions. How then does Tagaq artistically advocate for environmental justice? How do her artistic eco-activist strategies both emerge from and perpetuate decolonization? In the final two chapters of this thesis, I answer such questions by approaching Tagaq's eco-activist music from two standpoints: first, I attend to Tagaq's music as participating in broader Inuit activism strategies and discourses. Second, following that Inuit and other Indigenous worldviews are holistic and interconnected, I explore how Tagaq's focus on gender and sexuality speaks to environmental justice. Through both discussions it becomes possible to pinpoint Tagaq's method of decolonizing activism: she deconstructs colonial representations implicit in mainstream environmentalist strategies, she centers Inuit voices, actions, experiences, and traditions, and she works through Inuit frameworks to establish non-Western advocacy methods. 


\section{Chapter Three: Embodied Environmentalism}

Although her albums are largely non-lyrical, Tagaq has a lot to say directly to audiences.

"Canadians want to feel good about themselves. But it isn't until we reconcile the past and present effects of colonialism that Canadians can feel good about themselves," Tagaq says in a Globe and Mail article (Lewis 2016). While the "past and present effects of colonialism" Tagaq continues to address range from the continued legacies of residential schools, systemic racism in current Canadian legislations, and the violence against Indigenous women, the next two chapters of my thesis focus on Tagaq's performance of environmental activism. In this chapter, I explore how Tanya Tagaq uses contemporary Inuit eco-activist strategies and discourses in her performances. First, I demonstrate that Tagaq's practice of embodying the Earth in the songs "Fracking," "Sulfur," and "Retribution" aligns with broader discussions in Arctic climate studies that similarly position Arctic peoples as representatives and embodiments of the Earth in a time of climatic crisis. I further suggest that Tagaq's characterization of the planet emerges from Inuit experiences of climate change. Second, I explore how Tagaq combines this strategy of embodiment with another important concept within Indigenous discourses: environmental injustices and violence against women are linked through common ideological roots. Here, I look to the vocalist's performance at the 2014 Polaris Prize awards ceremony and the music videos for "Uja" and "Retribution." Such a discussion will demonstrate that Tagaq brings current Inuit concerns, experiences, and activist strategies into her practice. In this way, Tagaq's artistic practice further embodies those issues invoked in her performances - the need to decolonize environmental ethics and activism. 


\section{Background, Methodology}

In Chapters One and Two, I investigated how Tagaq translates her visions of nature, rooted in Inuit culture, into music. When I began the research for this thesis, I thought this meant looking at Inuit traditional views of the natural world and humanity's place within it. Although I looked primarily for cultural information, what I found instead were many environmental reports that detailed the devastation Inuit communities experience due to climate change. A skim through these made it obvious that the Arctic's transforming environments are among the most urgent concerns for Arctic peoples. Only slightly more digging revealed that many Inuit have been at the front of environmental advocacy for decades.

Encountering these facts set me on the path of wondering how Tagaq puts contemporary experiences of a warming North on stage. Tagaq states in interviews that her Inuk identity and attachment to her northern community inform her artistic practice and her social concerns:

People tend to make artwork surrounding what they know and what they care about. I'm a human being and I'm concerned about the state of the planet and I'm Inuk, and spent a lot of time living on the land. So I'm concerned sociologically about Inuit and minorities and Indigenous people, and concerned for humanity with the global prospects of climate change (Tagaq in Beaulne-Steubing 2016).

Beyond performing a local sense of place that implicates international forces, ${ }^{35}$ how does Tagaq musically allude to the challenges that northern communities experience as ice and permafrost melt away? How does her practice align with other Indigenous eco-activists, specifically those Inuit who are actively working on the global stage to raise awareness and create change, such as Alethea Arnaquq-Baril and Rosemarie Kuptana? In this chapter, I answer such questions by

\footnotetext{
${ }^{35}$ As I discussed in Chapter One, Tagaq's sonic construction of the Arctic demonstrates that neither northern ecosystems or Inuit communities are absolutely isolated from nonlocal people or activity.
} 
comparing specific songs, music videos, and performances ${ }^{36}$ with rhetorical strategies used by other Inuit environmentalists to address climate change, especially those established by Sheila Watt-Cloutier. Watt-Cloutier, former international chair of the Circumpolar Inuit Council, is arguably the most recognized Inuk environmental and human rights activist. Well-known for her work on environmental issues like persistent organic pollutants and global warming, WattCloutier's reframing of environmental issues as matters of human rights in the early 2000's was ground-breaking for subsequent Inuit-led environmental advocacy. For her prominence in Inuit environmentalist discussions and her duty to represent Inuit voices during the years she was appointed Inuit Circumpolar Council's international chair, I compare Watt-Cloutier's advocacy rhetorical strategies to Tagaq's practice. By doing so, I aim to see Tagaq's eco-activism within its socio-cultural context.

Face, Body, Voice of the Earth

In 2005, a team of environmental lawyers, Inuit women, and Inuit hunters challenged the world to re-think "climate change" in human terms. This group filed a petition with the InterAmerican Commission on Human Rights, "asking that the protection from climate change be recognized as a fundamental human right" (Watt-Cloutier 2016, 10). In this project, Sheila WattCloutier, the chair of the International Circumpolar Council at the time, told the stories of Inuit experiencing climate change. She explained that as a people economically and culturally tied to the land, Inuit encounter climate change in ways far more visceral than other societies: travel routes and camping destinations become inaccessible and dangerous as sea ice thins and

\footnotetext{
${ }^{36}$ I chose these songs/videos/performances based on Tagaq's comments about them, wherein she states that these are about environmental degradation.
} 
permafrost melts. Familiar coast lines erode, and lakes of fresh drinking water drain into the ocean. Dangerous chemicals are found in the fat stores of marine mammals, infecting the bodies of those Inuit who rely on hunting to supplement their diets. Daily subsistence activities are disrupted as animal populations and distributions change due to extreme and unpredictable freeze-thaw cycles. Many cultural, psychological, and spiritual goods become inaccessible as Inuit can no longer access the land and sea in the same ways as previous generations. Hunting, for example, is not just a matter of subsistence, but is a multivalent activity for passing on worldviews; as Watt- Cloutier explains in a recent memoir,

Hunting... is, in reality, a powerful process where we prepare our young for the challenges and opportunities not only for survival on the land and ice but also for life itself. The character skills learned on the hunt, of patience, boldness, tenacity, focus, courage, sound judgment and wisdom, are very transferable to the modern world that has come so quickly to the Arctic world. We are seeing this powerful training ground on the land and ice being destroyed before our very eyes. Not only are our livelihoods being threatened but also we are losing lives as a result of those dramatic changes as the sea ice depletes and creates precarious situations for our hunters and their families (WattCloutier 2016, 254).

The efforts of Watt-Cloutier and other Inuit activists on the global stage "put the human face on the climate change debate" (Watt-Cloutier 2016, xix) by using Inuit experience to "speak out on behalf of the land" (Salvini 2007, 397). In a speech during her time as ICC chair, WattCloutier claimed that "we [Inuit] are the land and the land is us," and implored listeners to “... see that a poisoned Inuk child, a poisoned Arctic, and a poisoned planet are one and the same" (Salvini 2007, 397). Such a positioning of Inuit as mediators for, and even embodiments of, the Arctic is part of a trend of "growing political activism of Arctic Indigenous peoples who present themselves as representatives or embodiments of climate change" (Martello 2008, 351). In a study of such representations, Marybeth Long Martello writes that in their response to an 
Arctic Climate Impact Assessment (ACIA) report, Terry Fenge, Paul Crowley, and Sheila WattCloutier characterize Inuit as "the environment's voice, talking indicators of the world's environmental health" (Martello 2008, 367). Martello further finds that Inuit interlocuters "similarly described the Arctic as the world's barometer and Inuit peoples as mercury in the barometer" (Martello 2008, 367). Within Martello’s study, Inuit describe themselves as human versions of environmental changes, as issues such as extreme pollutant concentrations and melting ice sheets have had direct impact on their lives and well-being.

Tanya Tagaq's practice manifests a similar positioning of Inuit as the Earth. In specific performances, Tagaq chooses to perform as the voice of the Earth—not only speaking out for the land but vocalizing as the land. She further embodies the Earth in music videos, positioning herself as the Earth's personification. Tagaq's intertwined practice of embodying and voicing the Earth in a time of climatic crisis characterizes the Earth as sick, distressed, and angry. These characterizations emerge from Inuit experiences of climate change, which encompass physical, mental, spiritual, and cultural well-being. In the following sections, I describe instances where Tagaq's practice on stage, in studio, and on video participate in this Inuit eco-activist strategy.

\section{Sickness}

First, like Watt-Cloutier and others, Tagaq draws clear comparisons between physical health and environmental degradation. In the album recording and music video of "Sulfur" from Retribution (2016), Tagaq performs the voice of one who is physically ill, as the video correspondingly demonstrates that the diseased is the Earth itself. In a commentary about the album with Carl Wilson, Tagaq explains: 
Sulfur is the by-product of the processing of bitumen from the tar sands in Alberta. I just think that place is so evil... [I'm] just hoping that it's a good wake-up call for people to understand that you can't keep making something sick and expect to be healthy while you're living in sickness... We're not giving the health back [to the land] (2016).

Together, the video and audio demonstrate Tagaq's metaphors of resource extraction as sickness. The music video opens with a long groan over a shot of flowing black tar, pumpjacks and grey clouds from a bitumen refinery. As the video ${ }^{37}$ juxtaposes clips of protestors marching, tar sticking to human hands, drilling rigs, refineries releasing gaseous by-products into the atmosphere, and people refueling their cars, Tagaq's frequent collaborator Jesse Zubot creates a new sonic texture by rubbing viola strings to create a creaking, rhythmic chug, which is then momentarily overtaken by a thick layer of pulsing white noise. This layer of noise seems to mimic those physiological sounds recorded through mechanical means - like the rapid heartbeat of a fetus as recorded by an ultrasound scan. The sound creates a vague sense of the inorganic meeting the organic, and although it decreases in volume, it persists through the rest of the track, fading from the listener's focus while continuously imparting a sense of anxiety. Tagaq's voice rejoins the fray with another long groan as the video switches to shots of deep-sea drilling and water fowl covered with black oil. The video continues to connect shots of invasive resource extraction practices (blasts, drills), affected landscapes (deforested areas, melting sea ice), and signifiers of pollution (heavy traffic, oil refineries) as Tagaq creates the wet sound of a weak heartbeat growing increasingly stuttered and irregular. Around the two-minute mark, the track turns more frenetic. The layers of sonic activity - extended techniques on the violin, vocalizations from the experimental choral group Element Choir-increase in energy and volume as Tagaq creates a mixture of gargles, voiced inhalations and exhalations, groans and

\footnotetext{
${ }^{37}$ Available at https://www.youtube.com/watch?v=U20JGI7s3Qs
} 
weeping sounds. These vocalizations are common elements of Tagaq's practice, however as the video here quickly flips between shots of seeping oil, tailing ponds, and floating rigs, the liquid visuals render Tagaq's vocalizations as chokes and gargles, as if she were gagging, choking, and drowning. The music video continues to build tension as Tagaq morphs a groan into weeping, wailing, and screaming, the Elemental Choir continues to hold rising, dissonant washes of crescendoing sound, and the video continues to mix together short clips of industry and Indigenous protestors, ending with one final shot of waters churning around a sea drill.

In "Sulfur," Tagaq turns environmental devastation into a matter of physiological health by using her own vocalizations to demonstrate that harmful resource extraction practices are akin to a sickness or injury inflicted upon human body. Beyond pure metaphor, Tagaq's practice is rooted in the reality that Inuit physical health is suffering from resource extraction and refinement practices that contribute to climate change. Rising temperatures and changing precipitation levels are linked to increased frequency and distribution of foodborne, waterborne, and vectorborne diseases (Fugal and Seguin 2006; Harper et al. 2011; Martin et al. 2007; Parkinson and Butler 2005 as cited by Willox et al. 2015, 169). Hazardous travel conditions and extreme weather events have increased mortality and morbidity (Willox et al. 2015). Persistent organic pollutants biomagnify through Arctic food chains, ultimately transferring to Inuit, endangering future generations: "As we put our babies to our breasts," writes Sheila WattCloutier, "we feed them a noxious chemical cocktail that foreshadows neurological disorders, cancers, kidney failure, [and] reproductive dysfunction” (cited in Lucas 2004, 191). Tagaq's practice in music videos like "Sulfur" thus participate in Watt-Cloutier's strategy of representation and embodiment in a variety of ways: Tagaq strategically places herself, an Inuk, as the voice of the Earth, enacting Watt-Cloutier's rhetorical methods. Further, Tagaq 
characterizes the Earth as suffering in the same way as Inuit— physically deteriorating — reinforcing the practice of using Inuit experience to represent the planet's experience of global warming.

\section{Suffering}

Health is not just a matter of physiology. Anthropologists George Wenzel and Arlene Stairs (1992) describe Inuit identity as "eco-centric," which Laurence Kirmayer, Christopher Fletcher, and Robert Watt summarize as giving "a central role to connections among individuals and to place in the health or well-being of the person" $(2009,292)$. In Inuit communities, being on the land rejuvenates the body and mind, and interacting with the environment through camping, hunting and fishing are essential to gaining a sense of well-being. Furthermore, many cultural values and traditional knowledges are taught on the land and in the sea, and directly relate to living within Arctic ecosystems. Given these ties, Ashlee Cunsolo Willox, current director at the Labrador Institute of Memorial University, has built up a body of research in collaboration with other scholars investigating the mental and emotional impacts of environmental change on Inuit communities (Willox et al. 2012, 2013a, 2013b, 2015). She and her co-researchers have found that when "individual and collective identities, health and wellbeing, livelihoods, histories, and emotion-spiritual connections are emergent from the land on which people live," climate change is experienced as an attack on the person (Willox et al. 2012, 539), and results in mental and emotional stress (Kirmayer 2009). When a place that is "a site for deep healing, renewal, and revival and is vital to concepts of well-being, [and] enrichment of the mind, body, and spirit, and resilience" suddenly deteriorates, those with strong place-based attachments experience significant emotional responses: anxiety, fear, stress, anger, grief, 
aggression and withdrawn behaviour, for example (Willox et al. 2015, 175). In Willox's study

with community members from Rigolet, Nunatsiavut, participants describe being on the land in terms of mental and emotional solace. One participant states:

I think for the Inuit, going out on the land is just as much a part of our life as breathing. Really, we are so close to the land. We are land people. So if we don't get out then, for our mental well-being, it's like taking part of your arm away. ... It's like you are not fulfilled. There is just really something missing. I think we take great pride in being able to go on the land and just feel that energy when you get out on the land. For some people, it's just like taking medicine $(2013 \mathrm{~b}, 261)$.

Another hunter-forager explains:

For some reason, we just need to be out on the land. And the more I'm learning in mental health and wellness about it, the more I understand that I think it has a lot to do with the energy that you feel when you are outdoors, when you are out on land, when you are away. It is just really good energy... it's a way of life for us to be out on the land and to do things and to feel, you know, that you are part of Mother Nature. It's just the same as bathing everyday. It feels good (2013b, 261-262).

Tanya Tagaq reiterates these sentiments in interviews with journalists. For example, when asked how the landscape of Nunavut influences her art, Tagaq responds by emphasizing the fulfillment and rejuvenation she feels when she is home:

It follows me everywhere I go and it isn't until I'm on the land and at home... that I get my full sense of self-worth and fulfillment because I'm absolutely nothing up there and everything. When it's so sparse and flat and frozen. I'm looking out and there's nothing: not a house, not one vehicle and you don't know if anyone has ever walked there before. It's really humbling and it's okay to die. That's probably one of the only times I feel that it's okay to die. I could die at that second and everything would just be fine. I find that when I've been on tour for six months, I begin worrying about really stupid things like if I'm fat or what if this happens or what if the car crashes, what if this person, and what if this. And you start getting really neurotic. You just don't feel that if you're up there; you don't worry about these kinds of stupid things. So I always start off a tour really clean (Callen 2010). 
While the sense of well-being and peacefulness may be located in other areas of her artistry, Tagaq's embodiment of the Earth characterizes the planet as experiencing the same emotional reactions to environmental degradation as the Inuit. Where "Sulfur" sounds an unhealthy body, "Fracking" from Animism sounds an angry, sorrowful, and distressed Earth. In a conversation with Laura Beaulne-Steubing from Ottawa Beat, Tagaq says "At the ending of... Animism I did a song about fracking and I was just trying to kind of imagine what it would be like if you were the Earth and someone was doing fracking on you, and I just thought about how horrible and sick that would feel" (Beaulne-Steubing 2016). Hydraulic fracturing is a process that blasts water, chemicals, and sand into rock formations to release oil and gas deposits. The song "Fracking" 38 explores how an embodied Earth would express the feeling of being injected with high pressure water and steam: "I wanted a song to be unlistenable, so ugly and disgusting, so I imagined my whole body was the Earth and that someone was doing fracking on me," Tagaq tells Sarah Rogers from Nunatsiaq News. "I wanted to sonically shove that in people's faces" (2014). Tagaq thus intentionally positions herself again as the Earth's voice, and rather than focusing on the physiological, she takes listeners along a journey of physical and emotional pain. Tagaq opens the track with a groan punctuated by sharp, sobbing inhalations. As dissonant strings slowly enter the texture, Tagaq continues to gasp and groan in distress. After two minutes, Tagaq switches from groans of pain to growls and snarls, tinging pain with anger. Thirty seconds later, Tagaq adds wails and sobs as both the strings and electronics create a rising tension through ever increasing pitch, dissonance, and volume. The tension suddenly releases with a sharp thinning of the sonic texture - here, a sense of disorientation undergirds Tagaq's vocal motives as the electronic bass shifts between the left and right channels and the strings

\footnotetext{
${ }^{38}$ Available at https://www.youtube.com/watch?v=iQPIHPJvQrE
} 
maintain a scratchy sound. Tagaq closes with short, whimpering motives, leaving listeners in the final few seconds with the pulsing low bass swinging between sound channels. In "Fracking" Tagaq creates a journey of both physical pain and emotional suffering. Anxiety, aggression, and grief are all apparent in her vocalizations and heightened through the additional instruments. The last few seconds of low bass leave listeners with a sense of disorientation and apprehension, feelings shared by some Inuit as they think about the future of their communities (Willox 2015).

The Earth as voiced by Tagaq changes from anguished in "Fracking" to wrathful in "Retribution.” As Tagaq tells Wilson, "On the last album, [in] Fracking I was kind of thinking about what it would be like, to be Mother Earth and have that pain going in you, in your surface. So I kind of started thinking... at some point she's just going to go, 'Enough of you!' And what would she be saying if she could warn us" (2016). In the first two minutes of the song "Retribution," Tagaq positions herself as an emissary for the Earth in a spoken poem:

Our mother grows angry

Retribution will be swift

We squander her soil and suck out her sweet black blood to burn it

We turn money into God and salivate over opportunities to crumple and crinkle our souls for that paper, that gold

Money has spent us

Left us in small boxes, dark rooms, bright screens, empty tombs

Left investing our time in hollow philosophies

To placate the fear of our bodies returning back into our mother

Demand awakening

The path we have taken has rotted

Ignite, stand upright, conduct yourself like lightning because

The retribution will be swift 
Here, Tagaq lyrically sets up the characteristics she performs in the next section of the recording, when she changes positions from emissary to embodiment. She clearly describes the Earth as a living person, specifically a mother, perhaps invoking Inuit cultural traditions that recognize a significant shared creative power between mothers and nature. ${ }^{39}$ While Tagaq disavows the excess and waste of capitalist economic systems_-"We squander" the Earth's resources, allowing greed to "spen[d] us" - she also refers to the cyclical patterns of death and birth that are part of Inuit cosmology, in which women also hold a special position. I will explore the significance of this performance of femininity more fully in Chapter Four, but in this chapter's context the point is that the motherly Earth Tagaq describes is not one that emerges from Western frameworks but is more informed by Inuit traditions.

Tagaq's characterization of the Earth becomes more explicit in the last six minutes of the recording, when her voicing of the Earth takes the sonic foreground. "Fracking" centered long cries and groans, but "Retribution" 40 features belted vocalizations and frenzied growls and buzzes sounding through rapid articulatory action, all keeping to a steady, driving rhythm. The rhythmic drive of Tagaq's vocals and Jean Martin on drums give the track a sense of aggression and portrays the Earth as active and assertive. Although listeners know from the initial poem that this Earth is female, Tagaq's vocals do not clearly reference popular archetypes of womenwhether it be a nurturing mother or provocative siren. Tagaq discusses this choice with Wilson: "I like the idea of it [not] being this idea of sweet Mother Earth, and actually defeminizing that idea and having it be on a scientific level, or an asexual level" (2016b). Such a characterization speaks directly to common constructions of both femininity and nature in colonial projects. In

\footnotetext{
${ }^{39}$ See Chapter Four for more information.

${ }^{40}$ Available at https://www.youtube.com/watch?v=xNYTA6SV6tM
} 
her theorization of a "Queer Ecofeminism," Greta Gaard suggests that colonialist discourses feminize and eroticize "nature" to justify its domination (Gaard 2004, 38). Tagaq's pointed rejection of a hyperfeminized and erotic Earth in "Retribution" subverts these expectations, creating an Earth that is rational, non-sexual, and autonomous. ${ }^{41}$ These qualities are further reinforced by Tagaq's physical gestures and staging in the music video for "Retribution," where she embodies the Earth. The music video sets Tagaq and Greenlandic Inuk mask dancer Laakkuluk Williamson Bathory in an empty warehouse and a city street, depicting "nature being forced into unnatural spaces" (Mertens 2016). The vocalist's body gestures do not give a sense of eroticism as they do elsewhere in her practice: rather, Tagaq contorts her face and limbs in jarring, spastic motions heightened by the video's editing. Like the opening poem indicated, this is an Earth that is an active person.

Paired with Williamson Bathory, Tagaq's embodiment of the Earth takes on further nuance. In its traditional form and context, uaajeerneq (Greenlandic Inuit mask dancing) used sexuality, humour, and fear to teach children how to negotiate those same emotions in the real world (Møller 2013). Williamson Bathory's practice recontextualizes mask dancing to speak to contemporary issues - for example, her performance Timiga Nunalu, Sikulu ("My Body, The Land and The Ice") challenged stereotypes about Inuit women that perpetuate sexual violence against all Indigenous women (CBC Arts 2016). While Williamson Bathory's message to the viewer-listener in "Retribution" is open-ended (Chan Centre 2019) we see here a co-operation between traditional pedagogical approaches and contemporary Inuit strategies as represented by Williamson Bathory and Tagaq. Although each performer is unique in their practice, there are foundational similarities within both mask dancing and Tagaq's strategical personification: the

\footnotetext{
${ }^{41}$ More about Tagaq's layered approach to social and eco-activism and critique in Chapter Four.
} 
integration of the mind and body to know, to experience, and to teach-“embodiment" as discussed in the previous chapter. Thus "Retribution" makes known the continuity of Inuit ontologies across traditional and innovated practices, the possibilities for Inuit ontologies to encounter contemporary problems, and artistically demonstrates a co-operative vision of alternate Indigenous strategies working together.

\section{Rape of Women, Rape of the Land}

In "Retribution" Tagaq continues to take part in Inuit environmentalist strategies that position Inuit peoples as representatives and embodiments of the planet. Her characterization of the Earth as wrathful resonates with the psychological impacts of climate change in Arctic communities, but perhaps even more so represents Tagaq's own feelings about the state of the planet. "I'm so angry," she repeats throughout interviews and articles (see for example Edwards 2016) wherein she discusses the nexus of injustices that Indigenous people endure from past and present systemic colonialism:

Where I'm really, really miserable is the ridiculous government bureaucratic thing. Like, it was the government who stick handled this whole situation in the first place and there's a lot of yapping about reconciliation and making things great, but no one's really doing anything. And that's where I get angry. That's where it goes from reconciliation to retribution. [I'm] saying retribution because reconciliation is too slow. That peaceful wording for people to have just spew hot air and talk about how things are great and they're going to be great (Beaulne-Steubing 2016).

One of the key issues to which Tagaq brings specific attention is the crisis of missing and murdered Indigenous women in Canada. While she discusses the matter in many interviews and lectures (see for example, Red Bull Music Academy 2016), Tagaq's artistic output performs 
criticism and frustration by conceptually linking violence against women to environmental degradation. Here, Tagaq contributes to another broader discourse within Indigenous studies: colonial ideologies manifest both violence against Indigenous women and violence against the Earth—including natural resource extraction, issues in land rights, industrial pollution, etc. In Kim Anderson's interview with Sarah Laronde in A Recognition of Being, Laronde states "how women are treated is how the Earth is treated" (Anderson 2016, 167). Leanne Betasamosake Simpson further explains the roots of these issues in the Nations Rising Blog's series "It Ends Here:"

Really what the colonizers have always been trying to figure out is "how do you extract natural resources from the land when the people's whose territory you're on believe that those plant, animal, and mineral's [sic] have both spirit and therefore agency?" It's a similar answer: You use gender violence to remove Indigenous peoples and their descendants from the land, you remove agency from the plant and animal worlds and you reposition aki (the land) as "natural resources" for the use and betterment of white people... Gender violence and murdered and missing Indigenous women are a symptom of settler colonialism, white supremacy and genocide. They are symptoms of the dispossession of Indigenous peoples from our territories (Simpson 2014).

Tagaq's performances of this conceptual link have grown more and more overt through the last decade. The earliest allusion to the common link between gender and environmental injustice appears to be in Tagaq's 2014 music video for "Uja." The video ${ }^{42}$ juxtaposes clips of an Indigenous woman in an urban setting with visual signifiers of urban violence and corruption, such as burning money and police raids. The second half of the music video switches to an Arctic setting, including clips of wolves, polar bears, foxes and owls in a snowy landscape. Shots of this seemingly pristine forest are juxtaposed with clips of blood dripping from the woman's hand into the snow, ending with the woman disappearing into the wintery scenery.

\footnotetext{
${ }^{42}$ Available at https://www.youtube.com/watch?v=BCuayGvy3i8
} 
While the allusion in this video that violence against women is ecologically significant is speculative, Tagaq's performance at the 2014 Polaris Prize awards ceremony make the ties clearer. During a medley of "Uja" and "Umingmak" — a song that recalls muskoxen grazing near the Augustus Hills (Rogers 2016)_-Tagaq performed in front of a scrolling list of the names of known missing and murdered Indigenous women in Canada. The screens above the Element Choir panned over artistic renderings of naked figures from Emanuel Vigeland's fresco Vita—in its context, the fresco is a celebration of life, however isolated and placed beside the list of Indigenous women who have been murdered or are missing, it takes on more violent significance. Singing in front of these images, Tagaq's vocal improvisations included a mix of sonic allusions to the environmental thematic content from both Auk/Blood and Animism. She began the performance with an embedded vocal motive from "Tiriganiak" from Auk/Blood, a recording that refers to the fox population in Cambridge Bay (Prasad 2010). After five minutes Tagaq switched to more sonorous motives, singing the refrain from "Rabbit" on Animism. In the last two minutes of the performance, Tagaq introduced the main "Umingmak" vocal motive and abruptly transformed it into a series of growls, yells, and screams, ending the entire performance with fox-like yips and a long wolf howl that morphed into a feminine groan. This 10-minute performance brought national attention to the crisis of violence against Indigenous women, and while Tagaq sprinkled environmental allusions throughout the performance, closing the journey with such a fusion of environmental and feminine signifiers demonstrates that the two are inseparable - one suffers as the other.

The conflation of violence against women and environmental injustice is even more clearly defined in Tagaq's album Retribution. On her official website, Tagaq writes: 
[Retribution] is a cohesive, whole statement. Why sugarcoat it? This album is about rape. Rape of women, rape of the land, rape of children, despoiling of traditional lands without consent... Retribution is Tanya Tagaq's portrait of a violent world in crisis, hovering on the brink of destruction. It's a complex, exhilarating, howling protest that links lack of respect for women's rights to lack of respect for the planet, to lack of respect for Indigenous rights. It's an album about celebrating the great strength of women, it's about rejecting the toxic, militaristic masculinity that's taken over the world since the rise of Western industrial capitalism and is rapidly destroying human life support systems through climate change and pollution (Tagaq 2019).

Intersections between violence against women and violence against nature is performed most evidently in the music video for the title track "Retribution." As discussed above, Tagaq positions herself as the Earth's embodiment—for most of the music video, Tagaq portrays the Earth as an enraged autonomous, non-sexualized being. However, there are specific instances where Tagaq portrays the Earth as a rape victim. Four minutes into the video, ${ }^{43}$ overhead shots of a construction site join Tagaq's video collage. These moments pan over concrete and steel, showing an area completely transformed from industry and devoid of all animal or plant life. The third time this setting reappears, Tagaq is shown lying on her back, body shaking and face registering pain and fear. Here, Tagaq is still costumed in the same hair and dress as the rest of the music video, demonstrating that this is indeed the same Earth-figure that we have seen as assertive and autonomous. The meaning is clear: "I wanted to draw a line with non-consensual land grabs and non-consensual, non-renewable resource development and the day-to-day horrors we inflict on each other and in particular, women" (Tagaq in Warner 2016). While Tagaq's characterization of the Earth in "Fracking" and "Sulfur" flowed from Inuit experiences of global warming, here Tagaq depicts the experiences of Indigenous women. Therefore, Tagaq's music video "Retribution" can be seen as a convergence of multiple Indigenous eco-activist strategies

\footnotetext{
${ }^{43}$ Available at https://www.youtube.com/watch?v=xNYTA6SV6tM
} 
and discourses. The vocalist presents herself as Earth's representative and embodiment in order to explicitly demonstrate that gender violence and environmental degradation are intricately related.

\section{Conclusion}

In November 2018, Tagaq sat down with Mike Doherty from Maclean's to discuss her recently published book Split Tooth. While discussing the book's dedication to missing and murdered Indigenous women and girls, Tagaq remarks,

I'm always doing work for a reason: this desperate attempt to alleviate some of the suffering that comes from living under such horrific statistics as an Indigenous person in Canada. It's a personal thing because I feel the pain from the daily news from home, and from around the country (Doherty 2018).

Although this statement emerged from a conversation about the book, it can offer insight to other areas of Tagaq's artistry. As Tagaq performs her vision of the environment, this necessarily includes her concern for the current crises faced by both people and place. In her desire to create "a collective shift in our consciousness" (Tagaq in Lewis 2016), Tagaq participates in current Inuit activist strategies: using her own voice and body, she positions Inuit as representatives and embodiments of the Earth and performs the connections between environmental injustices and violence against Indigenous women.

Tagaq's artistic environmental advocacy contributes to an overall process of decolonization within environmentalism. As discussed, Tagaq affirms Inuit voices, experiences, and knowledges by taking lead from Inuit like Sheila Watt-Cloutier. By building upon the work of Inuit thinkers and intellectuals, Tagaq indirectly and artistically partakes in the "citational 
rebellion" prompted by Sarah Ahmed (2014). Ahmed states that in order to decolonize public and academic discourses, actors must not depend on frameworks, concepts, and methodologies of famed Western thinkers to gain social legitimacy. At the same time, Tagaq's eco-activism challenges colonial formulations about Indigenous peoples, indigeneity, and the environment: historically, Western constructions of indigeneity view 'authentic' Indigenous peoples as uncorrupted by modern rational thought and technology, thus having the ability commune with primordial natural forces. Such stereotypes subjugate Indigenous peoples, as "liberal multicultural societies pressure Indigenous subjects to perform authentic difference as a condition of admission into mainstream aesthetic, commercial, and political spheres" (TaylorNeu 2018, 119). Furthermore, as ecofeminist Greta Gaard summarizes, conceptually linking nature and Indigenous peoples has progressed colonialist agendas since the seventeenth century (2004). From this perspective, it is possible to view Tagaq's performance as the voice and body of the Earth as perpetuating these harmful constructions. However, Tagaq is not catering to a specific audience, but rather is interested in expressing her own perspectives. "I'm Inuk right to my bones," she repeats throughout many interviews (Rogers 2016). By performing her viewpoints on climate change through Inuit-based strategies, Tagaq forwards Inuit ecological perspectives while also subverting the expectations of mainstream society. "Exposing deconstructions," writes German scholar Harmut Lutz, "helps us [Westerners] in the often painful process of seeing our own racism and letting go of cherished stereotypes" $(2015,240)$. Thus, Tagaq's eco-activist practices participate with the work of other Indigenous artists (Inuk Alootook Ipellie, Anishinaabe Ahmo Allen Angeconeb, Metis Bob Boyer) who similarly “[use] the master's tools to dismantle the masters' house" (Lutz 2015, 240). ${ }^{44}$ Through her

\footnotetext{
${ }^{44}$ This is also seen in Chapter One, in the discussion of Tagaq's musical use of animal sounds.
} 
simultaneous subversion of harmful stereotypes and participation in Inuit-led advocacy methods, Tagaq performs a decolonized eco-activism. 


\section{Chapter Four: Feminism as Environmentalism}

In Chapter Three I explored Tagaq's deliberate, explicit performances against

environmental threats. These performances demonstrate a decolonized approach to eco-activism through Tagaq's evocation of contemporary Inuit experiences and perceptions of climate change, and her participation in Inuit approaches to advocacy and education. However, to gain a fuller sense of Tagaq as an eco-activist it is necessary to consider how Tagaq uses the interconnectedness of Inuit worldview to creatively implicate many environmental and social issues at the same time.

I began my initial research for this entire project with an ear for the land. I combed through Tagaq's output, listening to anything that could demonstrate whatever Tagaq meant when she stated that she aims to "bring a little a bit of the land" into music (Kronos Quartet 2016). As I explored Tagaq's signature musical style, her emphasis on femininity in terms of fertility and eroticism were unescapable. In interviews and on stage, Tagaq is very open about performing her sexuality: she equates good food and good music to good sex (Dickie 2018), rubs her body on stage, and sings about menstruation. My overall study is one of linking Inuit views of the environment, not sexuality, to Tagaq's practice, so I was prepared to leave these elements of Tagaq's performance for future research projects. However, after reading Kim Anderson's $A$ Recognition of Being (2016), I learned that Indigenous femininity has particular connections to the environment not only in Indigenous views of womanhood, but also in the ways that womanhood and land have been victims of colonization. Furthermore, according to Elizabeth Weatherford, director of the 2011 Native American Film and Video Festival (NAFVF), within Indigenous art and film an environmental consciousness often pervades critiques of social injustices like language loss, alcoholism, stereotypes, and violence against women (Manoni 
2014, 232). These artworks and films (see for example Jeff Barnaby's File Under Miscellaneous, 2010) "spotlight how eco-identity permeates Indigenous experience outside battles for environmental conservation and autonomy" (Manoni 2013, 288). ${ }^{45}$ In the preceding chapter I found explicit eco-critique in Tagaq's performance by following visual and sonic signifiers of nature, even when they also spoke to social issues. Following Anderson's characterization of the interconnectivity of Indigenous worldviews and Weatherford's suggestion that eco-criticisms are present when there seems to be no allusion to nature, in this chapter I investigate Tagaq's artistic activist practices as intersectional: ${ }^{46} \mathrm{I}$ argue that Tagaq uses expressions of femininity on the album Retribution (2016) as alternative sites to engage environmental justice. First, I engage Tagaq's presentation of motherhood, fertility and menstruation in the songs "Ajaaja" and "Centre," and then I discuss Tagaq's performance of a "sovereign erotic" in the song "Aorta." In the final discussion, I consider Tagaq's mobilization of an Indigenous feminine perspective on the environment within broader environmental discourses, noting that the vocalist challenges societal pressures that have marginalized Indigenous women's ways of knowing the land. Through both her remediation of colonial erasures of Inuit knowledges and use of Inuit perspectives to intercede in contemporary environmental justice issues, Tagaq performs a decolonized and indigenized activism.

\footnotetext{
${ }^{45}$ Writers such as Joni Adamson (2001), Winona LaDuke (1999), and Anna Willow (2009) have further explored the environmental nuances in many areas ofIndigenous activism and policy battles.

46 "Intersectionality," as it has been taken up by scholars, advocates, and activists since the early twenty-first century, recognizes that many diverse factors shape "the complexity in the world, in people, and in human experiences" (Collins and Bilge 2016, 11). Social divisions of class, race, gender, ethnicity, citizenship, sexuality, and ability, for example, are understood to work together and influence each other to create social inequalities. These factors converge with environmental justice in a multitude of ways. The authors in the anthology New Perspectives on Environmental Justice: Gender, Sexuality, and Activism (Stein 2004) for example, explore how gender and sexuality intertwine with environmental justice. Intersectionality then is a useful tool to analyse aspects of Tagaq's practice, as she forwardly identifies herself as an Inuk woman concerned with the land (BeaulneSteubing 2016).
} 


\section{Womb-Core}

In performances, on albums, and in interviews, Tagaq intertwines the theme of womanhood with the environment. "In both Western and Indigenous frameworks, Native women have historically been equated with the land" writes Kim Anderson in A Recognition of Being $(2016,80)$. In Western history, this comparison was used as a tactic to justify the domination of both: "Equating woman and nature became symbolic of what man must control and overcome if he is to transcend and evolve," Michelle McGeough explains $(2008,64)$. "Within the construct of Cartesian dualism, women were associated with the body, emotion, the primitive and animality and were thus diametrically opposite to man and reason" (McGeough 2008, 64). By contrast, understanding women's bodies through Indigenous ecologies leads to an understanding of femininity as power. Anderson writes that a close relationship with the land, along with strong families and a sense of community, provides Indigenous women "the strength to defy the many oppressive experiences that an Indigenous woman is likely to encounter" (Anderson 2016, 95). This relationship between Indigenous women and nature flows from an understanding that each share the same creative, cyclical powers. First Nations teachings about water, for example, "instill a sense of responsibility among women who make the connection between the waters of the earth and their own body's capacity to sustain life" (Anderson 2016, 163). In Inuit contexts, women "figure significantly in the world of Inuit religion, myths and legends" (Billson and Mancini 2007, 74) and thus the environment, as Inuit spirituality and cosmology are at the foundations of environmental values. Sedna, the spiritual indweller of Arctic waters and authority of all marine life, for example, is a pivotal female Inuit figure that speaks to the prominence of women in spiritual matters (Leduc 2010). According to social scientists Janet Billson and Kyra Mancini, "all versions of the Sedna story credit her with creating the sea life 
that has nourished the Inuit for centuries. Her place as protector of the sea animals has earned her a place in Inuit mythology and religion forever" (Billson and Mancini 2007, 74). In his ethnography of Keewatin Inuit in Eskimo Underground, Robert Williamson writes that women represent "creativity and... the life-giving powers of the cosmos" $(1972,55$, as cited in Billson and Mancini 2007, 74). Women are known to have a special proclivity with the environment and spiritual world: ${ }^{47}$ Williamson describes that during his field work women made charms for hunters to ensure their success and were thought to have special healing powers. A storyteller in Stories in Pangnirtung further remarks that female shamans healed people not by using plants, but by eating food (as cited Billson and Mancini 2007, 74). As the consumption of country foods is one of the primary ways for Inuit to connect with the land, stories like this insinuate that there is power available to women through a connection with the environment. Other Inuit legends demonstrate the links between fertility, menstruation, and the environment. For example, "The moon, Aningaaq, controls ebb and flow and has an influence on fertility, menstruation and abortion. The sun, Seqineq, is the life-giving, warm nurturer" (Kleist 2008, 17). This view of Indigenous women's bodies as intimately connected to the nonhuman world can be located in the artistic choices Tagaq makes on the album Retribution (2016).

As discussed in Chapter Three, Retribution is an album about social and environmental injustices and the earth's ability to retaliate. The album begins with "Ajaaja," a sonic collage that does not include Tagaq herself, but features Inuk singer Ruben Komangapik and Tagaq's daughter Inuuja. At the song's beginning, recordings of Inuuja singing “ajaaja," a vocal refrain typical in Inuit traditional songs, plays over recordings of blowing wind. According to the album's description on Tagaq's official website, Inuuja represents "the hope of the future" and

\footnotetext{
47 The separation of these two is for clarity’s sake. They are inextricable in customary Inuit practices.
} 
"elicit[s] shame for the betrayals we are visiting on the generations to come" (Tagaq 2019). In “Ajaaja" Inuuja is joined by an Inuit drum, and Komangapik sings a traditional Inuit naming song. As the opener for the rest of the album, "Ajaaja" establishes that the subsequent musical journey through Retribution is underpinned by Inuit perspectives: Inuit traditions (as invoked by the traditional Inuit song), Inuit kinship and cosmology, ${ }^{48}$ and contemporary Inuit concerns. The music video for the track further establishes these as the foundation for the rest of the album. "Ajaaja's" music video ${ }^{49}$ is a collage of Inuuja playing in a park — the clips reversed perhaps to connote both ecological and social regression-Inuit drum-dancers, Komangapik singing, and traditional Inuit masks. While such masks served a variety of functions in Inuit cultural practices, they were traditionally incorporated into shamanic rituals and ceremonial dances. By opening the album Retribution with sonic and visual references to Inuit traditions, Tagaq frames the artistic political statement of the entire album as an engagement through Inuit perspectives. The track that follows "Ajaaja," "Retribution," needs to be understood through those same frameworks. As I discussed in the previous chapter, Tagaq's depiction of the Earth in this track performs Inuit visions of motherhood rather than Western constructions of femininity. By choosing to describe the Earth as "mother" in the track's lyrics, Tagaq invokes those connections between women and nature and their shared creative powers.

Tagaq makes these links between the environment and femininity_particularly fertility_explicit in the album's fifth track, "Centre," ${ }^{50}$ which features Canadian hip hop artist

\footnotetext{
${ }^{48}$ Tagaq explained to Carl Wilson that Inuuja shares the same name as Ruben's deceased grandmother. In a namesharing relationship (saunik), bearers of the same name are thought to share the same soul. As such, each namebearer shares in the other's kinship networks. In this case, Rueben treated Inuuja with the respect due to his grandmother, calling Inuuja "little grandmother." Tagaq told Wilson that through "Ajaaja," audiences hear Ruben and his grandmother reunited via Inuuja.

${ }^{49}$ Available at https://www.youtube.com/watch?v=V_Xyz4BAx7U

${ }^{50}$ Available at https://www.youtube.com/watch?v=aPpZex_QxGE
} 
Shad. Shad begins the track by rapping about the Earth as a reproductive entity, whose cycles form the basis of all existence: "The centre of the centre of the Earth/ Enterin' the entrance of a birth." While his rap continues in existentialist musings, Tagaq sings a short, repeating verse that expounds on Shad's first verse in more graphic terms:

Sing me a flash, catch, just the centre

Sing me a flash, catch, just the centre

Sacrifice

Our blood goes back into the Earth

In, out, womb, core

In, out, womb, core, womb, core

Womb, core, womb

"The song is about the idea of being centred," Tagaq writes in a correspondance with The Fader magazine, "being rooted, being present, all of those things that are about the knowing, knowing how to conduct yourself... As a woman, I know my centering happens where I make my babies...It's where we create. I find my womb very sacred and I wanted to address that" (Darville 2016). Tagaq's statements here resonate with Kim Anderson's argument that Indigenous women find strength and power as they realize their connections to the Earth as creative forces and sustainers of life. In discussion with Carl Wilson, Tagaq further explains:

Every single one of us has come out of a woman and yet our menstrual cycle is really seen as this dirty weird thing - when everybody's first bed was the blood of the inside of their mother. It's the most comforting thing.... I've always loved my moon, loved my cycle. Actually, singing in that Shad track, I'm talking about a time I went camping and let my blood back onto the tundra (Tagaq 2016).

Tagaq's realization of her own feminine body as sacred and a means of connecting with the land can be viewed as her own interpretation of Inuit womanhood. In Inuit society, women were responsible for a range of duties that included procurement activities, processing animal harvests, maintaining gear and households, child rearing, maintaining camps, and preparing food 
(Dowsley 2015, 540). ${ }^{51}$ As these activities interacted with the land-for example, through butchering seals and hunting berries-Inuit women gained unique perspectives on the environment separate from their male counterparts. However, with the termination of Inuit nomadism, relocation of Inuit in the 1950s and the imposition of a southern wage-based labour economy, traditional subsistence activities have decreased. As part of the adaptation process to this new way of life, women now fill labour roles in the Western-style economies while also fulfilling their customary roles. This pattern thus interrupts pre-relocation modes of forming land attachments through hunting and harvesting. However, as Inuit women continue in their traditional responsibilities in evolving ways, they also connecte with the land in new ways. For example, in Qikiqtarjuaq, formal community counselling projects helmed by Inuit women make land trips and participate in land-based activities like fishing and hunting to facilitate psychological healing from colonial trauma (Dowsley 2015). While this group of women continue to build a relationship to the land through healing projects, we see that the environment and Inuit womanhood are persistently tied together in other ways in other communities. For instance, after Alethea Arnaquq-Baril worked to recover Inuit traditional tattooing practices in the documentary Tunniit: Retracing the Lines of Inuit Tattoos (2011), Angela Hovak Johnston initiated a wide-scale revitalization of Inuit female tattooing practices, called the Inuit Tattoo Revitalization Project. Traditionally, these tattoos marked young females as mature women: "The tattoos are a statement of who we are and where we come from. In my homeland, only women had traditional tattoos," writes Johnston $(2017,3)$. In its revitalization, many women choose tattoo symbols and patterns that represent the land where they were born or from which their family came: symbols of mountains, animals, land formations, etc. For these women,

\footnotetext{
${ }^{51}$ This list is not complete and does not account for the multitude of socio-cultural goods, psychological goods and spiritual goods women propagated.
} 
womanhood is partly defined by the region to which they feel connected. Tagaq's practice demonstrates her own take on these connections. Her promotion of her body, particularly her menstrual cycle, as resonating with the environment can then be interpreted as the artist's interpretation of a wider viewpoint that hold mature womanhood and the land as connected.

In light of the interconnections between fertility, menstruation, and the environment, “Centre” presents Tagaq's celebration of her own womanhood, at least partly constructed through Inuit perspectives that recognize an intimate connection between women's bodies and the life-giving powers in the land. This explains how Tagaq's celebration in her own femininity overlaps and contributes to environmentalist advocacy. On stage, we can understand Tagaq's introduction of lullaby-like vocals, womb stroking, and other significations of womanhood to carry ecological import. An empowerment of one can be the empowerment of the other.

\section{Inuit Sexuality}

In "Ajaaja" and "Centre," we hear Tagaq demonstrating an Inuit perspective on the environment in relation to womanhood. Tagaq's practice resists colonialist frameworks that would construe this relationship negatively and instead celebrates Inuit conceptualizations of both women and the environment. A similar ambivalence towards Settler attitudes is found in Tagaq's performance of eroticism in music.

One of the most striking things about Tagaq's praxis is its emphasis on the erotic. Her style of kattajaq goes beyond the steady, rhythmic exchanges between song partners within the traditional practice. Rather, she builds intensity through accelerated vocal patterns and rising pitched inhalations, and releases the tension through prolonged whimpers and sighs. While 
feminized and accelerated breathing patterns are enough to signify sexual ecstasy (Woloshyn 2012, 192), Tagaq's lyrical texts — as few and far between as they may be — confirm the association between her vocals and sexual desire. "Hunger" from $A u k / B l o o d$, for example, sets an erotic text over sensual vocals. Her body staging also includes erotic elements - she arches her back, thrusts her pelvis on stage, and rubs microphones into her chest (Callen 2010). ${ }^{52}$

When asked about sexuality in her music, Tagaq freely discusses sex with the interviewers. "Sex is one of the most beautiful things you can be a part of. So, why are people so fucking uptight about it?" she tells Anil Prasad from Innerviews (2010). Along with describing sex as "sacred" (Nelles 2017), Tagaq further describes sexuality in terms of strength and power: "Giving birth takes a massive amount of strength. I often wonder in this society where that strength is going when we're not giving birth? How come we're not walking around in our beautiful, glorious, amazing, strong sexuality? And in our power?” (Greene 2017). Moreover, Tagaq notes that Inuit and Western ideas about sex are fundamentally different, and that the disparities between the two shocked her when she first moved away from Nunavut:

In [Canadian] mainstream culture, women are not supposed to enjoy their flesh. Inuit women have to be strong ... and sex wasn't seen as dirty. There are rules and taboos, but there are literally three months when the sun never rises and it is minus 50. So when you are watching your fifth movie, you look over at your best friend and you say, 'Do you want to hook up?'... It was such a huge culture shock when I went to university. The rules were: you act like you are a virgin, pretend you are drunk and then you hook up. I didn't understand why I had to pretend to not like sex! I love the ecstatic and extreme emotions I can convey on stage, but I like to mix together what is sexy. There's sex and deathprocreation, fear, anger and laughter (Khaleeli 2015).

\footnotetext{
${ }^{52}$ See for example Tagaq's performance in Pueblo, New Mexico (https://www.youtube.com/watch?v=pKJbziZlogk) and the Rifflandia music festival in Victoria BC (https://www.youtube.com/watch? $\mathrm{v}=\mathrm{J} 74 \mathrm{MrhVSIQk}$ ), and Utopia Festival 2011 in Vancouver, BC (https://www.youtube.com/watch?v=Wex20XB7t7w).
} 
Tagaq's open expression of delight in sex in interviews and on stage resonates with testimonies about pre-contact Inuit sexuality. In the essay "Pre-Christian Inuit Sexuality,” Makka Fleist $(2008,16)$ writes that sex was an open and common aspect of everyday life for the Inuit before the introduction of Christianity:

In our pre-Christian culture sexuality was considered a necessity to the body, as much as food and water, and hence we didn't have so many taboos or hidden agendas regarding sex. However, since we were so few people we had a strict rule against incest. Degeneration could wipe out a whole nation, so new blood was always welcome... No gender had an inherited dominance in matters of sexuality - both could take the initiative, and both could enjoy themselves. Sex was not only considered a physical necessity equal to water and food, but it was also regarded as a tool to help one's emotional well-being. Sex was not just connected to our genitals or just an act of procreation; it was a necessity to our sanity.

Inuit sexuality, however, came under the power of colonial forces as European and EuroCanadian explorers, anthropologists, scientists, missionaries, and governing bodies entered the Arctic. In his article "Certain Indecencies... That Need Not Here Be Mentioned: Inuit Men, Erotic Art," Norman Vorano offers a comprehensive description of how Inuit sexuality was colonized through the past centuries: "Historically, the systemic Qallunaat (white) misapprehension and denigration of Inuit sexuality, followed by the pervasive trafficking in the 'happy-go-lucky Eskimo,' created a flattened and manifestly asexual stereotype” (2008: 125). More specifically, Victorian-era missionaries, holding "medicalizing" notions of sexuality and hardened concepts of racial difference, suppressed Inuit sexual practices and stories, and implemented monogamous practices on the previously-polyandrous societies (Vorano 2008, 132). Vorano writes that this created a "negative sexual self-image," which was later exacerbated by the tragic sexual abuse rampant in Arctic residential schools. The trauma experienced by survivors of this abuse fostered a culture of shame on sexuality which continued through subsequent generations (Tungilik, 2008, 53). According to Pauktuutit Inuit Women of Canada, 
an organization that represents the interests of Inuit women, "fear, stigma, and discrimination" prevent Inuit youth from openly discussing issues in sexual health and intimacy. Compounded with other social determinants, the result is that Inuit in Canada are experiencing high rates of sexually transmitted and blood-borne infections (STBBIs) and high rates of teenage pregnancy (Pauktuutit 2012).

Tagaq's practice and comments consciously distance the vocalist from Western perspectives on sex and colonized Inuit sexuality. Cherokee poet and scholar Qwo-Li Driskill writes that "a colonized sexuality is one in which we have internalized the sexual values of dominant culture. The invaders continue to enforce the idea that sexuality and non-dichotomous genders are a sin, recreating sexuality as illicit, shocking, shameful, and removing it from any positive spiritual context" $(2004,54)$. A decolonized sexuality, then, is a healing from the trauma endured by Indigenous peoples, and a return or continuance of the complex sexualities that were erased by colonial cultures (Qwo-Li Driskill 2004, 57). Tagaq's praxis demonstrates Driskill's "Sovereign Erotic," as she reconnects with aspects of pre-colonial Inuit sexuality, but also challenges Western ideas of sexuality by asserting desire and sexual appetite (Stevance 2017, 54).

\section{Eroticism as Environmentalism}

My hope is that these two points are clear concerning Tagaq's performance of eroticism:

first, that sexuality has been a site of colonization; and second, Tagaq's performances showcase a decolonized sexuality. The question going forward, then, is how Tagaq's decolonized eroticism directly relates to the environment. To answer, I look again to Tagaq's album Retribution and 
discuss "Aorta," the "sexiest" track on the environmentally-minded album, in light of new perspectives in environmental justice.

"Aorta" is the fourth track on Retribution, preceding "Centre." Where the other songs have an open, improvisational quality that are true to Tagaq's live performances, "Aorta" is a highly structured, heavy rhythm jam (Tagaq 2016). The track is built on a steady industrial beat structured into 8-bar phrases. Rather than the sung verse-chorus structure of popular music, "Aorta" creates the semblance of verses by repeating distinct looped vocalizations to add pitch and texture to the background track. Most of these are gritty, voiced aspirations and inspirations typical of katajjaq; however Tagaq also adds a chant "kill or die" and long, sonorous open vowels. The steady, layering rhythms in "Aorta" create a corporeal listening experience: Simon Frith remarked that "a steady tempo and an interestingly patterned beat offer the easiest ways into a musical event. They enable the listeners without instrumental expertise to respond 'actively,' to experience music in a bodily as well as a mental manner' (1998, 143). With its highly repetitive rhythm and fixed time signature, "Aorta" is undeniably a dance track - the name of the track itself emphasizes body materiality and the sympathies between physiological and musical beats. The steady, driving beats of the track give a sensual quality as listeners feel intensely present: "Rhythm... is 'sexual' in that it isn't just about the experience of the body but also (the two things are inseparable) about the experience of time" (Frith 1998, 144). The track further takes on an erotic quality in its tension between the fluidity of Tagaq's more sonorous vocals and low harmonica drones and the rigidity of the firm beat. ${ }^{53}$

\footnotetext{
${ }^{53}$ Frith's 1998 publication Performing Rites further theorizes about the sensual qualities of popular music.
} 
The music video for "Aorta" confirms the erotic quality of the audio. ${ }^{54}$ The video is filmed inside the Emanuel Vigeland Museum in Oslo, Norway. ${ }^{55}$ This mausoleum-turnedmuseum is famous for the frescoes covering the wall and ceilings, named Vita. The frescoes display themes of the erotic, life, death, and the infinite:

The theme of Vita is eroticism and man's sexual instinct, conveyed through multitudes of naked bodies, women and men in impetuous intimacy. Lovemaking and procreation in the honour of God takes place in front of a dark and infinite universe, dimly lit by the life-giving, divine sun but also by the blazing fires of hell (Emanuel Vigeland Museum)

The music video opens with close-up pans over sections of Vigeland's frescoes that depict entangled naked bodies and human skulls. Particular emphasis is drawn to a motif beside the mausoleum's entrance — “A dead couple, still embracing in copulation, produces a mighty pillar of smoke and infants" (Emanuel Vigeland Museum). Tagaq enters the video between these shots, depicting erotic pleasure in her body movements and facial expressions. The rest of the music video continues in a similar fashion: close shots of copulating figures on the mausoleum's walls, interspersed with Tagaq moving to the music. At times, Tagaq's movements seem sensual, as they do the first time she enters the video: she strokes her chest and neck and writhes on the floor. The videography similarly emphasizes the erotic — Tagaq moves in and out of shadows dressed in a dark red dress, her bare skin catching the single light source. Close-ups follow Tagaq's movements, particularly her hands as she strokes her skin. Along the same vein, Tagaq also stages her body as one of the fresco's figures. Tagaq further mixes sensuality and animality throughout the video — she crawls on all fours towards the camera, bears her teeth, and tosses her head.

\footnotetext{
${ }_{54}^{54}$ Available at https://www.youtube.com/watch?v=SGNpz5tFUEE

${ }^{55}$ Portions of the fresco in this museum were also used in the set design of Tagaq's performance at the 2014 Polaris Prize Awards. See footnote 57 for the significance of this relationship.
} 
As previously discussed, Tagaq's display of eroticism reflects pre-colonial attitudes towards sex. In "Aorta," Tagaq performs sensuality proudly in a public space, resonating with the open attitude of pre-Christian Inuit sexuality that, in part, flowed from the constraints of living in darkness for a quarter of the year. She challenges both the culture of shame handed down through Inuit communities from colonial trauma and the mores of Western society that would relegate such eroticism to a more private sphere. At the same time, the Western pop music scene allows - perhaps even demands - a stereotypical hyper-femininity. As Stévance points out, Faupel and Schmutz (2011) suggest that gender stereotypes in popular music denigrate women's autonomy and agency through objectifying female musicians in terms of their attractiveness and sexual permissiveness (as cited by Stévance 2017, 54). Tagaq's practice consents to popular music standards of femininity, however she also actively challenges and subverts such standards. In "Aorta," Tagaq wears a red dress to index the crisis of missing and murdered Indigenous women in Canada. ${ }^{56}$ Notably, this is the same dress that she wore during her performance at the Polaris Prize awards ceremony in 2014, where she referenced the crisis of missing and murdered Indigenous women in Canada. ${ }^{57}$ She thus criticizes the hyper-sexualization of women, especially Indigenous women, in mainstream culture as perpetuating sexual violence. And as Stévance points out, Tagaq's apparent consent to mainstream popular music's requirements of staged

\footnotetext{
${ }^{56}$ Red dresses became a symbol to bring attention to the crisis of missing and murdered Indigenous women in Canada in 2014 when Metis artist Jaimie Black started the REDress Project in which she gathered and displayed over 600 red dresses in art installations across Canada as an aesthetic response to the crisis.

${ }^{57}$ As discussed in Chapter Three. Tagaq's performance at the 2014 Polaris Prize awards ceremony and the music video for "Aorta" are further tied together in that they both use Vigeland's fresco in their set designs. While "Aorta" takes place inside the museum, portions of the fresco were shown on the monitors behind Tagaq, beside the list of scrolling names of missing and murdered Indigenous women, during her performance at the Polaris Prize awards ceremony in 2014. This further reinforces the point that Tagaq artistically criticizes hypersexualization as contributing to violence committed against Indigenous women.
} 
sexuality subverts such standards by mixing eroticism with throat singing and animalistic body gestures $(2014,54)$.

Tagaq's performance of eroticism in "Aorta" takes on environmental significance due to its placement on an album about "rape of women, rape of the land... despoiling of traditional lands without consent" (Tagaq 2019). In New Perspectives on Environmental Justice, Rachel Stein suggests that gender and sexuality can be sites of environmentalism due to the intertwined history of sexual oppression and land dispossession, particularly in North America (2004, 6). As Vorano demonstrates in his summary of colonized Inuit sexuality, European perceptions of Inuit sexual practices as amoral and unclean provided further incentive for Western expansion into Inuit territories. Greta Gaard suggests that sexuality then can become a "means of resistance for women to exert control over their bodies, their cultures, and the natural environments" (Stein 2004, 9). Tagaq's practice articulates an extended form of environmental justice by demonstrating "land sovereignty," as the album's description suggests, through a performed "body sovereignty." Expressing the right to inhabit her own body mirrors the Indigenous fight

for the right to inhabit their own lands (Ybarra 2004). Tagaq's expressive decolonization of one habitat (her body) becomes a message of empowerment for a decolonization of the other (the land).

\section{Indigenous Women's Environmental Perspectives}

Tagaq's output demonstrates the artist's own understanding and application of the interconnections between the land and femininity in Indigenous thought. While this practice is significant for its challenge to colonial representations of Inuit knowledge and femininity and 
mobilization of Inuit worldviews, Tagaq also mitigates a continual issue in environmental discourses: the marginalization and erasure of Indigenous women's environmental knowledge.

In Living on the Land: Indigenous Women's Understanding of Place (2016) Isabel Altamirano-Jimenez and Nathalie Kermoal explain that in contemporary North America, negotiations on land-use, consultations with Indigenous communities, and other IndigenousSettler environmental dialogues often overlook Indigenous women's perspectives on the environment. Mark Nuttall attributes this to policy makers', environmental managers', and anthropologists' interest in subsistence activities such as hunting large game, overlooking the involvement of women in activities that "tend to be regarded as low in prestige" (Nuttall 1998, 163). Altamirano-Jimenez sees this pattern continued in the creation of Nunavut, when the territory's nation-building process emphasized male-centered activities:

Inuit tradition and culture were closely associated with the homeland and the hunter. The economic, political, and identity focus given to the land and its resources positioned Inuit men's concerns at the centre of the nation-building process. Hunting is a social and cultural institution, so it is not surprising that the image of the hunter is a central expression of Inuit tradition and identity (Searles 2001, 124-125). Through this image, hunting skills and the ability to survive in the Arctic's harsh climate are condensed to portray a male-centered Inuit identity while women's dynamic social, cultural, and economic roles are left out (Altamirano-Jimenez 2009, 147).

The resultant marginalization of Indigenous women's perspectives goes beyond land-based activities to include female-specific processes of observing, understanding, being, and participating in the world (Altamirano-Jimenez and Kermoal 2016, 10). Mark Nuttall writes that "cultural understandings of the environment can only be enhanced once emphasis is also placed on women's knowledge" (Nuttall 1998, 165). While women's shared knowledge enriches understandings of the environment, Aileen Moreton-Robinson points out that individual perspectives are also significant. In her delineation of an "Indigenous women's standpoint," 
Moreton-Robinson acknowledges that Indigenous women's ways of knowing are shaped by diverse, individual experiences of the shared realities of racism and colonialism (AltamiranoJimenez and Kermoal 2016,9). Indigenous women then provide a plurality of unique vantage points for understanding the land and analyzing and critiquing colonizing powers at work in the environment. Similarly, Indigenous women mobilize their unique perspectives in a variety of ways in contemporary contexts (Kermoal and Altamirano-Jimenez 2016; Billson and Mancini 2007; Krouse and Howard 2009). Therefore, a mobilization of an Indigenous female perspective will necessarily look different from person to person. For Tanya Tagaq, communicating a feminine perspective of the environment includes understanding eroticism as a site of decolonization and celebrating her own body as sharing in the earth's creative powers.

\section{Conclusion}

Tanya Tagaq's artistic output is rich with meaning. In my own cycles of listening, reading, thinking, and writing about Tagaq's work, each visit with Tagaq's albums reveals more dimension and nuance to her practice. In investigating the intersectional character of her artistic environmental activism, I find Tagaq's album Retribution particularly profound. In Retribution Tagaq criticizes colonialist representations of women and Inuit traditions - the former as the overly sexualized, the latter as pre-modern and irrelevant to the world today-and performs decolonized visions of each. Rather than acting through mainstream approaches to advocacy, Tagaq mobilizes those interconnections between femininity and the environment in Inuit

frameworks to creatively address injustices done to both, "providing [audiences] with a sense of how Indigenous identity can be intricately woven into ecological relations" (Monani 2013, 289). 
Furthermore, by using womanhood to speak to environmental issues, Tagaq mitigates a recurring issue in environmental discourses: the marginalization and erasure of Indigenous women's environmental knowledge. By looking at Tagaq's artistic environmentalism as intersectional we can then see a broader picture of her decolonization of eco-activism. For Tagaq, decolonizing environmental advocacy means first envisioning the environment through Inuit perspectives-in this case, the interconnections between women and nature; then, upon grasping how Indigenous philosophies frame environments, acting through models built on those concepts. Again, here it means advocating through the links between femininity and the environment. Tagaq thus brings Inuit epistemologies and ontologies to environmentalism. 


\section{Closing Remarks}

In their seminal article "Decolonization is Not a Metaphor," Eve Tuck and K. Wayne Yang remind readers that decolonization and environmental justice are deeply interconnected: "Decolonization brings about the repatriation of Indigenous land and life; it is not a metaphor for other things we want to do to improve our societies and schools" $(2012,1)$. "Decolonization," as it is theorized by many Indigenous scholars, artists, and activists, ${ }^{58}$ involves both disruptions and assertions - disruptions of harmful narratives about Indigenous peoples and the continued marginalization of non-Western voices; assertions of Indigenous philosophies, traditions, and contemporary perspectives. It is this circular cycle ${ }^{59}$ that initiates and perpetuates decolonization in Indigenous and non-Indigenous minds, bodies, and spaces. Following Tuck and Yang's logic, all these constituents of decolonization must also, ultimately, apply to ecological contexts. As I demonstrate in this thesis, Tanya Tagaq's musical practices do just that.

In Part I of this project, I asked how Tagaq performs a decolonized ecology—in other words, how Tagaq transforms the subject of environmental discussions. As Däwes and Maufort note, in order to develop ethical land and resource policies, we must recognize that the ideas we attach to defining "nature" are partly contingent on cultural context $(2014,11)$. In Tagaq's evocation of the Arctic, listeners encounter a local perspective of northern environments - a world constituted of socio-spiritual multispecies relationships and deeply impacted by globalization. Tagaq's practice is decolonized and decolonizing in its challenge to stereotypes about the Arctic's isolation and purity, and foregrounding of Inuit ecology and experience.

\footnotetext{
${ }^{58}$ See my introductory chapter.

${ }^{59}$ I mean here that the breakdown of stereotypes and narratives and promotion of Indigenous viewpoints feed into each other. Indigenous actors' enactment of local philosophies, for example, surely challenges colonial imaginations of indigeneity. Further deconstruction of treasured stereotypes opens more space for Indigenous peoples to then reclaim, revitalize, and reconstitute local traditions and philosophies
} 
However, Tagaq as a creator and performer also reminds us that decolonizing visions of nature is not enough. Ways of thinking must be reflected in ways of being. As I discussed in Chapter Two, Tagaq's artistic ways of being on stage demonstrates how Inuit ecological perspectives implicate the ways actors relate to and behave in the world around them.

The performance of decolonized ecological views (unaccompanied by explicit ecoactivism and eco-criticism) can itself be considered a political act. The assertion of Indigenous standpoints "push[es] back against the histories of (neo)colonial enforced marginalization of both Indigenous people and their other-than-human relatives" (Carroll and Lawson 2016, 130). Performers thus expose and mitigate "histories of attempted extinction of Indigenous people and their worldviews" (Mansbridge 2018,118). However, as Indigenous theorists like Alfred (2008), Smith (1999), and Tuck and Yang (2012) point out, decolonization also includes socio-political action to protect the land. In Part II of my thesis, I demonstrated how Tagaq performs a decolonized eco-activism. In Chapter Three, I drew connections between Tagaq's advocacy and the rhetorical strategies used by Inuit and Indigenous activists, suggesting that Tagaq's artistic eco-activism centers Inuit experiences, voices, and philosophies. In Chapter Four, I argued that Tagaq works through Inuit frameworks - specifically, the interconnection between women and the environment - to contribute to non-Western advocacy methods. Both chapters emphasize the decolonial cycle of disruption and affirmation as seen in Part I. Tagaq's eco-activism challenges the negative, colonialist conceptual links between Indigenous communities, Indigenous women, and nature, and reframes such links through Inuit standpoints. Tagaq simultaneously mobilizes those interconnections - now rooted in Inuit worldview — to advocate for both environmental and social injustices. In these ways, Tagaq performs a decolonized eco-activism that perpetuates decolonization. 
Having spent the last year digging into Tagaq's artistic output, I end this project not with a sense of closure but knowing that there is so much more to Tagaq's artistry and advocacy that warrants discussion. I attempted to focus my gaze at the intersections between music, environmentalism, and decolonization in Tagaq's work, and even there I've discovered I needed to narrow my inquiries even further. The sonic and embodied qualities of Tagaq's artistry were so meaningful that I felt I had to consciously set aside Tagaq's lyrical content, promotional strategies, and cross-cultural collaborations. Each of these areas requires their own focused investigations and would surely illuminate further complexities in Tagaq's environmental advocacy. My hope is that interested readers might further explore Tagaq's work according to their own tastes and interests. Although I've applied an ecocritical gaze to her work, I see many opportunities for fruitful engagements with Tagaq's work: her innovative musical practices and role at the fore of the contemporary "Indigenous music renaissance" 60 make her a vital figure to discuss Indigenous resurgences and modernities. Her acclaimed debut as an author contributes to discourses and traditions in Indigenous literature. Her partnering with musicians and artists across cultural boundaries is significant to discussions in eco-politics. These are just a few of the possibilities that I see for future research. Furthermore, at of the completion of this thesis (May 2019), Tagaq does not appear to be slowing down. As she continues to create, innovate, and advocate, I have little doubt that both listeners and researchers will continue to discover new depths of meaning within Tagaq's art.

\footnotetext{
${ }^{60}$ This term was coined by Ojibway artist-politician Wab Kinew and has recently risen to popularity through both
} CBC Radio's and Wolastoqiyik musician Jeremy Dutcher. 


\section{Works Cited}

Adamson, Joni. 2001. American Indian Literature, Environmental Justice, and Ecocriticism: The Middle Place. Tucson: University of Arizona Press.

Ahmed, Sara. 2014. "White Men.” Feminist Killjoys Blog. https://feministkilljoys.com/2014/11/04/white-men/, accessed March 14, 2019.

Alfred, Taiaiake. 2008. “Opening Words.” In Lighting the Eighth Fire: The Liberation, Resurgence, and Protection of Indigenous Nations, edited by Leanne Betasamosake Simpson, 9-14. Winnipeg: Arbeiter Ring Publishing.

---. 1999. Peace, Power, and Righteousness: An Indigenous Manifesto. Don Mills, ON: Oxford University Press.

---. 2008. “Opening Words.” In Lighting the Eighth Fire: The Liberation, Resurgence and Protection of Indigenous Nations, edited by Leanne Simpson, 9-14. Winnipeg: Arbeiter Ring Publishing.

Allen, Aaron S. and Kevin Dawe, editors. 2016a. Current Directions in Ecomusicology. New York: Taylor and Francis.

---. 2016b. "Ecomusicologies." In Current Directions in Ecomusicology, edited by Aaron S. Allen and Kevin Dawe, 1-15. New York: Routledge.

Altamirano-Jimenez, Isabel. 2009. "Nunavut: Whose Homeland? Whose Voices?” In First Voices: An Aboriginal Women's Reader, edited by Patricia A. Monture and Patricia D. McGuire, 143-154. Toronto: Ianna Publications and Education.

--- and Nathalie Kermoal. 2009. "Introduction: Indigenous Women and Knowledge." In Living on the Land, Indigenous Women's Understanding of Place, edited by Nathalie Kermoal and Isabel Altamirano-Jimenez, 3-18. Edmonton, AB: Athabasca University PressAmadahy, Zainab. 2003. "The Healing Power of Women's Voices." In Strong Women Stories: Native Vision and Community Survival, edited by Bonita Lawrence and Kim Anderson, 144-156. Toronto, ON: Sumach Press.

AMBY. 2016. "Interview with Tanya Tagaq.” YouTube video, 6:22. Posted July 2016. https://www.youtube.com/watch?v=FupatQbcTeM, accessed October 13, 2018.

Anderson, Kim. [2000] 2016. A Recognition of Being: Reconstructing Native Womanhood, second edition. Toronto: Women's Press.

Ansloos, Jeffrey Paul. 2017. The Medicine of Peace: Indigenous Youth Decolonizing Healing and Resisting Violence. Halifax and Winnipeg: Fernwood Publishing. 
Aporta, Claudio. 2016. "Land Use and Occupancy Project (1976) as a Landmark in Inuit Land Use Studies." In Early Inuit Studies: Themes and Transitions, 1850s-1990s, edited by Igor Krupnik, 354-373. Washington, D.C.: Smithsonian Institution Scholarly Press.

Attali, Jacques. 1985. Noise: The Political Economy of Music. Translated by Brian Massumi. Minneapolis: University of Minnesota Press.

Audet, Veroniqué. 2012. "Why Do the Innu Sing Popular Music? Reflections on Cultural Assertion and Identity Movements in Music." In Aboriginal Music in Contemporary Canada: Echoes and Exchanges, edited by Beverley Diamond and Anna Hoefnagels, 372-407. Montreal: McGill-Queen's University Press.

Battiste, Marie. 2000. "Introduction: Unfolding the Lessons of Colonization." In Reclaiming Indigenous voice and vision, edited by Marie Battiste, xvi - 2. Vancouver: University of British Columbia Press.

Beaulne-Steubing, Laura. 2016. "A Conversation with Tanya Tagaq." Ottawa Beat. https://ottawabeat.com/interviews/conversation-tanya-tagaq/, accessed September 4, 2018.

Bell, Jim. 2015. "Inuit National Leader to Environmentalists: Don't Put Inuit into a Bind." Nunatsiaq News. https://nunatsiaq.com/stories/article/65674inuit_national_leader_to_environmentalists_d ont_put_inuit_into_a_bind/, accessed March 21, 2019.

Bellarsi, Franca. 2003. "Ecocriticism, or 'Beyond' Eurocentric and Anthropocentric Antihumanism," NewBELL, Belgian Journal of English Literatures and Linguistics $1: 155-166$.

Bennett, Andy. 2002. "Music, Media, and Urban Mythscapes: A Study of the 'Canterbury Sound." Media Culture and Society 24: 87-104.

Bennett, John, and Susan Rowley, editors. 2004. Uqalurait. Montreal and Kingston: McGillQueen's University Press.

Billson, Janet Mancini, and Kyra Mancini. 2007. Inuit Women: Their Powerful Spirit in a Century of Change. Lanham, Md; Toronto: Rowman and Littlefield.

Blais-Tremblay, Vanessa. 2014. ““ Don't Pocahontas Me': Politics of Improvisation in Tanya Tagaq's Throat Games with Concert Stage String Ensembles.” SOCAN Foundation/MusCan.

Brennan, Teresa. 2004. The Transmission of Affect. Ithaca NY: Cornell University Press.

Brodkin, Karen, Sandra Morgen, and Janis Hutchinson. 2011. "Anthropology as White Public Space?” American Anthropologist 113 (4): 545-556. 
Buijs, Cunera. 2010. "Inuit Perceptions of Climate Change in East Greenland." Etudes/Inuit/Studies 34, no. 1: 39-54.

Callen, Jeffrey. 2010. "Living Outside the Box: An Interview with Tanya Tagaq." Pop Matters. https://www.popmatters.com/121637-living-outside-the-box-an-interview-with-tanyatagaq-2496172914.html, accessed September 15, 2018.

Cariou, Warren, and Isabelle St-Amand. 2017. "Introduction Environmental Ethics through Changing Landscapes: Indigenous Activism and Literary Arts." Canadian Review of Comparative Literature/Revue Canadienne de Littérature Comparée 44 (1): 7-24.

Carroll, Clint, and Angelica Lawson. 2016. "New Media, Activism, and Indigenous Environmental Governance: Politics and the Minnesota-Wisconsin Wolf Hunt." In Ecocriticism and Indigenous Studies: Conversations from Earth to Cosmos, edited by Salma Monani and Joni Adamson, 127-142. London; New York: Routledge.

CBC Arts. 2016. "This Iqaluit Artist is Using Her Body to Pull Stereotypes Apart.” CBC Arts. https://www.cbc.ca/arts/exhibitionists/this-iqaluit-artist-is-using-her-body-to-pullstereotypes-apart-1.3905816, accessed March 24, 2019.

Cohen, Sarah. 1995. "Sounding Out the City: Music and the Sensuous Production of Place." Transaction of the Institute of British Geographers 20 (4): 434-446.

Collignon, Béatrice. 2006. Knowing Places: The Innuinnait, landscapes, and the environment. Translated and edited by Linna Weber Muller-Wille. Edmonton: CCI Press.

---. 2016. “Coda: A Reminiscence of Transition 1992-2012.” In Early Inuit Studies: Themes and Transitions, 1850s- 1990s, edited by Igor Krupnik, 410-416. Washington, D.C.: Smithsonian Scholarly Press

Collins, Patricia Hill, and Bilge, Sirma. 2016. Intersectionality. Oxford: Polity Press.

Conlon, Paula. 2010. "Iglulik Inuit Drum-Dance Songs." In Music of the First Nations: Tradition and Innovation in Native North America, edited by Tara Browner, 7-20. Urbana: University of Illinois Press.

---. 2013. "World Music: Contemporary Inuit Music from Arctic Canada." World Literature Today 87 (2): 9.

Connell, John and Chris Gibson. 2003. Soundtracks: Popular Music, Identity, and Place. London and New York: Routledge.

.--. 2004. "World Music: Deterritorializing Place and Identity." Progress in Human Geography 28: 342-362. 
Coulthard, Glen Sean. 2014. Red Skin, White Masks: Rejecting the Colonial Politics of Recognition. Minneapolis: U of Minnesota Press.

Cresswell, Tim. 2015. Place: A Short Introduction. Chichester, West Sussex; Malden, MA: Wiley Blackwell.

Cruikshank, Julie. 2005. Do Glaciers Listen?: Local Knowledge, Colonial Encounters, and Social Imagination. Vancouver: UBC Press.

Cusick, Suzanne G. 1994. "Toward a Feminist Music theory: Feminist Theory, Music Theory, and the Mind/Body Problem.” In Perspectives of New Music 32 (1): 8-27.

Darville, Jordan. 2016. "Listen to "Centre," the First Single From Tanya Tagaq's New Album." The Fader. https://www.thefader.com/2016/09/08/tanya-tagaq-shad-centre-premiere, accessed August 4, 2018.

Davidson, Jane W. 2014. "Introducing the Issue of Performativity in Music." Musicology Australia 36 (2): 179-188.

Däwes, Birgit, and Marc Maufort. 2014. "A Chorus of Ecological Voices: Enacting Nature in Contemporary Indigenous Performance.” In Enacting Nature: Ecocritical Perspectives on Indigenous Performance, edited by Birgit Däwes and Marc Maufort, 11-20. Brussels: P.I.E. Peter Lang.

Deiter, Connie, Valerie Assinewe, Lucy Mulenkei , Beatriz Schultess, Priscilla Settee, and Leanne Simpson. 2002. "We Are the Land; Let us Heal Ourselves." Biodiversity 3 (3): 33-34.

Diamond, Beverley. 2011a. "Decentering Opera: Early Twenty-First-Century Indigenous Production." In Opera Indigene: Re/presenting First Nations and Indigenous Cultures, edited by Dylan Robinson and Pamela Karantonis, 31-56. Burlington, VT;Farnham, Surrey: Ashgate.

---. 2011b. "Medúlla, and: Sinaa (Review)." Journal of American Folklore 124 (491): 95-97.

---, M. Sam Cronk, and Franziska Von Rosen. 1994. Visions of Sound: Musical Instruments of First Nation Communities in Northeastern America. Chicago: University of Chicago Press..

Dickie, Bonnie, Terry Woolf, Rosmarie Kuptana, Gary Milligan, and Neil Ford. 2000. Sila Alangotok: Inuit Observations On Climate Change. International Institute for Sustainable Development. VHS video, 42 minutes.

Dickie, Mary. 2014. "Tanya Tagaq Grabs the World by the Throat." Musicworks Magazine. https://www.musicworks.ca/featured-article/tanya-tagaq-grabs-world-throat, accessed September 15, 2018. 
Doherty, Mike. 2018. “The Surprising Sounds and Sides of Tanya Tagaq.” Maclean's. https://www.macleans.ca/culture/books/tanya-tagaq-on-her-desperate-attempt-toalleviate-indigenous-suffering/,_accessed January 8, 2019.

Dorais, Louis-Jacques. 1997. Quaqtaq: Modernity and Identity in an Inuit Community. Toronto: University of Toronto Press.

Dowsley, Martha. 2015. "Identity and the Evolving Relationship Between Inuit Women and the Land in the Eastern Canadian Arctic." Polar Record 51 (260): 536-549.

Driskill, Qwo Li. 2004. "Stolen From Our Bodies: First Nations Two-Spirits/Queers and the Journey to a Sovereign Erotic." Studies in American Indian Literatures, 16 (2): 50-64.

Edwards, Samantha. 2016. “Tanya Tagaq Rules Our World.” Now Magazine. https://nowtoronto.com/music/features/tanya-tagaq-rules-our-world/, accessed September 20, 2018.

Emanuel Vigeland Museum. N.D. “Tomba Emmanuelle.” Emanuel Vigeland Museum. http://www.emanuelvigeland.museum.no/mausoleum.htm, accessed January 2, 2018.

Everett- Green, Robert. 2014. "Primal Scream: Inuk Throat Singer Tanya Tagaq is Like No One You've Ever Heard, Anywhere." The Globe and Mail. https://www.theglobeandmail.com/arts/music/primal-scream-inuk-throat-singer-tanyatagaq-is-like-no-one-youve-ever-heard-anywhere/article18923190/, accessed September 15, 2018.

Fienup-Riordan, Ann. 1994. Boundaries and Passages: Rule and Ritual in Yup'ik Eskimo Oral Tradition. Norman: University of Oklahoma Press.

---. 1999. "Collaboration on Display: A Yup'ik Eskimo Exhibit at Three National Museums.” American Anthropologist 101 (2): 339- 358.

Filipenko, Cindy. 2011. "Tanya Tagaq Takes Flight.” Herizons magazine. http://www.herizons.ca/node/561, accessed January 2, 2019.

Fiskio, Janet. 2016. "Dancing at the End of the World: The Poetics of the Body in Indigenous Protest." In Ecocriticism and Indigenous Studies: Conversations from Earth to Cosmos, edited by Salma Monani and Joni Adamson, 110-126. Routledge.

Fratila, Stefana. 2016. Decolonizing Reconciliation: Refusing Settler Innocence Through Sound. Unpublished graduate thesis: University of British Columbia.

Fredrickson, Rebecca. 2015. Orientations in Weather: A Northern Textual Ecology. Unpublished doctoral thesis. Edmonton: University of Alberta. 
Frith, Simon. 1996. Performing Rites: On the Value of Popular Music. Cambridge, MA: Harvard University Press.

Fuse TV. 2017. “Interview with Jesse Zubot.” Youtube video, 3:54. Posted March 9, 2017. https://www.youtube.com/watch?v=wlt_Z93W16M, accessed February 2, 2019.

Gaard, Greta. 2004. “Toward a Queer Ecofeminism.” In New Perspectives on Environmental Justice: Gender, Sexuality, and Activism, edited by Rachel Stein, 21-44. New Brunswick, NJ: Rutgers University Press.

Gablik, Suzi. 1991. The Reenchantment of Art. Vol. 500. New York: Thames and Hudson.

Gautier, Ana María Ochoa. 2016. "Acoustic Multinaturalism, the Value of Nature, and the Nature of Music in Ecomusicology." boundary 243 (1): 107-141.

Ghomeshi, Jian. 2014. "Tanya Tagaq brings “Animism” to Studio Q." $Q$ on $C B C$. Youtube video, 16:50. Posted May 2014. https://www.youtube.com/watch?v=ZuTIySphv2w, accessed July 4, 2018.

Giilck. 2017. "Tanya Tagaq Touched Souls at Meaford Hall." The Meaford Independent. https://www.themeafordindependent.ca/life-leisure/arts-culture/798046-tanya-tagaqtouched-souls-at-meaford-hall, accessed December 21, 2018.

Clegg, Stewart R. 1995. "Book Review: We Have Never Been Modern by Bruno Latour." Theory, Culture, and Society 12: 153-157.

Graburn, Nelson. “Culture as Narrative.” In Critical Inuit Studies: An Anthology of Contemporary Arctic Ethnography, edited by Pamela Stern and Lisa Stevenson, 136154. Lincoln: University of Nebraska Press.

Grace, Sherrill. 2001. Canada and the Idea of the North. Montreal and Kingston: McGill and Queens University Press.

Green, Sam. 2016. “Tanya Tagaq- Kronos' Fifty for the Future Composer Interview.” Kronos Quartet. Youtube video. 9:06. https://www.youtube.com/watch?v=Opn_11Cgadc, accessed February 1, 2019.

Greene, Sarah. 2014. “Tanya Tagaq: Inuk Throat Singer Makes Big Political and Social Statements with Very Few Words." NOW Magazine. https://nowtoronto.com/music/tanya-tagaq/, accessed September 15, 2018.

Greenwood, Margo. 2017. "Epilogue: The Value of Relational Ways of Knowing and Being." In Inuit Qaujimajatuqangit: What Inuit Have Always Known to be True, edited by Joe Karetak, Frank Tester, and Shirley Tagalik, 220-224. Halifax and Winnipeg: Fernwood Publishing. 
Guy, Nancy. 2009. "Flowing Down Taiwan's Tamsui River: Towards an Ecomusicology of the Environmental Imagination.” Ethnomusicology 53 (2): 218-48.

Guyette, Margaret Q. and Jennifer C. Post. "Ecomusicology, Ethnomusicology, and Soundscape Ecology: Scientific and Musical Responses to Sound Study." In Current Directions in Ecomusicology, edited by Aaron S. Allen and Kevin Dawe, 40-56. New York: Routledge.

Hasek, Samantha, and April E. Lindala. 2016. "Hearing the Heartbeat: Environmental Cultural Values in the Lyrics of Native Songwriters." In Indigenous Pop: Native American Musicfrom Jazz to Hip Hop, edited by Jeff Berglund, Jan Johnson, and Kimberli Lee, 123- 135. Tucson: University of Arizona Press.

Hudson, Ray. 2006. "Regions and Place: Music, Identity, and Place.” Progress in Human Geography 30, no. 5: 626-634.

Ingram, David. 2010. The Jukebox in the Garden: Ecocriticism and American Popular Music Since 1960. New York; Amsterdam: Rodopi.

Isuma TV. 2009. "Tungijuq.” Isuma TV. http://www.isuma.tv/tungijuq/tungijuq720p, accessed February 15, 2019.

Johnston, Angela Hovak. 2017. Reawakening our Ancestors'Lines: Revitalizing Inuit Traditional Tattooing. Iqaluit, Nunavut; Toronto: Inhabit Media Inc.

Karetak, Joe and Frank Tester. 2017. "Introduction: Inuit Qaujimajatuqangit, Truth and Reconciliation." In Inuit Qaujimajatuqangit: What the Inuit Have Always Known to Be True, edited by Joe Karetak, Frank Tester and Shirley Tagalik, 1-19. Halifax and Winnipeg: Fernwood Publishing.

Kartomi, Margaret. 2014. "Concepts, Terminology and Methodology in Music Performativity Research.” Musicology Australia 36 (2): 189-208.

Keast, James. 2016. "Tanya Tagaq: She the North.” Exclaim! Magazine. https://exclaim.ca/music/article/tanya_tagaq-she_the_north, accessed January 15, 2019.

Keil, Charles and Patricia Campbell. 2006. Born to Groove. Online at https://borntogroove.com/

Kembrey, Melanie. 2018. "Interview: Inuk throat singer Tanya Tagaq." The Sydney Morning Herald. https://www.smh.com.au/entertainment/music/interview-inuk-throat-singertanya-tagaq-20180528-h10mxk.html_,accessed August 10, 2018.

Kermoal, Nathalie and Isabel Altamirano-Jimenez, editors. 2016. Living on the Land: Indigenous Women's Understanding of Place. Edmonton, AB: Athabasca University Press. 
Khaleeli, Homa. 2015. "Tanya Tagaq: The Polar Punk Who Makes Bjork Sound Tame.” The Guardian. https:/www.theguardian.com/music/2015/may/17/tanya-tagaq-interviewanimism, accessed August 15, 2018.

Kirmayer, Laurence J., Christopher Fletcher, and Robert Watt. 2009. "Locating the Ecocentric Self: Inuit Concepts of Mental Health and Illness." In Healing Traditions: The Mental Health of Aboriginal peoples in Canada, edited by Gail Guthrie Valaskakis and Laurence J. Kirmayer, 289-314. Vancouver: UBC Press.

Kleist, Makka. 2008. "Pre-Christian Inuit Sexuality.” In Me Sexy: An Exploration of Native Sex and Sexuality, edited by Drew Hayden Taylor, 15-19. Vancouver: Douglas \& McIntyre.

Kopnina, Helen, and Eleanor Shoreman-Ouimet. 2011. "Introduction: Environmental Anthropology of Yesterday and Today." In Environmental Anthropology Today, edited by Helen Kopnina and Eleanor Shoreman-Ouimet, 1-34. Abingdon, Oxon, New York: Routledge.

Koskoff, Ellen. 2014. A Feminist Ethnomusicology: Writings on Music and Gender. Urbana: University of Illinois Press.

Kovach, Margaret. 2010. Indigenous Methodologies: Characteristics, Conversations, and Contexts. Toronto: University of Toronto Press.

Kramer, Lawrence. 2010. Interpreting Music. Berkeley; Los Angeles; London: University of California Press.

Kronos Quartet. 2016. “Tanya Tagaq-Kronos' Fifty for the Future Composer Interview.” Youtube video, 9:06. https://www.youtube.com/watch?v=Opn_11Cgadc, accessed January 4, 2018.

Krouse, Susan Applegate, and Heather A. Howard. 2009. Keeping the Campfires Going: Native Women's Activism in Urban Communities. Lincoln: University of Nebraska Press.

Krupnik, Igor. 2016. "From Boas to Burch: Eskimology Transitions." In Early Inuit Studies: Themes and Transitions, 1850s-1990s, edited by Igor Krupnik, 1-34. Washington D.C.: Smithsonian Scholarly Press.

Ladoucer, Liisa. 2006. “Transforming the Past.” Words \& Music vol 13 (4): 20-23.

LaDuke, Winona. 1999. All Our Relations: Native Struggles for Land and Life. Cambridge, MA: South End Press.

Lajeunesse, Felix, Paul Raphaël, Tanya Tagaq, and Zacharias Kunuk. 2009. Tungijuq. Short film. Directed by Felix Lajeunesse and Paul Raphaël. Isuma TV. http://www.isuma.tv/tungijuq/tungijuq720p , accessed March 1, 2019. 
Latour, Bruno. 1993. We Have Never Been Modern. Translated by Catherine Porter. Cambridge, Massachusetts: Harvard University Press.

Laugrand, Frédéric. 2016. "Ontology on the Ice: Inuit traditions, Ecology, and the Problem of Categories." In Routledge Handbook of Religion and Ecology, edited by Willis J. Jenkins, Mary Evelyn Tucker, and John Grim, 148- 157. New York: Taylor and Francis, 148-157.

Leduc, Timothy B. 2007. "Sila Dialogues on Climate Change: Inuit Wisdom for a Cross-Cultural Interdisciplinarity." Climatic Change 85: 237-250.

---. 2010. Climate Culture Change: Inuit and Western Dialogues with a Warming North. Ottawa: University of Ottawa Press.

---. 2011. “A Climate for Wisdom?” Tikkun. https://www.tikkun.org/a-climate-for-wisdom, accessed March 29, 2019.

---. 2013. “Ancestral Climate Wisdom: Return to a Thoughtful Etiquette.” In Global Ethics on Climate Change: The Planetary Crisis and Philosophical Alternative, edited by Martin Schonfeld, 107-120. New York: Taylor and Francis.

Leon, Alannah Young, and Denise Nadeau. 2018. "Embodying Indigenous Resurgence: “All Our Relations" Pedagogy.” In Sharing breath: Embodied learning and decolonization, editedby Sheila Batacharya and Renita Wong Yuk-Lin, 55-82. Edmonton, Alberta: AU Press.

Levesque, Francis. 2014. "Revisiting Inuit Qaujimajatuqangit: Inuit knowledge, culture, language, and values in Nunavut Institutions since 1999." Cultures Inuit, Governance et Cosmopolitiques 38 (1-2): 115-136.

Lewis, Carly. 2016. “Tanya Tagaq Finds Inner Peace in New Album Retribution.” The Globe and Mail. https://www.theglobeandmail.com/arts/music/tanya-tagaq-finds-inner-peacein-new-albumretribution/article32418950//, accessed October 4, 2018.

Leyshon, Andrew, David Matless, and George Revill. 1995. "The Place of Music: [introduction]." Transactions of the Institute of British Geographers 20 (4): 423-433.

---. 1998. The Place of Music. New York: Guilford Press.

Live at Massey Hall. 2015. “Tanya Tagaq Live at Massey Hall.” Presented by TD. Youtube video, 38:26. Posted April 2017. https://www.youtube.com/watch?v=8cFUPJmAGMI\&t=1676s , accessed November 4, 2018.

Luber, Sigrid. 2018. "Turning the tide on ocean noise." The Circle 3: 3. 
Lucas, Anne E. 2004. "No Remedy for the Inuit: Accountability for Environmental Harms under U.S. and International Law." In New Perspectives on Environmental Justice: Gender, Sexuality, and Activism, edited by Rachel Stein, 191-206. New Brunswick, NJ: Rutgers University Press.

Lutz, Hartmut. 2015. “'Indianthusiasts' and 'Mythbusters': (De-)Constructing Transatlantic Others. ” In Twenty-First Century Perspectives on Indigenous Studies: Native North America in (Trans)Motion, edited by Birgit Dawes, Karen Fitz, and Sabine N. Meyer, 236-256. London; New York: Routledge.

Mansbridge, Joanna. 2018. "Animating Extinction, Performing Endurance: Feathers, Angels, and Indigenous Eco-Activism." Theatre Topics 28 (2): 113-123.

Martello, Marybeth Long. 2008. "Arctic Indigenous Peoples as Representations and Representatives of Climate Change.” Social Studies of Science 23 (3): 351-376.

Massumi, Brian. 2002. Parables for the Virtual: Movement, Affect, Sensation. London: Duke University Press.

McClary, Susan. 1991. Feminine Endings: Music, Gender, and Sexuality. Minneapolis: University of Minnesota Press.

McGeough, Michelle. 2008. "Norval Morrisseau and the Erotic." In Me Sexy: An Exploration of Native Sex and Sexuality, edited by Drew Hayden Taylor, 59-86. Vancouver: Douglas \& McIntyre.

Merkur, Daniel. 1983. "Breath-Soul and the Wind Owner: The Many and the One in Inuit Religion." American Indian Quarterly 7 (3): 23-39.

---. [1993] 2014. Becoming Half Hidden: Shamanism and Initiation Among the Inuit. New York and London: Routledge.

Mertens, Max. 2016. “Inuk Throat Singer Tanya Tagaq Demands 'Retribution' in Aggressively Kinetic New Video.”Vice. https://www.vice.com/en_ca/article/8q7dqz/tanya-tagaqretribution-music-video-watch, accessed January 4, 2019.

Mihesuah, Devon Abbott. 2003. Indigenous American Women: decolonization, empowerment, activism. Lincoln, Nebraska; London: University of Nebraska Press.

Møller, Karina. 2013. "Uaajeerneq-An ancient Inuit Form of Entertainment." GreenlandToday. http://greenlandtoday.com/uaajeerneq-greenlandic-mask-dance/?lang=en, accessed March 5, 2019.

Monani, Salma. 2013. "Indigenous Film Festival as Eco-Testimonial Encounter-The 2011 Native Film + Video Festival." NECSUS: The European Journal of Media Studies 2 (1): 285-291. 
Monani, Salma. 2014. "Evoking Sympathy and Empathy: The Ecological Indian and Indigenous Eco- Activism.” In Moving Environments: Affect, Emotion, Ecology, and Film, edited by Alexa Wek von Mossner, 225-247. Waterloo: Wilfred Laurier University Press.

--- and Joni Adamson, eds. 2016. Ecocriticism and Indigenous Studies: Conversations from Earth to Cosmos. New York: Routledge.

Morrison, Krystal. 2018. Musicology, Discourse, and the Performer's Body: Understanding Music from the Inside. Unpublished graduate thesis. Ottawa: University of Ottawa.

Munday, Rob. 2012. “Tungijuq.” Director's Notes.

https://directorsnotes.com/2012/05/16/tungijuq/, accessed February 15, 2019.

Murphy, Jacqueline Shea. 2007. The People Have Never Stopped Dancing: Native American Modern Dance Histories. Minneapolis, Minn: University of Minnesota Press.

Nattiez, Jean-Jacques. (2006) 2019. “Inuit Vocal Games.” In The Canadian Encyclopedia. Historica Canada. https://www.thecanadianencyclopedia.ca/en/article/inuit-vocalgames-emc, accessed April 4, 2019.

Nelles, Drew. 2017 [2015]. "Howl: Why Tanya Tagaq Sings." The Walrus. https://thewalrus.ca/howl/, accessed July 5, 2018.

Ng, Roxana. 2018. "Decolonizing Teaching and Learning through Embodied Learning: Toward an Integrated Approach." In Sharing breath: Embodied learning and decolonization, edited by Sheila Batacharya and Renita Wong Yuk-Lin, 33-54. Edmonton, Alberta: AU Press.

Nuttall, Mark. 1992. Arctic Homeland: Kinship, Community, and Development in Northwest Greenland. Toronto: University of Toronto Press.

---. 1998. Protecting the Arctic: Indigenous Peoples and Cultural Survival. Amsterdam: Harwood Academic Publishers.

Pauktuutit Inuit Women of Canada. 2012. Tukisiviit: Do You Understand? Tukisiviit Summary Report 2012-2014. Ottawa. https://www.pauktuutit.ca/wp-content/uploads/TukisiviitSummary-Report_English_WEB.pdf, accessed January 15, 2019.

Pedelty, Mark. 2012. Ecomusicology: Rock, Folk, and the Environment. Philadelphia: Temple University Press

Prasad, Anil. 2010. “Tanya Tagaq: Instinctual Invocations.” Innerviews. https://www.innerviews.org/inner/tagaq.html, accessed August 24, 2018.

Preston, VK. 2016. "Tanya Tagaq in Concert with Nanook of the North by Tanya Tagaq, Robert J. Flaherty (review).” Theatre Journal 38 (4): 649-650. 
Price, Jackie. 2008. "Living Inuit Governance in Nunavut." In Lighting the Eighth Fire: The Liberation, Resurgence, and Protection of Indigenous Nations, edited by Leanne Betasamosake Simpson, 127-138. Winnipeg: Arbeiter Ring Publishing.

Randerson, Janine, and Amanda Yates. 2016. "Negotiating the Ontological Gap: Place, Performance, and Media Art Practices in Aotearoa/ New Zealand." In Ecocriticism and Indigenous Studies: Conversations from Earth to Cosmos, edited by Salma Monani and Joni Adamson, 35-55. Routledge.

Rasmussen, Knud. 1929. Intellectual Culture of the Iglulik Eskimos. Copenhagen: Gyldendalske Boghandel.

Red Bull Music Academy. 2016. "Tanya Tagaq Lecture (Montreal 2016).” YouTube video, 1:15:21. https://www.youtube.com/watch? $\mathrm{v}=\mathrm{YkD} 00 \mathrm{mGqBxE}$, accessed December 5, 2018.

Riel, Louis. 1885. Retrieved from “Louis Riel Quotes.” Manitoba Metis Federation. 2019. http://www.mmf.mb.ca/louis_riel_quotes.php, accessed March 23, 2019

Robinson, Dylan, and Pamela Karantonis. 2011. "Introduction." In Opera indigene: Re/presenting First Nations and Indigenous cultures, edited by Dylan Robinson and Pamela Karantonis, 1-14. Burlington, VT; Farnham, Surrey: Ashgate.

Rogers, Sarah. 2014. "Tanya Tagaq's New Album Captures the Spirit of Good and Evil." Nunatsiaq News.

https://nunatsiaq.com/stories/article/65674tanya_tagaqs_new_album_captures_the_spiri t_of_good_and_evil//, accessed November 4, 2018.

Rule, Elizabeth. 2018. "Seals, Selfies, and the Settler State: Indigenous Motherhood and Gendered Violence in Canada." American Quarterly 70 (4): 741-754.

Ryall, Anka, Johan Schimanski, and Henning Howlid Waerp. 2010. "Arctic Discourses: An Introduction." In Arctic Discourses, edited by Arka Ryall, Johan Schimanski, and Henning Howlid Waerp, x-xxii. Newcastle upon Tyne: Cambridge Scholars Publishing.

Salvini, Laura. 2007. "Sheila Watt-Cloutier: The Inuit Way of Environmental Peace.” In USA: Identities, Cultures, and Politics in National, Translational, and Global Perspectives, edited by Marian Camboni, Valerio Massimo De Angelis, Danile iorention, Tatiana Petrovich Njegosh, 395-399. Macerata: A.I.S.N.A. Associazione Italiana di Studi Nord Americani.

Scrimshaw, Will. 2013. "Non-cochlear Sound: On Affect and Exteriority. In Sound, Music, Affect: Theorizing Sonic Experience, edited by Marie Thompson and Ian Biddle, 27-44. London: Bloomsbury. 
Seeger, Anthony. 2016. "Natural Species, Sounds, and Humans in Lowland South America: The Kisêdjê/ Suyá, Their World, and the Nature of Their Musical Experience." In Current Directions in Ecomusicology, edited by Aaron S. Allen and Kevin Dawe, 89-98. New York: Routledge.

Simonett, Helena. 2016. "Of Human and Non-human Birds: Indigenous Muisc Making and Sentient Ecology in Northwestern Mexico. In Current Directions in Ecomusicology, edited by Aaron S. Allen and Kevin Dawe, 100-108. New York: Routledge.

Simpson, Leanne. 2001. "Aboriginal peoples and knowledge: Decolonizing our processes." The Canadian Journal of Native Studies 21(1): 137-148.

Simpson, Leanne Betamosake. 2014. "Not Murdered, Not Missing: Rebelling Against Colonial Gender Violence.” https://www.leannesimpson.ca/writings/not-murdered-not-missingrebelling-against-colonial-gender-violence, accessed December 4, 2018.

Six Shooter Records. 2014. "Tanya Tagaq Talks Animism (EPK).” Six Shooter Records. Youtube video, 5:25. Posted September 4, 2014. https://www.youtube.com/watch?v=pFHL341OpHU , accessed September 5, 2018.

Smith, Linda Tuhiwai. 1999. Decolonizing Methodologies: Research and Indigenous peoples. London: Zed Books Ltd.

Smith, Sarah E.K., and Carla Taunton. 2018. "Unsettling Canadian Heritage: Decolonial Aesthetics in Canadian Video and Performance Art." Journal of Canadian Studies/ Revue d'études canadiennes 52 (1): 306-341.

Stairs, Arlene, and George Wenzel. 1992. “"I am I and the Environment”: Inuit Hunting, Community and Identity. Journal of Indigenous Studies, 3(1), 1-12.

Steckley, John L. 2008. White Likes about the Inuit. Toronto: University of Toronto Press.

Stein, Rachel. 2004. "Introduction." In New Perspective on Environmental Justice: Gender, Sexuality, and Activism, edited by Rachel Stein, 1-20. New Brunswick, NJ: Rutgers University Press.

Stévance, Sophie. 2014. “Tanya Tagaq: L'Ethno-Pop Comme Mise en Spectacle.” In Quand la Musique Prend Corps, edited by Serge Lacasse, Monique Desroches, and Sophie Stévance, 208-328: Montreal: Les presses de 1'Universite de Montreal.

---. 2017. "From Throat singing to transcultural expression: Tanya Tagaq's Katajjaq musical signature." In The Routledge Research Companion to Popular Music and Gender, edited by Stan Hawkins, 48- 62. London; New York: Routledge. 
Stevenson, Lisa. 2006. "Introduction.” In. Critical Inuit Studies: An Anthology of Contemporary Arctic Ethnography, edited by Pamela Stern and Lisa Stevenson, 1-22. Lincoln: University of Nebraska Press.

Stokes, Martin. 1994. Ethnicity, Identity, and Music. Oxford: Berg Publishers.

Strachan, Robert. 2010. "Uncanny Spaces: Theory, Experience, and Affect in Contemporary Electronic Music." TRANS: Revista Transculturel de Musica 14. https://www.sibetrans.com/trans/articulo/14/uncanny-space-theory-experience-andaffect-in-contemporary-electronic-music, accessed January 28, 2018.

Tagaq, Tanya. 2019. “About Tanya Tagaq.” Tanya Tagaq. http://tanyatagaq.com/about/, accessed August 8, 2018.

Taylor-Neu, Robyn. “'All There Is': The Reconciliatory Poetics of a Singing Voice.” American Anthropologist 120 (1): 113-125.

The Chan Centre for the Performing Arts. 2019. "Q \& A with Laakkuluk Williamson Bathory." The Chan Centre for the Performing Arts. https://chancentre.com/news/q-a-withlaakkuluk/, accessed March 15, 2019.

Thompson, Marie, and Ian Biddle. 2013. "Introduction: Somewhere Between the Signifying and the Sublime." In Sound, Music Affect: Theorizing Sonic Experience, edited by Marie Thompson and Ian Biddle, 1-24. London: Bloomsbury.

Titon, Jeff Todd. 2016. "Why Thoreau?” In Current Directions in Ecomusicology, edited by Aaron S. Allen and Kevin Dawe, 69-80. New York: Routledge.

Todd, Zoe. 2016. “An Indigenous Feminist's Take on the Ontological Turn: 'Ontology' is Just Another Word for Colonialism.” Journal of Historical Sociology 29 (1): 4-22.

Tuck, Eve, and K. Wayne Yang. 2012. "Decolonization is not a metaphor.” Decolonization: Indigeneity, Education, and Society 1 (1): 1-40.

Tungilik, Marius P. 2008. "The Dark Side of Sex." In Me Sexy: An Exploration of Native Sex and Sexuality, edited by Drew Hayden Taylor, 50-58. Vancouver: Douglas \& McIntyre.

van den Scott, Jeffrey. 2016. "Music of the "True North": A Study of the Interaction of Canadian Music and an Inuit Community. ProQuest Dissertations Publishing.

Vorano, Norman. 2008. "Inuit Men, Erotic Art: Certain indecencies... that need not here be mentioned." In Me Sexy: An Exploration of Native Sex and Sexuality, edited by Drew Hayden Taylor, 84-99. Vancouver: Douglas \& McIntyre.

Wagner, Tom. 2010. "Web Site Reviews: Born to Groove, a Collaboration Between Charles Keil and Patricia Campbell." Yearbook for Traditional Music 42: 243-44. 
Warner, Andrea. 2016. "Inuk Throat Singer Tanya Tagaq Will Make You See Canada in a Chilling New Light." Pitchfork. https://pitchfork.com/thepitch/1351-inuk-throat-singertanya-tagaq-will-make-see-canada-in-a-chilling-new-light/, accessed August 12, 2018.

Waterman, Ellen, and Alice W. Boyle. 2016 "The Ecology of Musical Performance: Towards a Robust Methodology." In Current Directions in Ecomusicology, edited by Aaron S. Allen and Kevin Dawe, 25-39. New York: Routledge.

Watt-Cloutier, Sheila. 2016. The Right to be Cold: One Woman's Story of Protecting her Culture, the Arctic and the Whole Planet. Toronto, ON: Penguin.

Wenzel, George. 1991. Animal Rights, Human Rights: Ecology, Economy, and Ideology in the Canadian Arctic. Toronto; Buffalo: University of Toronto Press.

---. 2004. "From TEK to IQ: Inuit Qaujimajatuaqangit and Inuit Cultural Ecology." Arctic Anthropology 41 (2): 238-250.

Willow, Anna. 2009. "Clear-Cutting Colonialism: The Ethnopolitical Dynamics of Indigenous Environmental Activism in Northwestern Ontario.” Ethnohistory 56 (1): 35-67.

Willox, Ashlee Cunsolo, Sherilee L. Harper, James D. Ford, Karen Landman, Karen Houle, Victoria L. Edge, the Rigolet Inuit Community Government. 2012. "From This Place and of This Place:' Climate Change, Sense of Place, and Health in Nunatsiavut, Canada." Social Science and Medicine 75: 538-547.

---. 2013a. "The Land Enriches the Soul: On Climatic and Environmental Change, Affect, and Emotional Health and Well Being in Rigolet, Nunatsiavut, Canada.” Emotion, Space, and Society 6: 14-24.

---, Sherilee L. Harper, James D. Ford, Victoria L. Edge, Karen Landman, Karen House, Sarah Blake, and Charlotte Wolfrey. 2013b. "Climate Change and Mental Health: An Exploratory Case Study from Rigolet, Nunatsiavut, Canada." Climatic Change 121: 255-270.

---, Eleanor Stephenson, Jim Allen, Francois Bourque, Alexander Drossos, Sigmund Elgarsy, Michael J. Kral, Ian Mauro, Joshua Moses, Tristan Pearce, Joanna Petrasek MacDonald, and Lisa Wexler. 2015. "Examining Relationships Between Climate Change and Mental Health in the Circumpolar North.” Regional Environmental Change 15 (1): 169- 182.

Woloshyn, Alexa. 2012. The Recorded Voice and the Mediated Body in Contemporary Electroacoustic Music. ProQuest Dissertations Publishing.

---. 2017. "'Welcome to the Tundra': Tanya Tagaq's Creative and Communicative Agency as Political Strategy." Journal of Popular Music Studies 29 (4): 1-14. 
Woynarski, Lisa. 2015. "Ecological Sentinels: Ecological Heroes or Colonial Cliché?" RiDE: The Journal of Applied Theatre and Performance 20 (2): 186-89.

Ybarra, Priscilla Solis. 2004. "“Lo Que Quiero es Tierra': Longing and Belonging in Cherrie Moraga's Ecological Vision.” In New Perspectives on Environmental Justice: Gender, Sexuality, and Activism, edited by Rachel Stein, 240-248. New Brunswick, NJ: Rutgers University Press.

Young, Alannah Earl, and Denise Nadeau. 2005. "Decolonising the body: Restoring sacred vitality." Atlantis 29 (2): 13-21.

\section{Music Videos and Albums Cited}

Lajeunesse, Félix, and Paul Raphaël. 2009. “Tungijuq.” IsumaTV video, 7:03. http://www.isuma.tv/tungijuq/tungijuq720p , accessed January 24, 2019.

Neel, Marcia. 2018. “Tanya Tagaq Uja and Umingmak live Polaris Music Prize 2014.” YouTube video, 10:28. https://www.youtube.com/watch?v=pydRzYrEZec , accessed January 24, 2019.

Tagaq, Tanya. 2005. Sinaa. Jericho Beach Music, compact disc.

---. 2008. Auk/Blood. Ipecac Recordings, compact disc.

---. 2014. Animism. Six Shooter Records, compact disc.

---. 2015a. "Tanya Tagaq-Aorta." YouTube video, 3:36. https://www.youtube.com/watch?v=SGNpz5tFUEE, accessed September 2, 2018.

---. 2015b. “Tanya Tagaq-Uja.” YouTube video, 2:55. https://www.youtube.com/watch?v=BCuayGvy3i8, accessed September 2, 2018.

---. 2016a. Retribution. Six Shooter Records, compact disc.

---. 2016b. Retribution Commentary with Carl Wilson. Six Shooter Records, available https://open.spotify.com/album/3mia3hcmaAHzcBkaAzxeJD? si=4ijosy86TzaWVfmjuP QhA

---. 2016c. "Tanya Tagaq-Retribution." YouTube video, 8:05. https://www.youtube.com/watch?v=xNYTA6SV6tM, accessed September 5, 2018.

---. 2016d. “Tanya Tagaq-Sulfur.” YouTube video, 3:02. https://www.youtube.com/watch?v=U20JGI7s3Qs , accessed September 5, 2018.

---, Jesse Zubot, and Jean Martin. 2011. Anuraaqtuq. Les Disques VICTO. CD. 